Aus der Abteilung Unfallchirurgie, Plastische und Wiederherstellungschirurgie (Prof. Dr. med. K. M. Stürmer) im Zentrum Chirurgie der Medizinischen Fakultät der Universität Göttingen

\title{
Einfluss von Parathormon auf die Frakturheilung der proximalen metaphysären Tibia im Rattentiermodell
}

\author{
INAUGURAL - DISSERTATION \\ zur Erlangung des Doktorgrades \\ der Medizinischen Fakultät \\ der Georg-August-Universität zu Göttingen
}

vorgelegt von

Florian August

aus

Frankfurt a.M.

Göttingen 2012 
Dekan:

I. Berichterstatter:

II. Berichterstatter/in:

III. Berichterstatter/in:

Tag der mündlichen Prüfung: 22.08 .2012
PD Dr. med. S. Sehmisch

Prof. Dr. med. H. Siggelkow 


\section{Inhaltsverzeichnis}

1 Einleitung $\quad 1$

2 Grundlagen 3

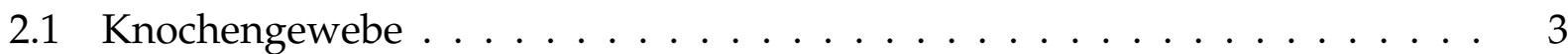

2.1.1 Geflechtknochen und Lamellenknochen . . . . . . . . . . . . . . . . . 4

2.1.2 Knochenspezifische Zellen . . . . . . . . . . . . 5

2.1.3 Knochenmatrix .................... 6

2.2 Funktionen des Knochens . . . . . . . . . . . . . . . . . . . 6

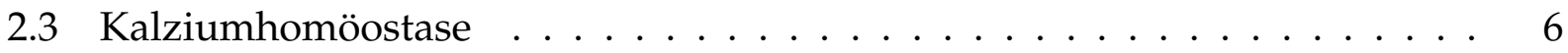

2.3.1 Parathormon .................. 8

2.3 .2 Kalzitriol (Vitamin D) . . . . . . . . . . . . . . . . . . 10

2.3 .3 Kalzitonin ......................... 11

2.4 Therapeutischer Einsatz von Parathormon . . . . . . . . . . . . . . . 11

2.4 Nebenwirkungen ....................... 13

3 Frakturentstehung und Frakturheilung $\quad 15$

3.1 Frakturentstehung . . . . . . . . . . . . . . . . 15

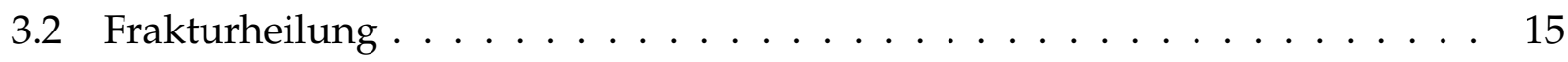

3.2.1 Indirekte Frakturheilung . . . . . . . . . . . . . 16

3.2.2 Direkte Frakturheilung . . . . . . . . . . . . . . 17

3.3 Inhibitoren der Frakturheilung $\ldots \ldots \ldots$

3.3.1 Endogene Faktoren . . . . . . . . . . . . . . . 20

3.3.2 Exogene Faktoren . . . . . . . . . . . . . . . . . 21

3.4 Frakturbehandlung: Therapieoptionen . . . . . . . . . . . . . 22

3.5 Verzögerte Frakturheilung und Pseudarthrose . . . . . . . . . . . . . . 23 
3.5 .1 Ätiologie . . . . . . . . . . . . . . . . . . . 23

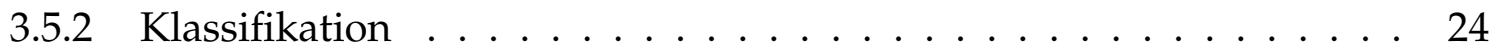

3.5.3 Therapieoptionen der Pseudarthrose . . . . . . . . . . . . . 26

3.5.4 Kombination verschiedener Faktoren $\ldots \ldots \ldots$. . . . . . 32

4 Material und Methoden 33

4.1 Versuchstiere und -haltung, Substanzen und Probengewinnung . . . . . . 33

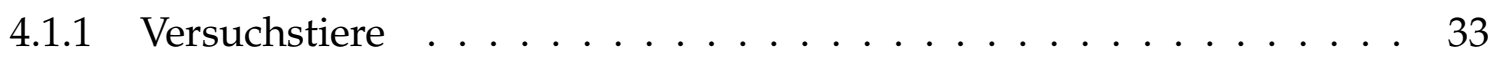

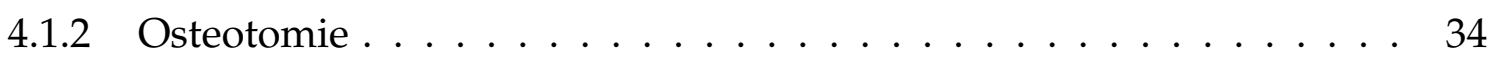

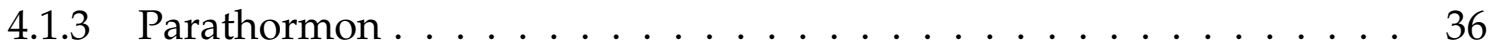

4.1.4 Intravitale Fluoreszenzmarkierung . . . . . . . . . . . . 36

4.1 .5 Obduktion und Präparation . . . . . . . . . . . . . 37

4.1 .6 Präparation der Tibiae . . . . . . . . . . . . . . 38

4.2 Biomechanischer Biegeversuch an der Tibia . . . . . . . . . . . 38

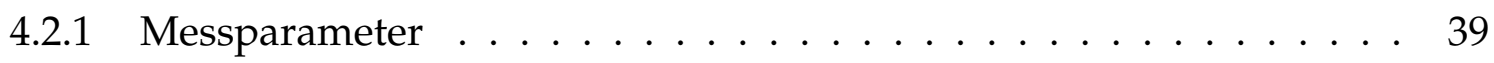

4.2 .2 Auswertung . . . . . . . . . . . . . . . . 41

4.3 Mikroradiographie ....................... 41

4.3 .1 Probenerstellung . . . . . . . . . . . . . . 41

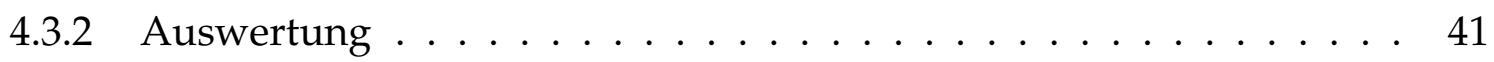

4.3 .3 Messparameter . . . . . . . . . . . . . . . 44

4.4 Polychrome Fluoreszenzmarkierung . . . . . . . . . . . . . . 46

4.4.1 Betrachtung und Digitalisierung der histologischen Präparate . . . . 46

4.4 Auswertung ......................... 46

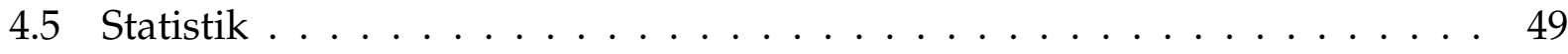

5 Ergebnisse $\quad 50$

5.1 Körpergewicht und Futteraufnahme der Versuchstiere . . . . . . . . . . . . 50

5.2 Ergebnisse des Biegeversuchs an der Tibia . . . . . . . . . . . . . . . 52

5.3 Ergebnisse der Mikroradiographie . . . . . . . . . . . . . . 54

5.4 Ergebnisse der polychromen Fluoreszenzmarkierung . . . . . . . . . 60

5.5 Gesamtübersicht über die Versuchsergebnisse . . . . . . . . . . . . . . 65 
5.5.1 Biomechanischer Biegeversuch . . . . . . . . . . . 65

5.5 .2 Mikroradiographie ..................... 66

5.5 .3 Fluoreszenz ....................... 67

$\begin{array}{lll}6 & \text { Diskussion } & 68\end{array}$

6.1 Frakturheilung und Heilungsverzögerung . . . . . . . . . . . . . . 68

6.2 Stimulationsmöglichkeiten der Frakturheilung . . . . . . . . . . . . . 69

6.3 Medikamentöse Stimulation der Frakturheilung . . . . . . . . . . . . 70

6.3 .1 Parathormon $(\mathrm{PTH}) \ldots \ldots \ldots \ldots$. . . . . . . . . . . . . .

6.3.2 Alternative medikamentöse Stimulatoren der Frakturheilung . . . 76

6.4 Mechanische Stimulation der Frakturheilung . . . . . . . . . . . . . 77

6.5 Die Ratte als Versuchstier für die Frakturheilung . . . . . . . . . . . . . . 78

$\begin{array}{llr}7 & \text { Zusammenfassung } & \mathbf{8 0}\end{array}$

$\begin{array}{ll}\text { Abkürzungsverzeichnis } & 82\end{array}$

$\begin{array}{lr}\text { Literaturverzeichnis } & 84\end{array}$ 


\section{Abbildungsverzeichnis}

2.1 Schematische Darstellung des Knochenaufbaus . . . . . . . . . . . . . . 7

2.2 Schematische Darstellung der Kalziumhomöostase . . . . . . . . . . . . . . 12

3.1 Frakturheilung . . . . . . . . . . . . . . . . . 18

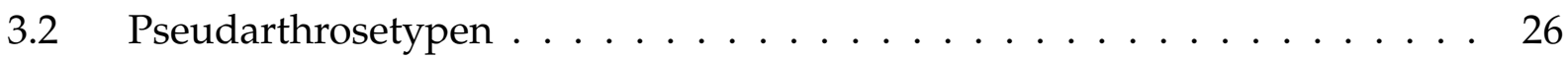

4.1 Zeitlicher Versuchsablauf . . . . . . . . . . . . . . . . 34

4.2 Skelett einer Ratte . . . . . . . . . . . . . . . . . . . . 35

4.3 Osteotomierte Rattentibia und implantierte Platte . . . . . . . . . . . 36

4.4 Biomechanischer Biegeversuch einer Rattentibia . . . . . . . . . . . . 39

4.5 Graph eines biomechanischen Biegeversuchs an einer Rattentibia . . . . 40

4.6 Mikroradiographie und schematische Erläuterung . . . . . . . . . . . . . . 43

4.7 Mikroradiographien und Beispielabbildungen des Fluoreszenzversuches . 47 


\section{Tabellenverzeichnis}

3.1 Risikofaktoren für eine verzögerte Frakturheilung . . . . . . . . . . . . . . 19

4.1 Farbstoffe der polychromen Fluoreszenzmarkierung . . . . . . . . . . . . 37

4.2 Messparameter der Mikroradiographie . . . . . . . . . . . . . . . 45

4.3 Messparameter der Fluoreszenz . . . . . . . . . . . . . . . . . . . . 48

5.1 Graphische Darstellung der Gewichtsentwicklung der Versuchstiere . . . . 51

5.2 Wöchentliche Futteraufnahme während des Versuchs . . . . . . . . . . . . 51

5.3 Yield Load . . . . . . . . . . . . . . . . . . . . . . . . 52 52

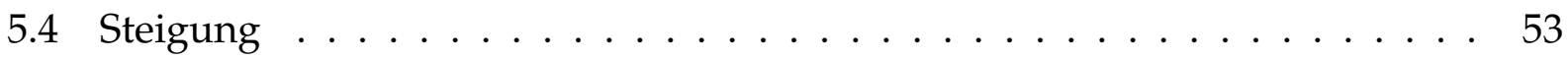

5.5 Kortikalisdicke distal . . . . . . . . . . . . . . . . . . . . . . . 54

5.6 Knochenflächendichte Trabekel distal . . . . . . . . . . . . . . . . . 55

5.7 Knochenflächendichte Kortikalis distal, ventral . . . . . . . . . . . . . . . . . 55

5.8 Knochenflächendichte Kallus . . . . . . . . . . . . . . . . . . . 56

5.9 Kallusdicke ventral . . . . . . . . . . . . . . . . . . . . 57

5.10 Anzahl Trabekelkreuzungen . . . . . . . . . . . . . . . . . . 58

5.11 Dichte Trabekelkreuzungen . . . . . . . . . . . . . . . 58

5.12 Mittlere Trabekeldicke . . . . . . . . . . . . . . . . . . . . . . . 59

5.13 Gesamtübersicht Kallusfläche . . . . . . . . . . . . . . . . . . . . . 60

5.14 Gesamtkallusfläche . . . . . . . . . . . . . . . . . 61

5.15 Kallusfläche Fluoresceinkomplexon (Grün) . . . . . . . . . . . . . . . . 62

5.16 Kallusfläche Alizarinkomplexon (Rot) . . . . . . . . . . . . . . . . 63

5.17 Kallusfläche Tetracyclin-Hydrochlorid (Gelb) . . . . . . . . . . . . . . . . . 64

5.18 Biegeversuch: Ergebnisübersicht . . . . . . . . . . . . . . . 65

5.19 Mikroradiographie: Ergebnisübersicht . . . . . . . . . . . . . . . 66

5.20 Fluoreszenz: Ergebnisübersicht . . . . . . . . . . . . . . . . . 67 


\section{Kapitel 1}

\section{Einleitung}

Die Frakturheilung ist ein komplexer Prozess, der die Regeneration des Knochens und die Wiedererlangung seiner ursprünglichen Belastbarkeit zum Ziel hat. Die Belastbarkeit ist bei einem komplikationslos ablaufenden Heilungsprozess erst nach einigen Wochen bis Monaten erreicht. In 5-10 \% aller Frakturen kommt es zu einer verzögerten oder unvollständigen Heilung (Einhorn, 1995). Dadurch erhöht sich nicht nur für den Patienten der Leidensdruck, es resultieren aus dem protrahierten Verlauf auch erhebliche sozioökonomische Belastungen (Andersson et al., 2011; Aspenberg und Johansson, 2010; Busse et al., 2008). Multiple Faktoren wie Nikotinkonsum, Diabetes mellitus, infektiöse Prozesse oder hohes Lebensalter, aber auch Unter- bzw. Mangelernährung können die Knochenheilung erheblich beeinträchtigen (Mutschler und Haas, 2004; Runkel und Rommens, 2000). Schon allein aufgrund der zunehmenden Lebenserwartung der Bevölkerung ist mit einer weiteren Zunahme an Komplikationen im Rahmen der Frakturheilung in den kommenden Jahren zu rechnen.

Die Frakturheilung ist in den vergangenen Jahren zunehmend in den Fokus der Wissenschaft gerückt. Verzögerte oder unvollständige Vereinigung von Frakturen, auch Pseudarthrosen genannt, werden derzeit in erster Linie durch autologe Knochentransplantationen therapiert. Im Rahmen dieser Verfahren, welche immer einer chirurgischen Intervention bedürfen, kommt es jedoch ebenfalls in 8-10\% der Fälle zu Komplikationen wie Nervenund Gefäßläsionen oder Infektionen (Barnes et al., 2008). Neuerdings stehen osteoinduktive Substanzen wie „bone morphogenetic protein” (BMP) zur Stimulation der Knochenheilung zur Verfügung, welche jedoch ebenfalls direkt in den Frakturspalt eingebracht werden müssen, wozu ein operativer Eingriff notwendig ist.

Parathormon (PTH) reguliert die extrazellulären Kalzium-, Phosphat und Vitamin-D-Konzentrationen und wirkt bei intermittierender Gabe anabol auf den Knochenstoffwechsel 
(Siegenthaler, 2006). Es ist bereits seit 2002 für die Behandlung der Osteoporose zugelassen (Subbiah et al., 2010). Im Gegensatz zu sämtlichen anderen Präparaten, welche den im Rahmen der Osteoporose stattfindenden Knochenabbau verzögern oder verhindern, stimuliert PTH den Knochenstoffwechsel und führt zu einer Erhöhung der Knochendichte und -neubildung (Hodsman et al., 2005). Die systemische Wirkung erfordert zudem keine chirurgische Intervention. Diese Eigenschaften machen Parathormon zu einem vielversprechenden Medikament zur Optimierung der Frakturheilung und Prophylaxe von Pseudarthrosen.

Im Rahmen dieser Arbeit wurde die Wirkung von Parathormon auf den Knochenstoffwechsel und die metaphysäre Frakturheilung von gesunden Ratten untersucht. 


\section{Kapitel 2}

\section{Grundlagen}

\subsection{Knochengewebe}

Als spezialisiertes Bindegewebe nimmt der Knochen neben seiner Stütz- und Haltefunktion auch eine zentrale Stellung im Kalziumhaushalt ein. Knochen setzt sich aus organischen und anorganischen Teilen zusammen. Der ausdifferenzierte Knochen enthält in der Trockensubstanz etwa $35 \%$ organische und $65 \%$ anorganische Bestandteile. Den größten Anteil der anorganischen Salze macht Kalziumphosphat aus. Weiterhin finden sich Kalziumkarbonat, Magnesiumphosphat, Kalziumfluorid und -chlorid sowie Alkalisalze (Frick et al., 1992). Das menschliche Skelett besteht aus 220 Einzelknochen und wiegt insgesamt ca. $10 \mathrm{~kg}$ (Bartl, 2008).

Der gesamte Knochen ist von innen (Endost) und außen (Periost) mit einer Bindegewebeschicht bedeckt. Im Knochen befinden sich zusätzlich rotes und gelbes Knochenmark, Gefäße und Nerven sowie Knorpel- und Bindegewebe (Frick et al., 1992).

Die dichte Substantia corticalis umgibt die schwammartig aufgebaute Substantia spongiosa. Die Substantia corticalis ist von mikroskopisch kleinen Kanälen durchzogen. Die Knochenbälkchen der Substantia spongiosa sind entsprechend der mechanischen Beanspruchung ausgeprägt, wobei sich die Architektur des Knochens der mechanischen Beanspruchung anpasst (Lanyon, 1996). Die Substantia corticalis macht etwa 80\% der Knochenmasse des menschlichen Skeletts aus. Die restlichen $20 \%$ bestehen aus Substantia spongiosa (Liebschner, 2004).

Die Blutversorgung des Knochengewebes erfolgt über den Markraum und das Periost. Die Osteone der langen Röhrenknochen führen ein zentrales Blutgefäß, welches in einem Kanal - dem sogenannten Havers-Kanal - verläuft. Querverbindungen zwischen den Osteonen nennt man Volkmann-Kanäle, welche ebenfalls ein Blutgefäß führen (Drenckhahn 
und Zenker, 1994). Während mechanische Beanspruchung zu einer Zunahme der Knochendichte führt (Courteix et al., 1998), bildet sich der Knochen ohne entsprechende Beanspruchung zurück (Zerwekh et al., 1998). 1892 beschrieb Wolff die Fähigkeit des Knochens, seine Form und Architektur den auf ihn einwirkenden mechanischen Belastungen anzupassen (Wolff, 1892). Im Rahmen dieses permanenten Knochenumbaus, dem sogenannten „Remodeling” , bauen Osteoklasten und Osteoblasten Knochensubstanz parallel auf und ab. Es gibt viele Faktoren, die ein Überwiegen eines der beiden Prozesse bewirken können.

Der spezielle Aufbau des Knochens ermöglicht eine hohe physikalische Härte trotz biologischer Elastizität. Darüber hinaus ist Knochen trotz seiner hohen mechanischen Belastbarkeit verhältnismäßig leicht. Er zählt gemeinsam mit dem Zahnschmelz und dem Zahnbein zu den härtesten Substanzen des Körpers und besitzt eine Druckfestigkeit von ca. $15 \mathrm{~kg} / \mathrm{mm}^{2}$ und eine Zugfestigkeit von ca. $10 \mathrm{~kg} / \mathrm{mm}^{2}$ Querschnitt (Junqueira et al., 2001; Frick et al., 1992).

\subsubsection{Geflechtknochen und Lamellenknochen}

Der Geflechtknochen, auch Primärknochen genannt, entsteht im Rahmen der Knochenentwicklung sowie im Verlauf der Frakturheilung. Nur im Ansatzbereich einiger Sehnen, im Bereich der Suturen der Kalottenknochen des Schädels sowie in den Alveolen der Zähne findet sich beim Erwachsenen Geflechtknochen. Im Vergleich zum Lamellenknochen ist der Mineralgehalt beim Geflechtknochen geringer, was seine höhere Röntgendurchlässigkeit erklärt.

Das erwachsene Skelett besteht hauptsächlich aus Lamellenknochen, auch Sekundärknochen genannt. Makroskopisch sieht man beim Lamellenknochen die äußere kompakte Substantia compacta sowie die zentral gelegene, schwammartig strukturierte sogenannte Substantia spongiosa (Frick et al., 1992).

Die Substantia kortikalis des Erwachsenen besteht aus Osteonen, welche von äußeren und inneren Generallamellen umgeben sind. Die Lamellen können entsprechend der Lokalisation und Beanspruchung ihre Ausrichtung anpassen. Osteone sind ca. 0,5 mm lange, zylindrische Strukturen mit einem zentral verlaufenden Blutgefäß (Drenckhahn und Zenker, 1994). 


\subsubsection{Knochenspezifische Zellen}

\subsubsection{Osteoblasten}

Osteoblasten synthetisieren und sezernieren die organischen Komponenten der Knochenmatrix. Im Wesentlichen handelt es sich hierbei um Typ-I-Kollagen, Proteoglykane und Glykoproteine. Außerdem sind sie an der Bildung der Hartsubstanz beteiligt. Diese Zellen finden sich an der Knochenoberfläche der Trabekel der Substantia spongiosa.

Die noch nicht verkalkte Matrix wird als Osteoid bezeichnet. Sie wird durch Einlagerung von Kalziumphosphat in die stabilere Knochenmatrix umgewandelt. Dieser Vorgang des oberflächlichen Wachstums wird Apposition genannt (Junqueira et al., 2001). Die Aktivierung der Osteoblasten erfolgt durch Hormone, Wachstumsfaktoren sowie durch mechanische Stimulation (Papachroni et al., 2009).

\subsubsection{Osteozyten}

Als Osteozyten bezeichnet man die während des Verkalkungsprozesses in die neu entstandene Matrix eingelagerten Osteoblasten. Die Osteozyten lagern in Knochenhöhlen, den Lacunen. Mit benachbarten Osteozyten sind sie über Gap Junctions am Ende ihrer Fortsätze verbunden. Diese Zellen nehmen eine zentrale Rolle in der Verarbeitung mechanischer Reize und der daraus resultierenden Stimulation zum Knochenaufbau ein (Junqueira et al., 2001; Burger und Klein-Nulend, 1999). Wenn Osteozyten sterben, wird die umgebende Knochenmatrix abgebaut (Junqueira et al., 2001).

\subsubsection{Osteoklasten}

Im Gegensatz zu den Osteoblasten resorbieren Osteoklasten Knochengewebe. Sie differenzieren sich aus mit den Monozyten und Makrophagen verwandten Vorläuferzellen des Knochenmarks und verschmelzen an der Knochenoberfläche zu mehrkernigen Synzytien. Sie liegen in Howship-Lakunen, welche flache Aushöhlungen der Knochenoberfläche sind. Kalzitonin hemmt die Aktivität dieser Zellen, wohingegen bestimmte, von Osteoblasten sezernierte Zytokine eine aktivierende Wirkung haben. Darüber hinaus gibt es zahlreiche andere Faktoren wie Interleukin-1, TNF, Interferon- $\gamma$, koloniestimulierende Faktoren, die die Aktivität der Osteoklasten modulieren (Frick et al., 1992). 


\subsubsection{Knochenmatrix}

Wie anfangs beschrieben, bestehen die anorganischen Knochenbestandteile zum größten Teil aus Kalziumphosphat (85\%). Weiterhin finden sich Kalziumkarbonat (10\%), Magnesiumphosphat (0,3\%), Kalziumfluorid (0,2\%), Kalziumchlorid (0,2\%) und etwa $2 \%$ Alkalisalze (Frick et al., 1992). Der organische Anteil besteht zu 95\% aus Kollagen Typ I. Der Rest besteht aus Proteoglykanen und Glykoproteinen (z.B. Osteokalzin, Sialoprotein). Diese sind vermutlich für die Verkalkung der Matrix verantwortlich, da normalerweise andere, aus Kollagen Typ I bestehende Gewebe nicht kalzifizieren. Diese Baustoffkombination verleiht dem Knochen seine charakteristischen mechanischen Eigenschaften: Entkalkt man den Knochen, wird dieser biegsam, obwohl er seine Form beibehält. Dagegen wird er zerbrechlich und spröde, wenn das Kollagen entfernt wird. Die Kollagenfasern sind in erster Linie für die Zugfestigkeit, die im Knochen enthaltenen Minerale für die Druckfestigkeit verantwortlich (Junqueira et al., 2001).

\subsection{Funktionen des Knochens}

Das menschliche Skelett hat eine Stützfunktion, indem es das Körpergewicht trägt. Es schützt Thorax- und Bauchorgane sowie das Zentrale Nervensystem. Den über Sehnen ansetzenden Skelettmuskeln dienen die Skelettknochen als Hebel bei der Bewegungsausführung. Knochen haben jedoch darüber hinaus eine zentrale Stellung bei wichtigen Stoffwechselvorgängen. Das Skelett stellt ein wichtiges Speicherorgan vor allem für Kalzium und Phosphat dar. Die Konstanthaltung des Serumkalziumspiegels ist eine lebensnotwendige Voraussetzung, welche durch den Kalziumstoffwechsel, an dem das Skelett maßgeblich beteiligt ist, gewährleistet wird. Unter dem Einfluss hormoneller Substanzen wird entsprechend dem aktuellen Bedarf Kalzium in die Knochen eingelagert oder im Serum bereit gestellt. Auch am Phosphatstoffwechsel ist das Skelett beteiligt (Frick et al., 1992).

\subsection{Kalziumhomöostase}

Die Kalziumhomöostase läuft zwischen dem Skelett, dem Magen-Darm-Trakt und den Nieren ab. Sie wird von drei Hormonen - Parathormon, Kalzitriol und Kalzitonin - reguliert. Die Kalziumresorption erfolgt über den Magen-Darm-Trakt, wobei die tägliche optimale Zufuhr $1.000 \mathrm{mg}$ beträgt. Hiervon werden etwa $400 \mathrm{mg}$ in die Blutbahn resorbiert, 


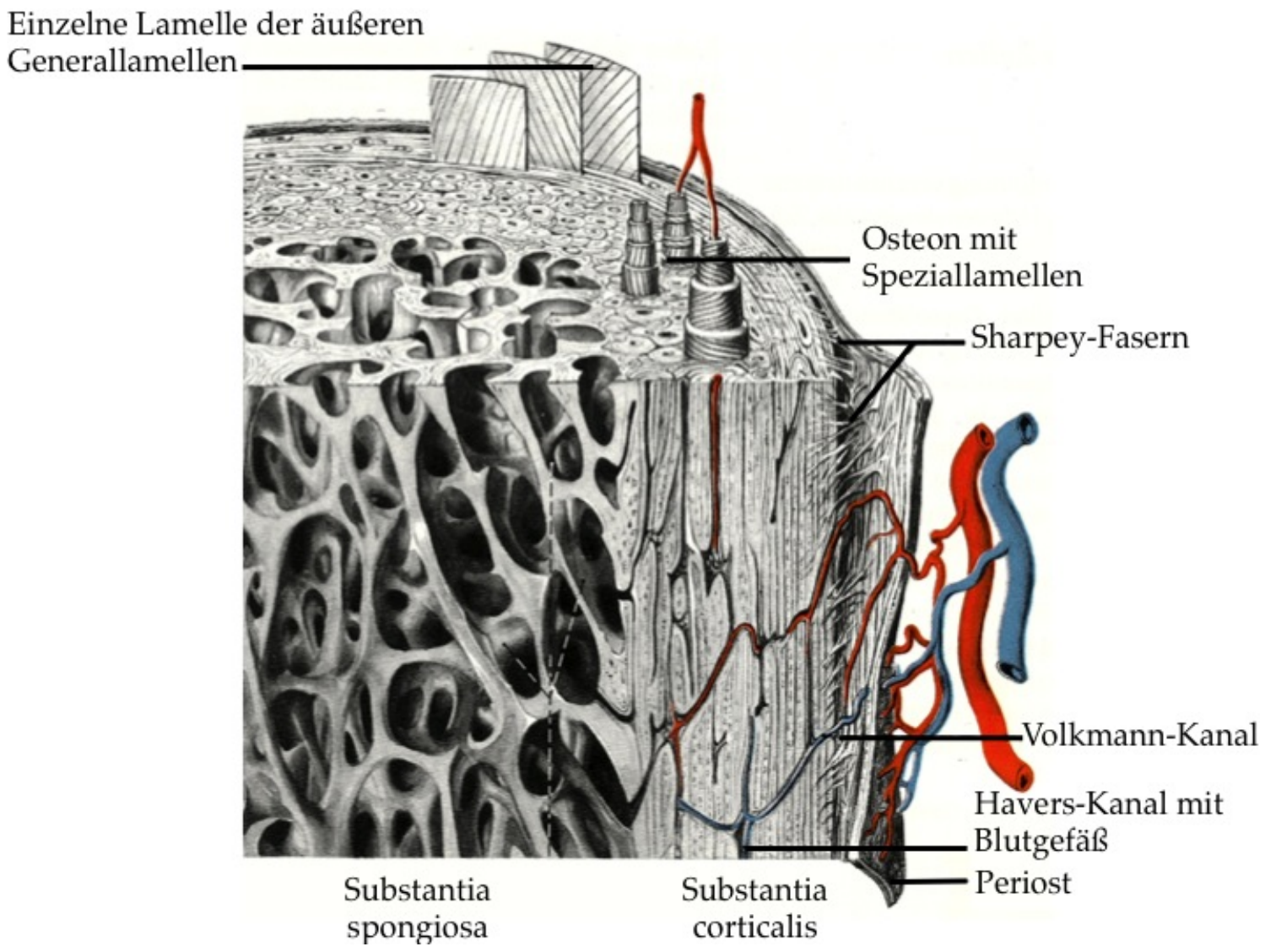

Abbildung 2.1: Schematischer Knochenaufbau: Die zylinderförmig herausragenden Strukturen entsprechen den Osteonen. Sie bestehen aus Kollagenfasern mit unterschiedlichem Steigungswinkel, welche sich entsprechend der Lokalisation und Beanspruchung ausrichten. Die äußeren Generallamellen grenzen die Substantia compacta nach außen ab. Innere Generallamellen (nicht dargestellt) grenzen die Substantia compacta zum Markraum ab. Die Blutversorgung erfolgt über den Markraum und das Periost. Von außen gelangen die Blutgefäße über Volkmann-Kanäle in die Havers-Kanäle. Die Sharpey-Fasern sind im Rahmen des Ossifikationsprozesses eingemauerte Kollagenfasern (modifiziert nach Drenckhahn und Zenker, 1994, S. 147 
wovon die Hälfte wieder in das Darmlumen zurück sezerniert wird. Der Niere kommt gemeinsam mit dem Darm die Funktion der Ausscheidung von überschüssigem Kalzium zu. Da über die Niere etwa $10.000 \mathrm{mg}$ Kalzium pro Tag filtriert werden, wovon etwa $9.800 \mathrm{mg}$ rückresorbiert werden, ist die Gesamtbilanz von Magen-Darm- und Harntrakt ausgeglichen. Im Skelett wird Kalzium gespeichert. Der tägliche Kalziumumsatz im Skelett beträgt etwa $500 \mathrm{mg}$. Das Gesamtgewicht des im Skelett gespeicherten Kalziums beträgt etwa ein Kilogramm (Siegenthaler, 2006).

\subsubsection{Parathormon}

Parathormon (PTH) nimmt eine zentrale Rolle in der Kalziumhomöostase ein. Seine Hauptaufgabe besteht in der Konstanthaltung des Serumkalziumspiegels (Rosen und Bilezikian, 2001). Ein erniedrigter extrazellulärer Kalziumspiegel führt in der Nebenschilddrüse zu einer vermehrten PTH-Produktion und -sekretion. Hemmend auf die PTH-Sekretion wirken erhöhte Kalziumserumspiegel sowie eine erhöhte Kalzitriolkonzentration, wobei die Sekretion dieses Hormons wiederum durch PTH stimuliert wird (Hodsman et al., 2005).

\subsubsection{Biosynthese}

Die Synthese erfolgt im endoplasmatischen Retikulum der Nebenschilddrüsen, wobei das aus 84 Aminosäuren bestehende Prä-Pro-Hormon (hPTH 1-84) eine Präsequenz bestehend aus 25 Aminosäuren und eine Prosequenz bestehend aus sechs Aminosäuren enthält. Die Speicherung erfolgt in Sekretionsvesikeln. Bei der Sekretion werden 31 Aminosäuren abgespalten (Hodsman et al., 2005).

\subsubsection{Wirkung}

Die Regulierung des Kalziumspiegels bewirkt Parathormon über drei verschiedene Wege:

1. Förderung der Kalziumreabsorption an der Niere

2. Steigerung der Phosphatausscheidung über die Niere durch Hemmung der Phosphatreabsorption

3. Förderung der Kalzitriolbildung aus Kalzidiol durch Stimulation der 1- $\alpha$-Hydroxylase. Kalzitriol steigert die Kalziumabsorption aus dem Darm 
Am Knochen regt PTH den Knochenumbau an, indem es die Osteoklasten aktiviert. Es kommt zu einem Kalzium- und Phosphatanstieg in der Blutbahn. Das überflüssige Phosphat wird über die Niere ausgeschieden (Siegenthaler, 2006).

Allerdings besitzen Osteoklasten keinen eigenen PTH-Rezeptor. Vielmehr kommt es unter dem Einfluss von Parathormon zu einer gesteigerten Expression von „receptor activator of NF-kB ligand" (RANKL) und einer Hemmung der Expression von Osteoprotegerin (OPG). Beide sind wesentliche Bestandteile des RANKL-Osteoprotegerin-Zytokinsystems. Osteoprotegerin (OPG) gehört zur Tumornekrosefaktor (TNF)-Rezeptorfamilie. Es wird von Osteoblasten produziert und blockiert die Ausdifferenzierung der Osteoklasten aus Vorläuferzellen, wodurch es die Knochenresorption hemmt. Antagonistisch wirkt RANKL. Es gehört auch zur Familie der TNF und ist als Hauptstimulans für die Osteoklastenreifung essentiell für deren Überleben. Es wird von T-Lymphozyten und Osteoblasten produziert und aktiviert den Rezeptor RANK. Dieser Rezeptor befindet sich auf der Oberfläche von Osteoklasten, dendritischen Zellen, glatten Muskelzellen sowie Endothelzellen (Bartl, 2008).

Die Sekretion und Biosynthese des Hormons wird durch niedrige Serumkalziumspiegel getriggert. Gegenteilig wirken erhöhte Serumkalziumspiegel sowie Serumkalzitriolwerte auf die PTH-Sekretion. Kalzitriol wird durch die PTH-Wirkung vermehrt gebildet. Über einen „,negative feedback”-Mechanismus hemmt Kalzitriol jedoch die PTH-Sekretion. Eine Hypermagnesiämie hemmt ebenfalls die PTH-Sekretion. Katecholamine und Lithium hingegen können die Sekretion von PTH fördern. PTH gelangt über den Blutweg an den Wirkungsort (Siegenthaler, 2006). Abbildung 2.2 auf Seite 12 zeigt eine schematische Darstellung des Kalziumstoffwechsels und der drei ihn regulierenden Horomone. Der hormonelle Gegenspieler von Parathormon ist Kalzitonin (siehe Abschnitt 2.3.3 auf Seite 11).

\section{Wirkung von PTH auf die Knochenreparatur}

Eine Vielzahl an tierexperimentellen Studien belegt die stimulierende Wirkung von PTH auf die Kallusbildung. Die genauen Mechanismen sind noch nicht vollständig geklärt, allerdings greift PTH an mehreren Phasen des komplexen Knochenheilungsprozesses (siehe Abschnitt 3.2.1 auf Seite 16) an (Ellegaard et al., 2010).

\section{Stimulation der Proliferation und Differenzierung mesenchymaler Stammzellen}

Während der frühen Phase der Frakturheilung differenzieren sich mesenchymale Stammzellen zu Osteoblasten. Dieser Prozess wird durch PTH verstärkt (Nakajima et al., 2002; 
Kaback et al., 2008). Darüber hinaus kommt es zu einem Anstieg von Chondroprogenitorzellen (Nakajima et al., 2002).

\section{Förderung der enchondralen Ossifikation}

Eine Untersuchung der Frakturheilung von Femurfrakturen an Mäusen zeigte, dass die mit PTH behandelten Tiere eine bis zu dreifach erhöhte Chondrogenese in Relation zur Osteogenese im Vergleich zu den nicht behandelten Tieren aufwiesen. Dadurch kommt es zunächst zu einer gesteigerten weichen Kallusbildung und im Anschluss durch die Chondrozytenreifung zu einer erhöhten Mineralisation dieses Kallus (Kakar et al., 2007).

\section{Steigerung des Remodelings}

Nach der initialen Frakturüberbrückung durch den weichen Kallus und Geflechtknochen (siehe Abschnitt 3.2.1 auf Seite 16) kommt es zum Umbau zu Lamellenknochen. Es bilden sich Havers-Systeme, Periost und Endost sowie eine neue Kortikalis (Mutschler und Haas, 2004). Unter dem Einfluss von PTH wird dieser Umwandlungsprozess von Geflecht- in Lamellenknochen beschleunigt (Komatsubara et al., 2005). PTH stimuliert direkt die Osteoblasten und hemmt deren Apoptose (Jilka, 2007).

\subsubsection{Kalzitriol (Vitamin D)}

Vitamin D wird mit der Nahrung aufgenommen oder vom Organismus endogen produziert. Es ist der wesentliche Regulator des Kalziumhaushalts und essentiell im Mineralisierungsprozess des Skeletts. Die Aufnahme dieses fettlöslichen Vitamins erfolgt über den Darm. Es kommt in zwei Varianten vor: Cholekalziferol (Vitamin $\mathrm{D}_{3}$ ) und Ergokalziferol (Vitamin $\mathrm{D}_{2}$ ). Ergokalziferol wird ausschließlich von Pflanzen synthetisiert, wohingegen Cholekalziferol tierischer Herkunft ist und somit auch vom menschlichen Organismus produziert werden kann. In der Haut werden beide Moleküle durch UV-B-Strahlen in Vitamin- $\mathrm{D}_{3}$ - bzw. Vitamin- $\mathrm{D}_{2}$-Prohormon umgewandelt, indem der B-Ring geöffnet wird. Die Aktivierung erfolgt, indem beide Vitamin-D-Prohormone nacheinander zunächst in der Leber an C-25 und anschließend in der Niere an C-1 unter dem Einfluss von Parathormon hydroxyliert werden. Hierdurch entsteht entweder $1,25(\mathrm{OH})_{2} \mathrm{D}_{2}$ oder $1,25(\mathrm{OH})_{2} \mathrm{D}_{3}$ (Marcus et al., 2010; Schmidt und Thews, 1995).

Ein niedriger Serumkalziumspiegel führt zur vermehrten Ausschüttung von Parathormon, welches wiederum die Umwandlung der Prohormone in die biologisch wirksamen 
1,25-dihidroxylierten Vitamin-D-Hormone steigert. Hierdurch wird die Resorption von Kalziumionen am Darmepithel gesteigert. Über einen „,negative-feedback” -Mechanismus inhibieren die Vitamin-D-Hormone die Parathormonsekretion (Schmidt und Thews, 1995). Die Wirkung von Vitamin D auf den Kalziumstoffwechsel ist in Abbildung 2.2 auf Seite 12 dargestellt.

\subsubsection{Kalzitonin}

Kalzitonin wird von den C-Zellen der Schilddrüse produziert. Es besteht aus 32 Aminosäuren. Die Ausschüttung wird durch erhöhte Blutkalziumspiegel getriggert. Kalzitonin bewirkt eine Steigerung des Kalziumeinbaus in den Knochen und eine Reduktion der osteolytischen Prozesse. Somit wirkt es antagonistisch zu Parathormon. Gastrointestinale Hormone wie Gastrin, Glukagon, Pankreozymin und Cholezystokinin steigern die Kalzitoninausschüttung ebenfalls, was zu erhöhten Spiegeln dieses Hormons während der Nahrungsaufnahme führt. Dadurch kommt es zum Einbau des mit der Nahrung aufgenommenen Kalziums in den Knochen. Darüber hinaus wird der Verdauungsprozess durch Kalzitonin gebremst. Unter anderem wird die Magenentleerung verlangsamt und die Magen- und Pankreassekretion reduziert, wodurch ein rascher postprandialer Anstieg des Kalziumserumspiegels verhindert wird. Hohe Kalziumkonzentrationen im Serum inhibieren die PTH-Sekretion und somit die kalziumerhaltende Wirkung von PTH an der Niere. In der Folge würde das über die Nahrung aufgenommene Kalzium unmittelbar über die Niere ausgeschieden (Schmidt und Thews, 1995). Siehe auch Abbildung 2.2 auf Seite 12.

\subsection{Therapeutischer Einsatz von Parathormon}

Im klinischen Alltag wird Teriparatid bereits bei postmenopausalen Frauen mit Osteoporose zur Frakturprophylaxe eingesetzt. Eine Genehmigung zum Einsatz im Rahmen der Frakturbehandlung existiert noch nicht. Teriparatid ist ein synthetisches Polypeptid, welches das 1-34-Aminofragment des rekombinanten humanen Parathormons enthält. Sämtliche andere im Rahmen der Osteoporosetherapie zum Einsatz kommenden Präparate wirken, indem sie die Knochenresorption hemmen. Teriparatid ist das einzige zur Therapie der Osteoporose zugelassene Präparat, welches anabol auf den Knochenstoff- 


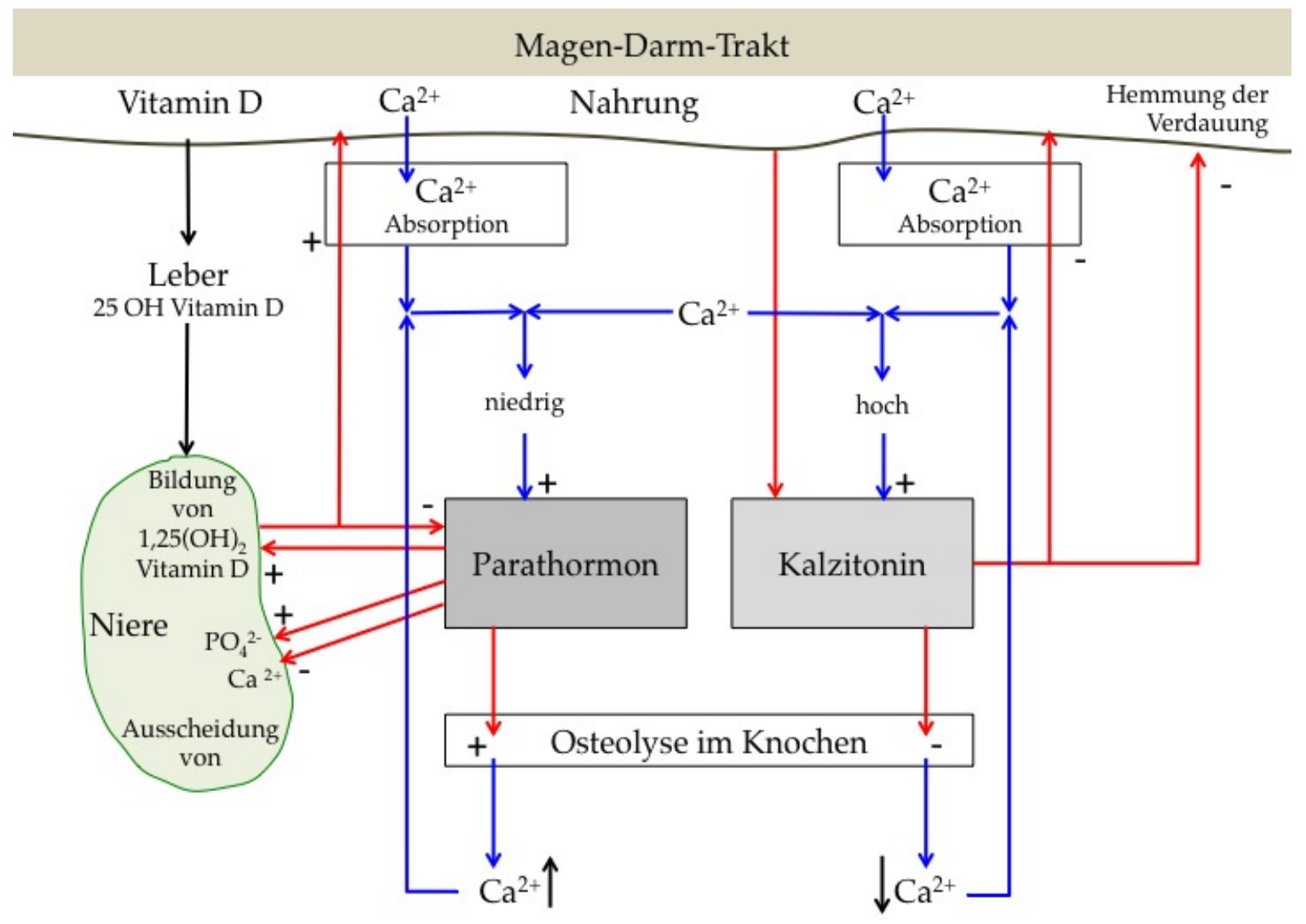

Abbildung 2.2: Kalziumhomöostase (modifiziert nach Schmidt und Thews, 1995, S. 404): Durch niedrige Kalziumserumspiegel kommt es zu einer vermehrten PTH-Sekretion, was den Knochenabbau fördert. Durch eine Steigerung der Vitamin-D-Produktion in der Niere kommt es zu einer vermehrten Kalziumresorption aus dem Darm. Hohe Kalziumserumspiegel führen dagegen zu einer Sekretion von Kalzitonin aus den C-Zellen der Schilddrüse. Knochenabbau und Kalziumresorption aus dem Darm werden gedrosselt. Die Kalzitoninsekretion wird außerdem bei Nahrungsaufnahme gesteigert 
wechsel wirkt (Ellegaard et al., 2010). Diese osteoanabole Wirkung von PTH tritt nur bei intermittierender Gabe auf. Die kontinuierliche Applikation wirkt katabol auf den Knochenstoffwechsel (Ma et al., 2001; Wang et al., 2005). Beim Menschen führt die tägliche subkutane Applikation zu einer Steigerung der Knochendichte an der Lendenwirbelsäule und dem Schenkelhals (Cipriano et al., 2009).

Tierexperimentelle Versuche an Mäusen zeigten, dass Knorpelschäden unter dem Einfluss von Parathormon besser regeneriert wurden als bei der Kontrollgruppe, welche mit Kochsalzlösung behandelt worden war (Sampson et al., 2011; Sampson, 2009b).

Tierexperimentelle Studien an Kaninchen zeigten eine bessere Regenerationsfähigkeit von an der Femurkondyle gesetzten Knorpeldefekten unter der Wirkung von PTH als die Kontrollgruppe, welche Kochsalz verabreicht bekam (Sampson, 2009a; Kudo et al., 2011).

Teriparatid wird derzeit subkutan injiziert, da die Substanz innerhalb kurzer Zeit von den im Verdauungstrakt vorkommenden Enzymen Trypsin, Chymotrypsin und Pepsin abgebaut wird (Werle et al., 2006). Bis dato existiert keine alternative Applikationsform, um eine der subkutanen Applikation äquivalente systemische Konzentration zu erzielen (Chalidis et al., 2007).

Erste klinische Studien zur Wirkung von Teriparatid auf die Frakturheilung beim Menschen zeigen, dass Parathormon die Knochenheilung positiv beeinflusst. (Aspenberg und Johansson, 2010); (Aspenberg et al., 2010); (Barnes et al., 2008).

\subsubsection{Nebenwirkungen}

Übelkeit (18\%) und Kopfschmerzen (13\%) waren die häufigsten Nebenwirkungen im Rahmen eines Patientenkollektivs von 59 Frauen, welche eine tägliche Dosierung von $40 \mu \mathrm{g} / \mathrm{kg}$ erhielten (Neer et al., 2001). Geringe Serumkalziumspiegelanstiege können innerhalb von sechs Stunden nach Verabreichung auftreten. In einer Studie an 350 postmenopausalen Osteoporosepatientinnen überstiegen sie jedoch nicht die physiologischen Werte (Satterwhite et al., 2010). Als Zeichen einer Hyperkalzämie kann es zu Schwindel, Beinkrämpfen, Benommenheit, Verstopfung, Abgeschlagenheit und Muskelschwäche kommen (Cipriano et al., 2009).

In einigen tierexperimentellen Studien wurde ein Zusammenhang zwischen der Therapie mit PTH und der Inzidenz von Osteosarkomen bei den Versuchstieren nachgewiesen. Das Osteosarkom ist der häufigste primäre Knochentumor beim Menschen. Am häufigsten tritt er bei Jugendlichen auf. Einige Autoren haben eine Korrelation zwischen dem 
schnell wachsenden Knochen während der Pubertät und diesem Knochentumor hergestellt (Broadhead et al., 2011). Ein zweiter Häufigkeitspeak ergibt sich bei der Bevölkerungsgruppe der 7. und 8. Lebensdekade. Nicht selten sind es dann jedoch sekundäre Formen als Folge z.B. eines Morbus Paget oder einer vorbestehenden benignen Knochenläsion. Seine Inzidenz ist jedoch selten und liegt unter $1 \%$ aller in den USA neu diagnostizierten Malignome. Durch die Einführung neuer Therapieoptionen, u.a. Chemotherapie, konnte die 5-Jahres-Überlebensrate von $20 \%$ vor 1980 auf ca. $70 \%$ gehoben werden (Mirabello et al., 2009).

Als Risikofaktoren werden in der Literatur physikalische, chemische und biologische Noxen erwähnt. Unter den physikalischen Noxen gelten ultraviolette und ionisierende Strahlen als gesichert. Als chemische Noxen sind in der Literatur diverse Substanzen erwähnt, darunter auch Asbest. Des Weiteren gelten diverse genetische Faktoren als Risikofaktor für die Entstehung eines Osteosarkoms. Außer Parathormon werden diverse Wachstumsfaktoren wie „transforming growth factor” (TGF) als Risikofaktoren oder Faktoren, welche zu einer schlechteren Prognose führen können, erwähnt (Broadhead et al., 2011). 


\section{Kapitel 3}

\section{Frakturentstehung und Frakturheilung}

\subsection{Frakturentstehung}

Frakturen resultieren aus einer die Stabilität des Knochens übersteigenden von außen einwirkenden Kraft. Es gibt exogene und endogene Faktoren, die eine Fraktur begünstigen können. Sie entstehen in Abhängigkeit von der Dauer und Richtung der Krafteinwirkung sowie der Intensität und dem Ort. Außerdem spielen Knochenrigidität und -volumen eine entscheidende Rolle (Mutschler und Haas, 2004).

\subsection{Frakturheilung}

Ziel der Frakturheilung ist die Wiederherstellung der Knochenstruktur, seines Aufbaus und seiner Funktion. Etwa 90-95 \% sämtlicher Frakturen in den Vereinigten Staaten von Amerika werden erfolgreich behandelt (Einhorn, 1995). Es sind multiple Faktoren bekannt, die den Heilungsverlauf einer Fraktur verzögern oder gänzlich verhindern können. Hierzu zählen Art und Schwere der Verletzung, Vorerkrankungen, Medikamente, exogene Noxen. Außerdem kommt es an bestimmten Frakturlokalisationen wie dem Kahnbein der Hand, dem Talus des Fußes und dem Oberschenkelhals überdurchschnittlich häufig zu Problemen während der Frakturheilung. Ursächlich hierfür ist die Gefäßversorgung, welche an diesen Lokalisationen nur spärlich ist (Runkel und Rommens, 2000). Im Rahmen des Traumas können diese Gefäße verletzt und die lokale Durchblutung erheblich beeinträchtig werden, wodurch die Heilung verzögert oder verhindert wird. Vergleiche hierzu Tabelle 3.1 auf Seite 19.

Man unterscheidet die direkte von der indirekten Frakturheilung. Im folgenden sind bei- 
de Prozesse beschrieben.

\subsubsection{Indirekte Frakturheilung}

Es bildet sich zunächst ein periostaler und endostaler Kallus, welcher im Verlauf des Heilungsprozesses umgebaut wird, bis es zur vollständigen Frakturheilung kommt. In der Regel heilt Knochen auf diesem Wege. Sowohl bei der konservativen Frakturbehandlung als auch bei den meisten operativen Verfahren tritt diese Form der Frakturheilung auf. Die indirekte Frakturheilung läuft analog der Wundheilung über fünf Phasen ab.

Verletzungsphase: Durch eine die Festigkeit des Knochens übersteigende Gewalteinwirkung kommt es zur Fraktur.

Entzündungsphase: Unmittelbar nach der Frakturierung des Knochens bildet sich in der Umgebung ein Hämatom. Dieses wird von Granulozyten, Mastzellen und Monozyten infiltriert. Die Mastzellen setzen Histamin frei, was im Rahmen der Entzündungsreaktion zu einer Dilatation der Kapillaren im Verletzungsgebiet führt. Aus den eingewanderten Monozyten bilden sich Makrophagen. Außerdem sind Monozyten die Ursprungszellen für Osteoklasten. Weiterhin finden sich im Hämatom pluripotente Stammzellen mesenchymaler Herkunft als Vorläufer der Osteoblasten. Die pluripotenten Stammzellen sezernieren für die Angiogenese, Zellinfiltration und -differenzierung wichtige Zytokine und Wachstumsfaktoren. Die sich neu bildenden Gefäße entspringen hauptsächlich aus den periostalen Gefäßen. Durch diese Hypervaskularisation kann das Frakturhämatom von zahlreichen einwandernden Entzündungszellen phagozytiert werden. Unter Beteiligung des Gerinnungsfaktors XIII bildet sich im Frakturspalt zunächst ein Fibringerüst (Mutschler und Haas, 2004). Siehe Abbildung 3.1 auf Seite 18.

Granulationsphase: Reguliert durch verschiedene lokal wirksame Wachstumsfaktoren bildet sich Granulationsgewebe entlang einer extrazellulären Matrix. Zu diesen Wachstumsfaktoren zählen TGF-131, IGF-1 und IGF-2, aFGF, bFGF, PDGF, BMP und B2-Mikroglobulin. Darüber hinaus passt der Organismus den Kalziumstoffwechsel über den Parathormon- und Vitamin-D-Stoffwechsel an. Über das mediatorgesteuert neu gebildete Gefäßgeflecht gelangen erforderliche Bausteine in die Frakturregion, und es entsteht in erster Linie Typ-I-Kollagen. Mediatorgesteuert kommt es zur Angiogenese. Zwischen diesen Kollagenfibrillen lagern sich zunehmend Mineraldepots ab, und nach vier bis sechs 
Wochen hat sich ein weicher Kallus (Fixationskallus) ausgebildet. Dieser Prozess geht von den Spindelzell- oder Osteoprogenitorzellen des Periosts aus und schreitet zentral in Richtung der Frakturzone voran. Die Spindelzellen differenzieren sich dabei zu Osteoblasten. Über die sogenannte „,bone metabolizing unit” (BMU), welche Osteoklasten, Matrixsubstanz und Osteoblasten beinhaltet, wird der zerstörte Knochen partiell abgebaut und durch Geflechtknochen ersetzt. Makrophagen schütten Matrixproteine wie Osteocalcin, Osteogenin und „bone morphogenetic protein” (BMP) aus, welche die Osteoblastenproliferation fördern. Der zentral gelegene, zum Teil nekrotische Knochen wird von Osteoklasten und Makrophagen abgebaut. Einwandernde chondroide Zellen, Osteochondroblasten und Osteoblasten führen im Verlauf zur enchondralen Ossifikation (Mutschler und Haas, 2004). Siehe Abbildung 3.1 auf Seite 18.

Kallusaushärtung: Der weiche Kallus wird zunehmend mineralisiert, wodurch Geflechtknochen entsteht. Diese Phase dauert etwa drei bis vier Monate an (Mutschler und Haas, 2004). Siehe Abbildung 3.1 auf Seite 18.

Umbauphase (Remodeling): Dieser Vorgang erstreckt sich über sechs bis 24 Monate. Über die BMU wird der Geflechtknochen progredient in lamellären Knochen mit HaversSystemen, Periost und Endost umgebaut. Hierdurch wird der Knochen zunehmend auf die reguläre Nutrition über das Havers- und Volkmann-Kanalsystem umgestellt (Mutschler und Haas, 2004). Siehe Abbildung 3.1 auf Seite 18.

\subsubsection{Direkte Frakturheilung}

Die direkte Frakturheilung ist ausschließlich bei Wiederherstellung der stabilen, anatomischen Knochenstruktur möglich und tritt nur bei Fissuren oder nach exakter operativer Reposition und Kompressionsplattenosteosynthese auf. Man unterscheidet zwischen Kontaktheilung und Spaltheilung (Mutschler und Haas, 2004).

Kontaktheilung Die Havers-Systeme wachsen in die gegenüberliegende Frakturzone, wobei Osteoklasten Kanäle in das gegenüberliegende Ende schneiden, welche zunächst von Kapillaren und Entzündungszellen und im weiteren Verlauf von Osteoblasten aufgefüllt werden. Hierdurch entstehen neue Knochenlamellen (Mutschler und Haas, 2004).

Spaltheilung Im Gegensatz zur Kontaktheilung besteht ein Frakturspalt von weniger als $0,5 \mathrm{~mm}$, welcher quer zur Achse mit Geflechtknochen aufgefüllt wird. Nachträglich 
a.

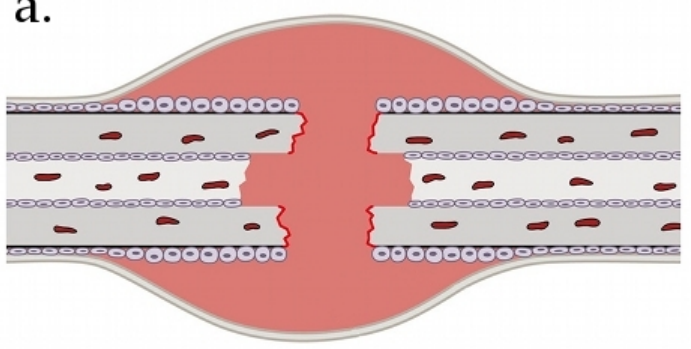

C.
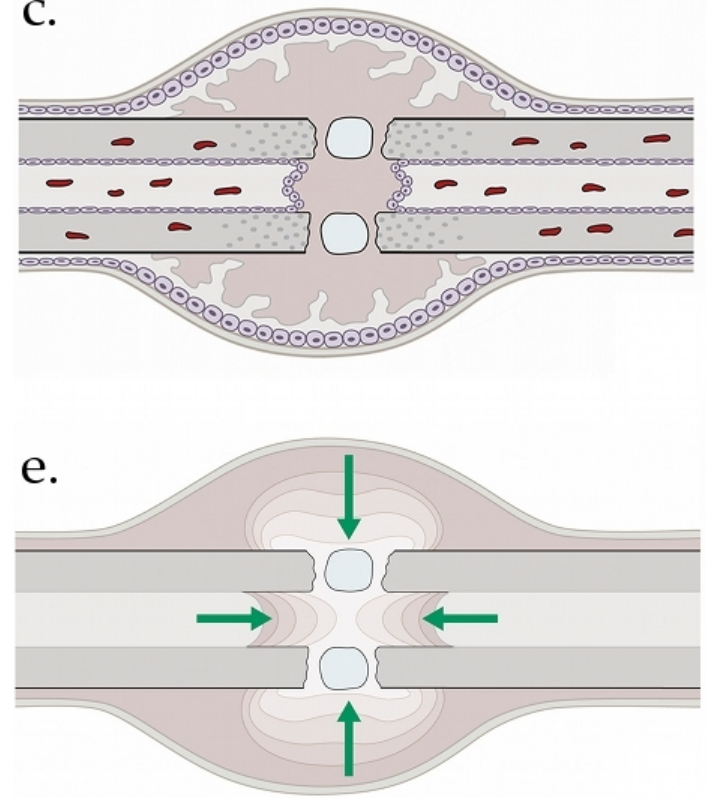

b.
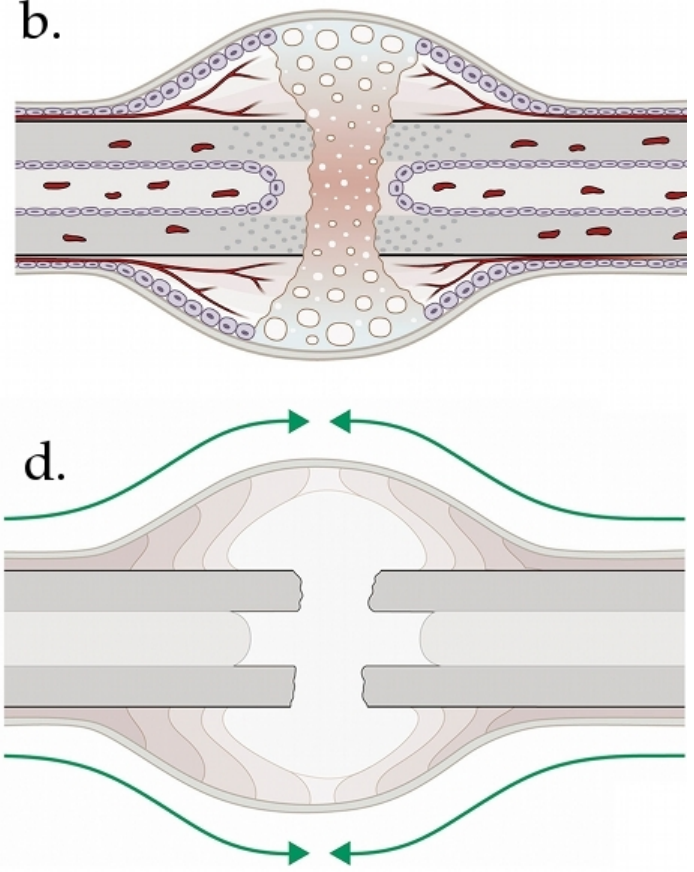

f.

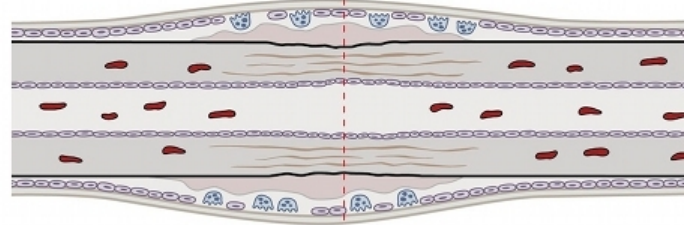

Abbildung 3.1: Die Frakturheilung läuft über fünf Phasen ab. Entzündungsphase (a.): Im Frakturspalt entsteht ein Hämatom. Hier befinden sich Fibroblasten, Granulozyten, Makrophagen und mesenchymale Stammzellen. Das Hämatom bildet sich graduell in Granulationsgewebe um. Im weiteren Verlauf bildet sich ein weicher Kallus (b.). Es bildet sich eine knöcherne Hülle. Das Granulationsgewebe wird graduell in fibrinöses Gewebe und Knorpelgewebe umgewandelt. Von beiden Frakturenden sprossen Kapillaren ein. Die Mineralisierung schreitet von peripher nach zentral voran. Entstehung des harten Kallus (c.-e.): Durch intramembranöse und enchondrale Knochenneubildung härtet der Kallus langsam aus. Im Zuge des Remodelings (d.) kommt es zum Umbau von Geflechtknochen in lamellären Knochen. Dies geschieht durch Oberflächenerosion und osteonalen Umbau (modifiziert nach Rüedi et al., 2008) 
wird dieser durch längsgerichtete Knochenkanäle ersetzt (Mutschler und Haas, 2004).

\subsection{Inhibitoren der Frakturheilung}

Verschiedene Einflussfaktoren können die Heilung von Frakturen fördern oder beeinträchtigen. Frakturlokalisation, Begleitverletzungen des Weichteilmantels oder große Knochendefekte haben einen negativen Einfluss auf die Frakturheilung. Darüber hinaus gibt es diverse Substanzen und Erkrankungen, welche die Frakturheilung beeinträchtigen können. Eine Auswahl ist im Folgenden dargestellt (Mutschler und Haas, 2004).

\begin{tabular}{ll}
\hline Störung der Durchblutung & $\begin{array}{l}\text { Vaskulopathien } \\
\text { traumatische Gefäßläsionen } \\
\text { Deperiostierung } \\
\text { Kompartmentsyndrom }\end{array}$ \\
\hline OP-technik-bedingt & $\begin{array}{l}\text { Instabilität } \\
\text { mangelnder Fragmentkontakt }\end{array}$ \\
\hline Infektion & \\
\hline Medikamente & Antibiotika \\
& Antikoagulanzien \\
& Glukokortikoide \\
& Nicht-steroidale Antiphlogistika \\
\hline Noxen & Nikotin \\
\hline weitere Faktoren & Diabetes mellitus \\
& hohes Alter \\
& Anämie \\
& Mangelernährung \\
\hline \hline
\end{tabular}

Tabelle 3.1: Risikofaktoren für eine verzögerte Frakturheilung: Die Tabelle listet die häufigsten Inhibitoren der Frakturheilung auf. Das Auftreten mehrerer dieser Faktoren gleichzeitig potenziert das Risiko für eine insuffiziente Frakturheilung (erstellt und modifiziert nach Mutschler und Haas, 2004; Runkel und Rommens, 2000; Stürmer, 1996) 


\subsubsection{Endogene Faktoren}

\subsubsection{Altersbedingte verzögerte Frakturheilung}

Mit zunehmendem Lebensalter steigt die Inzidenz für Begleiterkrankungen. Auch die Osteoporoseinzidenz nimmt mit steigendem Alter zu. Obwohl es keine gesicherten Daten zur Frakturheilung bei älteren Patienten gibt, wird eine Beeinträchtigung der Frakturheilung mit zunehmendem Alter angenommen (Gruber et al., 2006). Im Tierversuch zeigte sich, dass Knochen bei sechs Wochen alten Ratten vier Wochen nach Frakturentstehung ihre ursprüngliche biomechanische Belastbarkeit zurückgewonnen haben. Bei 26 Wochen alten Ratten waren es 10 Wochen, und bei einjährigen alten Ratten brauchte dieser Prozess über sechs Monate (Meyer et al., 2001). An welchen der vielen komplexen Schritte der Frakturheilung sich altersbedingte Veränderungen niederschlagen, ist noch nicht erforscht (Gruber et al., 2006).

\subsubsection{Diabetes mellitus}

Die weltweite Prävalenz für Diabetes mellitus für alle Altersgruppen lag im Jahr 2008 bei $2.8 \%$. Bis zum Jahr 2030 wird die Prävalenz schätzungsweise auf $4.4 \%$ ansteigen (Wild et al., 2004). In einer klinischen Studie stellte Loder eine um $87 \%$ verzögerte Heilungsrate bei nicht-dislozierten Frakturen der unteren Extremität von Diabetikern im Vergleich von Nicht-Diabetikern fest (Loder, 1988). Das Risiko, postoperativ eine Wundheilungsstörung zu erleiden, ist bei Diabetikern ebenfalls erhöht. Die pathophysiologischen Umstände, die hierzu führen, sind weitgehend unerforscht. Es gibt Hinweise, dass es zu einer verminderten Rekrutierung von mesenchymalen Stammzellen und einer limitierten Proliferation und Differenzierung der osteoblastischen Zellreihe kommt (Retzepi und Donos, 2010).

\subsubsection{Mangelernährung}

Im Tierversuch zeigte sich, dass eine niedrige Proteinzufuhr die Verankerung von Implantaten im Knochen beeinträchtigt (Dayer et al., 2006). Die Gabe von PTH konnte im Tiermodell den ernährungsbedingten negativen Einfluss auf die Frakturheilung aufheben (Dayer et al., 2007). Insbesondere geriatrische Patienten leiden nicht selten unter Malnutrition. 


\subsubsection{Exogene Faktoren}

\subsubsection{Nikotin}

In einer tierexperimentellen Studie am Kaninchenmodell wiesen Raikin et al. eine verzögerte Knochenheilung durch Nikotin nach. Darüber hinaus zeigte sich der Frakturkallus bei der mit Nikotin behandelten Kaninchengruppe biomechanisch weniger belastbar als bei der gesunden Gruppe (Raikin et al., 1998).

Es kommt unter dem Einfluss von Nikotin zwar zu einer vermehrten Kapillarisierung, die durch Nikotin verursachte Vasokonstriktion überwiegt jedoch und führt dadurch zu einer Beeinträchtigung der Durchblutung und somit der Frakturheilung (Zheng et al., 2008). Hollinger et al. zeigten, dass Nikotin die Frühphase der Frakturheilung weniger stark beeinträchtigt als die spätere Heilungsphase (Hollinger et al., 1999).

\subsubsection{Medikamente}

Nicht steroidale Antiphlogistika (NSAR): In einer tierexperimentellen Studie, in der die Wirkung von Indomethacin und Ibuprofen auf den Knochenheilungsprozess untersucht wurde, konnte für beide Medikamente ein negativer Einfluss auf die Frakturheilung nachgewiesen werden. Dabei war nach Absetzen der Medikamente die negative Auswirkung von Indomethacin rückläufig, die von Ibuprofen hingegen nicht (Altman et al., 1995). Beck et al. konnten ebenfalls in einem tierexperimentellen Versuch denselben negativen Effekt auf die Knochenheilung für Diclofenac nachweisen (Beck et al., 2003). Eine weitere Studie an Ratten zeigte ein erhöhtes Risiko für eine verzögerte Knochenheilung durch COX2-spezifische Inhibitoren, besonders, wenn sie in der frühen Heilungsphase verabreicht wurden (Endo et al., 2005). Dieser Effekt von COX-2-spezifischen Inhibitoren konnte allerdings in einer weiteren tierexperimentellen Studie nicht bestätigt werden (Brown et al., 2004).

Obwohl NSAR in der Orthopädie und Unfallchirurgie von unschätzbarem Wert, insbesondere auch in der perioperativen Phase sind, empfehlen einige Autoren mittlerweile, auf diese Medikamente beim Vorliegen zusätzlicher Risikofaktoren für eine Beeinträchtigung der Frakturheilung zu verzichten. Insbesondere beim Vorliegen eines Diabetes mellitus, einer pAVK oder bei Nikotinkonsum sollten alternative Analgetika in Betracht gezogen werden (Beck et al., 2005).

Antibiotika: Diese Medikamente werden in der Orthopädie und Unfallchirurgie ebenfalls häufig eingesetzt. Sie werden standardmäßig zur Infektionsprophylaxe als Single-Shot vor chirurgischen Eingriffen, aber auch zur Bekämpfung manifester Infekte prä- oder 
postoperativ verwendet. In einer tierexperimentellen Studie zur Wirkung auf die Frakturheilung von Ciprofloxacin, ein Fluorchinolon, stellten Huddleston et al. einen negativen Effekt auf die frühe Knochenheilungsphase fest (Huddleston et al., 2000).

Glukokortikoide: Die osteoporotische Wirkung von längerfristig applizierten Glukokortikoiden ist wissenschaftlich mehrfach belegt (den Uyl et al., 2011). Eine tierexperimentelle Studie zeigte einen negativen Effekt von Glukokortikoiden auf die Frakturheilung bei Ulnafrakturen von Kaninchen (Waters et al., 2000). Doyon et al. zeigten im Tierversuch, dass Glukokortikoide die osteoanabole Wirkung und den postiven Effekt von Parathormon auf die enchondrale Ossifikation im Rahmen der Frakturheilung beeinträchtigen (Doyon et al., 2010).

\subsubsection{Schwere Weichteilschäden}

Schwere Weichteilschäden begünstigen zum einen den Eintritt von Keimen in die Wunde, was die Infektionsgefahr und somit die Gefahr der Knochenheilungsstörung um ein Vielfaches erhöht. Zum anderen führt die im Rahmen offener Frakturen häufig auftretende Verletzung der versorgenden Gefäße und des Periosts zu einer erheblichen Beeinträchtigung der Blutversorgung des Knochens, was sich ebenfalls negativ auf die Frakturheilung auswirkt. Aus diesem Grund muss auch im Rahmen von operativen Eingriffen eine Denudierung, also ein Ablösen des Periosts vom darunter liegenden Knochen, unbedingt vermieden werden (Runkel und Rommens, 2000).

\subsubsection{Ungenügende Frakturreposition oder -retention}

Aufgrund ungenügender Reposition bzw. sekundärer Dislokation, basierend auf einer mangelhaften operativen Retention, kann es zu einer Beeinträchtigung der Knochenheilung kommen. Hierdurch kann es zu einer Störung der Durchblutung kommen, was zu Nekrosen der dislozierten Fragmente führt. Darüber hinaus führt die mangelnde Stabilität zu einer wiederholten Fraktur der neu gebildeten Knochenbälkchen (Runkel und Rommens, 2000; Stürmer, 1996).

\subsection{Frakturbehandlung: Therapieoptionen}

Man unterscheidet zwischen konservativer und operativer Frakturbehandlung. Erstere beinhaltet eine Ruhigstellung der entsprechenden Fraktur im Gips - wobei es in den letzten Jahren auf diesem Gebiet, insbesondere in Bezug auf die Entwicklung neuer Werk- 
stoffe, viele Neuerungen gegeben hat. Die operative Frakturversorgung richtet sich nach der Lokalisation und der Schwere der Verletzung. Es stehen verschiedene Implantate und Verfahren zur Auswahl, wobei viele Eingriffe in den letzten Jahrzehnten zunehmend in minimal invasiver Technik, also unter Schonung der umgebenden Weichteile, erfolgen.

\subsection{Verzögerte Frakturheilung und Pseudarthrose}

Von verzögerter Knochenheilung spricht man, wenn eine Fraktur nach vier bis sechs Monaten nicht verheilt ist. Eine Überbrückung ist jedoch grundsätzlich noch möglich. Eine Pseudarthrose - also ein Falschgelenk - liegt definitionsgemäß dann vor, wenn die Frakturenden nach sechs Monaten noch nicht vereint sind (Mutschler und Haas, 2004). Eine Frakturüberbrückung ist in letzterem Fall nicht mehr zu erwarten. Eine Heilung ist in der Regel nur durch eine chirurgische Intervention möglich. Einerseits ist jeder chirurgische Eingriff mit Risiken für den Patienten verbunden, darüber hinaus hat er bedeutende sozioökonomische Konsequenzen. In den Vereinigten Staaten von Amerika kommt es jährlich zu etwa 7,9 Millionen Frakturen, bei denen es in 5-20 \% der Fälle zu einer verzögerten oder insuffizienten Heilung kommt (Aspenberg et al., 2010). Bei Femurschaftfrakturen liegt die Pseudarthrosenrate nach Marknagelung bei 1-5\% und nach Plattenosteosynthese bei 10$15 \%$ der Fälle (Lögters et al., 2009). Eine relativ häufige Fraktur - die Tibiaschaftfraktur - führt je nach Lokalisation und Schwere der Verletzungen in 10-40\% der Fälle zu einer Pseudarthrose (Zimmermann et al., 2007). Mehrere Studien der letzten Jahre zeigen, dass die psychische Belastung und das Auftreten posttraumatischer Belastungsstörungen nach Verletzungen am stärksten mit dem „outcome” , also dem Gesundheitszustand nach Therapie, korrelieren. Erst dann folgen Faktoren wie „injury severity score” (ISS), Alter oder Vorerkrankungen (Zatzick et al., 2004).

\subsection{1 Ätiologie}

Einer der wichtigsten Faktoren, der eine Pseudarthrose bedingen kann, ist eine gestörte oder mangelnde Blutversorgung der Fraktur. Hierzu kann es bei offenen Frakturen mit schwerem Weichteiltrauma, aber auch im Rahmen der operativen Versorgung durch eine übermäßige Denudierung des Knochens mit Destruktion des Periosts kommen. Auch ein Kompartmentsyndrom kann die Frakturheilung beeinträchtigen (Reverte et al., 2011). Ein weiterer Faktor, der eine Pseudarthrose begünstigen kann, ist Instabilität der Fraktur. Insbesondere nach Ausbildung des Faserknochens, welcher den Frakturspalt vorüberge- 
hend überbrückt, ist übermäßige Belastung zu vermeiden, da dieser Knochen nur eine begrenzte Elastizitätsreserve hat. Hierdurch kann es zum Bruch der neu gebildeten Knochenbälkchen kommen. Besteht eine große Defektzone, oder ist die Fraktur im Rahmen einer Osteosynthese nicht suffizient reponiert worden, verhindert der mangelnde Fragmentkontakt die mechanische Stimulation der Frakturenden.

Infektionen treten durch bakterielle Kontamination auf. Sie kommen bei offenen Frakturen, aber auch als Folge von chirurgischen Eingriffen vor. Die körpereigenen Resorptionsvorgänge, welche infiziertes Gewebe abbauen, resorbieren auch das im Rahmen der Granulationsphase neu gebildete Knochengewebe, was den Heilungsprozess beeinträchtigt.

Weitere prädisponierende Faktoren sind ein reduzierter Allgemein- oder Ernährungszustand, hohes Alter, Vorerkrankungen wie Osteoporose, Diabetes mellitus und arterielle Verschlusskrankheit, bestimmte Medikamente wie nicht-steroidale Antiphlogistika, Steroide oder Zytostatika, Drogen- und Alkoholabusus sowie Nikotinkonsum (Runkel und Rommens, 2000).

Polytraumatisierte Patienten haben ein erhöhtes Risiko zur Pseudarthrosenbildung. Als Ursache wird die protrahierte Mobilisation und der damit verbundene verminderte Muskeltonus und die fehlende Belastung der entsprechenden Extremität diskutiert (Runkel und Rommens, 2000).

\subsubsection{Klassifikation}

Man unterscheidet zwischen angeborenen und erworbenen Pseudarthrosen. Bei den erworbenen, welche als Komplikation einer unzureichenden Frakturheilung auftreten, unterscheidet man zwischen hypertrophen und atrophen Pseudarthrosen. Hiervon abzugrenzen sind die Defektpseudarthrose und die Infektpseudarthrose (Runkel und Rommens, 2000; Meiners et al., 2009).

\section{Hypertrophe Pseudarthrose}

Sie entsteht auf der Basis intakter biologischer Heilungsprozesse bei unzureichender Ruhigstellung der Fraktur. Dies kann im Rahmen der konservativen Therapie geschehen oder nach einer insuffizienten osteosynthetischen Versorgung, aufgrund einer falschen Implantatwahl oder sekundärer Materiallockerung. Die übermäßige Unruhe im Frakturspalt provoziert eine überschießende Kallusproduktion (Meiners et al., 2009) (Vergleiche 
Abbildung 3.2 auf Seite 26).

\section{Atrophe Pseudarthrose}

Grundlage dieser Pseudarthrosenform ist eine gestörte biologische Knochenheilung. In Folge ausgedehnter begleitender Weichteilverletzungen, langstreckiger Trümmersituationen oder Deperiostierung des Knochens im Rahmen des Traumas oder des chirurgischen Eingriffs kommt es zu einer gestörten Blutversorgung. Die Pseudarthrose imponiert im Röntgenbild durch mangelnde Kallusbildung (Meiners et al., 2009) (Vergleiche Abbildung 3.2 auf Seite 26).

\section{Defektpseudarthrose}

Diese Form ist gekennzeichnet durch das Vorliegen eines Knochendefekts in der ehemaligen Frakturregion. Sie entsteht ebenfalls aufgrund gestörter Durchblutungsverhältnisse - häufig nach ausgedehntem begleitenden Weichteiltrauma. Die Vitalität des Knochens ist häufig beeinträchtigt (Rüter und Mayr, 1999) (Vergleiche Abbildung 3.2 auf Seite 26).

\section{Infektpseudarthrose}

Morphologisch ähnelt diese der atrophen Pseudarthrose. Hinzu kann eine lokale Entzündungsreaktion wie Rötung, Überwärmung und Schmerz kommen. Sie kann nach offenen Frakturen mit ausgedehnten Weichteilverletzungen auftreten. Hierdurch kommt es zu einer Kontamination mit Keimen, welche jedoch auch im Rahmen der operativen Frakturversorgung erfolgen kann. Als häufige Erreger sind in diesem Zusammenhang Staphylokokken, Enterokokken und Pseudomonas zu erwähnen. Ein zunehmendes Problem stellt die Infektion mit multiresistenten Erregern wie ORSA (Oxacillin-), MRSA (Methicillinresistenter Staphylococcus aureus) und ESBL (,extended spectrum beta lactamase” ) -Bildnern dar (Meiners et al., 2009). 


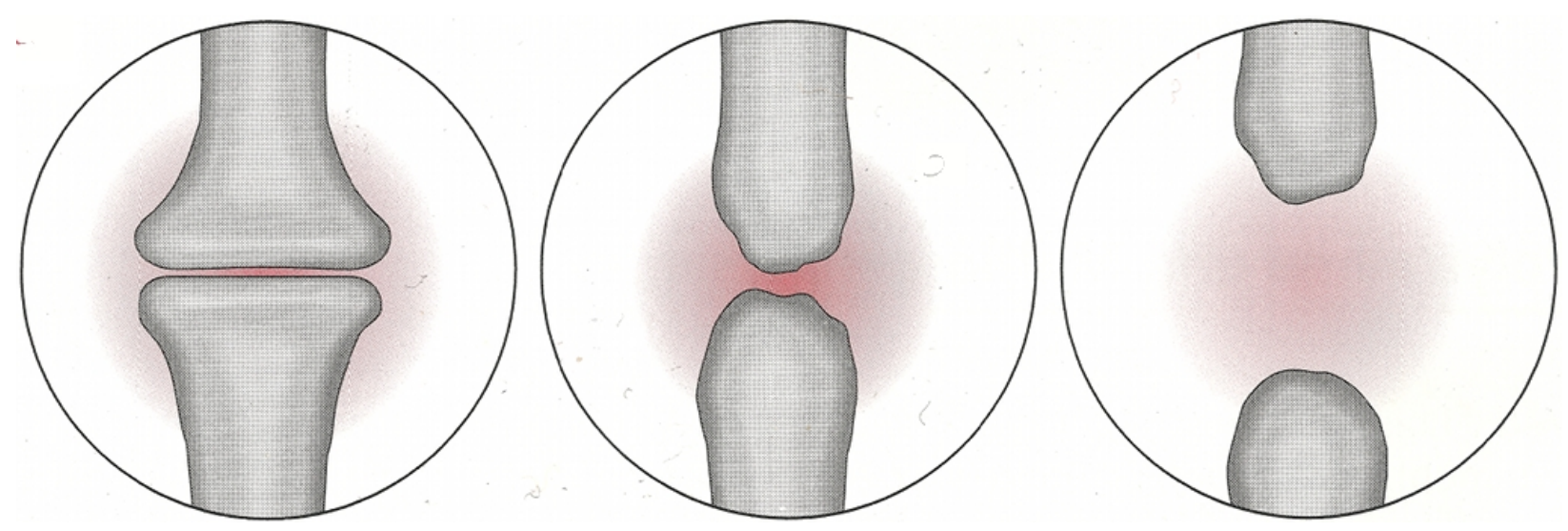

Abbildung 3.2: Pseudarthrosetypen. Links: Hypertrophe Pseudarthrose, Mitte: Atrophe Pseudarthrose, rechts: Defektpseudarthrose (aus Mutschler und Haas, 2004, S. 33)

\subsubsection{Therapieoptionen der Pseudarthrose}

\subsubsection{Operative Therapie der Pseudarthrose}

Die erfolgreiche Therapie einer Pseudarthrose erfordert in der Regel eine chirurgische Intervention. Diese richtet sich nach dem vorliegenden Pseudarthrosentyp.

Eine erfolgreiche Therapie der hypertrophen Pseudarthrose erfordert eine stabile Ruhigstellung. Ist die Pseudarthrose im Rahmen einer konservativen Behandlung im Gips entstanden, kann eine Plattenosteosynthese zum Therapieziel führen. Wenn die Pseudarthrose auf der Grundlage einer unzureichenden osteosynthetischen Ruhigstellung entstanden ist, muss absolute Stabilität im Frakturspalt erzeugt werden (Meiners et al., 2009). Dies kann durch verschiedene osteosynthetische Techniken erzielt werden, welche von der minimalinvasiven Einbringung einzelner Zugschrauben bis hin zu komplexen Osteosynthesen reichen.

Da die atrophe Pseudarthrose in der Regel avitales Gewebe im nicht verheilten Frakturspalt impliziert, ist die Resektion des toten Gewebes und eine Optimierung der lokalen Durchblutungssituation zur erfolgreichen Therapie unerlässlich. Der Defekt muss anschließend erneut aufgefüllt und ein stabiles Osteosyntheseverfahren angestrebt werden. In der Regel bietet sich in diesem Fall eine winkelstabile Plattenosteosynthese an (Meiners et al., 2009).

Analog kann bei der Therapie der Defektpseudarthrose verfahren werden. Besonders anspruchsvoll sind hier größere Defekte, welche nicht mehr mittels Spongiosa oder eines kortikospongiösen Spans aufgefüllt werden können. Die maximale Größe des Defekts, welcher mittels Knochentransplantation aufgefüllt werden kann, wird in der Literatur mit 
2 - $4 \mathrm{~cm}$ angegeben (Meiners et al., 2009; Rüter und Mayr, 1999). In diesen Fällen besteht die Möglichkeit eines Segmenttransports nach Ilisarov über einen Fixateur externe. Hierbei wird nach Resektion des Pseudarthrosengewebes vitaler Knochen von einem Ende über den Defekt transportiert. Hinter dem Transportsegment bildet sich dann neuer Knochen. Transportiert wird mit einer Geschwindigkeit von $1 \mathrm{~mm} / \mathrm{d}$ (Meiners et al., 2009). Infektpseudarthrosen erfordern meistens ein mehrzeitiges operatives Vorgehen. Nach intraoperativer Wundabstrichentnahme erfolgt zunächst eine radikale Infektsanierung. Sämtliche avitale Knochenanteile und infiziertes Gewebe wird durch ausgiebiges Debridemènt entfernt. In dieser ersten Phase sollte auch in unmittelbarer Infektnähe liegendes Osteosynthesematerial entfernt werden. Die Stabilisierung kann dann z.B. mittels Fixateur externe erfolgen. Die Einlage eines Medikamententrägers in den entstandenen Defekt kann erfolgen. Die systemische Antibiose sollte möglichst dem Erregerspektrum angepasst werden (Meiners et al., 2009). Wenn sich die Infektion klinisch und laborchemisch zurückgebildet hat, erfolgt die weitere Behandlung analog der Therapie der Defektpseudarthrose. Kritisch ist hier jedoch die Wahl des Osteosyntheseverfahrens zu treffen. Eine Ausheilung im Fixateur externe sollte im Hinblick auf die Infektsituation einem internen Fixationsverfahren ggf. vorgezogen werden (Rüter und Mayr, 1999; Meiners et al., 2009). Zum Auffüllen kleinerer Defekte unter $2 \mathrm{~cm}$ wird häufig autologes, spongiöses Knochenmaterial verwendet. Hiervon abzugrenzen sind ebenfalls allogene, kortikospongiöse Knochenspäne, welche aus Spongiosa, Kortikalis und Periost bestehen. Die Entnahme dieser Transplantate erfolgt meistens aus dem vorderen oder hinteren Beckenkamm in derselben Sitzung. Maßgeblich für den Erfolg dieses Verfahrens ist die Durchblutung des Transplantatlagers. Eine gute Durchblutung hat höhere Heilungsaussichten als ein schlecht durchblutetes Transplantatlager. Beim allogenen Knochenersatz wird tiefgefrorenes Knochengewebe aus einer Knochenbank in den Defekt eingebracht. Aufgrund des Risikos von Krankheitsübertragungen wie HIV und Hepatitis sowie des hohen logistischen Aufwands wird dieses Verfahren deutlich seltener angewendet.

In Sonderfällen, insbesondere bei einem ersatzarmen, schlecht durchbluteten Transplantatlager, können vaskularisierte Knochentransplantate zum Einsatz kommen (Mutschler und Haas, 2004).

In der Literatur wird die Erfolgsrate der chirurgischen Therapie der Pseudarthrose mit $75-100 \%$ angegeben (Gollwitzer et al., 2006). 


\subsubsection{Medikamentöse Therapie der Pseudarthrose}

\section{BMP - Bone Morphogenetic Protein}

Mittlerweile sind mehr als 20 Isoformen dieses Proteins bekannt. Die Wirkung auf die Frakturheilung von BMP-2 und BMP-7 ist vielfach im Tiermodell untersucht worden. Es handelt sich um osteoinduktive Substanzen, welche im menschlichen Organismus eine tragende Rolle bei Skelettentwicklung und Skelettwachstum sowie der Homöostase und der Frakturheilung haben. Sie gehören in die Gruppe der „transforming growth factors- $\Omega$ ” (TGF-ß) (Komatsu und Warden, 2010).

BMP muss im Rahmen eines chirurgischen Eingriffs in den Frakturspalt bzw. in das zuvor debridierte Pseudarthrosenlager eingebracht werden. Häufig wird es gemeinsam mit Spongiosa oder einem kortikospongiösen Span eingesetzt.

Zimmermann et al. zeigten, dass die Behandlung von Pseudarthrosen mit BMP erfolgsversprechender zu sein scheint als die alleinige Spongiosa- oder Knochenspantransplantation (Zimmermann et al., 2007). Im Jahr 2001 ist die Verwendung von BMP-7 zur Therapie von Pseudarthrosen langer Röhrenknochen durch die FDA genehmigt worden. BMP-2 wurde im Jahr 2004 zur Therapie offener Tibiaschaftfrakturen von der FDA genehmigt (Jacobs et al., 2008).

\section{PTH - Parathormon}

Parathormon ist als Antiosteoporotikum bereits im klinischen Einsatz. Unter allen Medikamenten, welche zur Therapie der Osteoporose eingesetzt werden, ist es das einzige mit osteoanaboler Wirkung. Zur Frakturbehandlung am Menschen ist es nicht zugelassen.

Die Applikation erfolgt per subkutaner Injektion. An oral verabreichbaren Präparaten wird bereits gearbeitet (Leone-Bay et al., 2001). Eine Operation zur Einbringung des Medikaments an seinen Wirkungsort, wie bei dem zuvor beschriebenen BMP, entfällt.

Im Tierversuch zeigte sich ein positiver Effekt auf die Frakturheilung und das Einheilen von Implantaten nach Gabe von PTH (Komrakova et al., 2011; Jørgensen und Schwarz, 2011; Bukata und Puzas, 2010; Manabe et al., 2007; Chalidis et al., 2007; Ellegaard et al., 2010).

Die bislang einzige randomisierte, placebokontrollierte Doppelblindstudie führten Aspenberg et al. durch. 102 postmenopausale Patientinnen mit konservativ behandelter Radiusfraktur wurden in die Studie eingeschlossen. Die Patientinnen wurden in drei Gruppen à 34 aufgeteilt und erhielten Placebo, $20 \mu \mathrm{g} / \mathrm{kg}$ oder $40 \mu \mathrm{g} / \mathrm{kg}$ Teriparatid einmal täglich s.c. über einen Zeitraum von acht Wochen. Die Studie zeigte keine signifikanten Un- 
terschiede zwischen den drei Gruppen (Aspenberg et al., 2010).

Daten zur Therapie von Pseudarthrosen mit Parathormon liegen nicht vor.

\section{Weitere Substanzen}

Andere Wachstumsfaktoren neben BMP wie „platelet-derived growth factor" (PDGF) haben in tierexperimentellen Studien eine Stimulation der Frakturheilung bewiesen (Al-Zube et al., 2009). Erste klinische Daten zeigen gute Ergebnisse bei der Verwendung von PDGF im Rahmen von Arthrodesen an der unteren Extremität und bei der operativen Therapie von distalen Radiusfrakturen (Hollinger et al., 2008).

Weitere Arbeiten zu "growth and differentiation factor-5" (GDF-5 = BMP-14), "transforming growth factors- $\Omega^{\prime \prime}$ TGF- $\Omega$, "insulin-like growth factor" (IGF-1) und "growth hormone" (GH) zeigten im Tierversuch ebenfalls einen positiven Effekt auf die Frakturheilung. (Komatsu und Warden, 2010). Untersuchungen zu „platelet-rich plasma” (PRP) ergaben begrenzten Anhalt für eine Förderung der Frakturheilung (Hakimi et al., 2011; Calori et al., 2009; Komatsu und Warden, 2010).

"Hypoxia-inducible-factor 1 alpha" (HIF-1 $\alpha$ ) ist ein Transkriptionsfaktor, welcher in verschiedenen Geweben von Säugetieren vorkommt. Er spielt in der Entzündungsphase der Frakturheilung eine wichtige Rolle. Das im Frakturspalt entstandene Hämatom ist nicht vaskularisiert. Die zentral gelegenen Chondrozyten, welche bei der Kallusentstehung eine zentrale Rolle einnehmen, sind also auf anaerobe Energiegewinnung in diesem Milleu angewiesen. HIF-1 $\alpha$ spielt im Rahmen dieses anaeroben Metabolismus und der Angiogenese eine wichtige Rolle, und erste tierexperimentelle Studien liefern vielversprechende Daten zu Angriffspunkten am HIF-1 $\alpha$-Pathway (Komatsu und Warden, 2010).

Prostaglandine sind Metabolite von enzymatisch gespaltenen, mehrfach ungesättigten Fettsäuren. Tierexperimente zeigen einen stimulierenden Effekt auf die Frakturheilung. Ferner führen Prostaglandine zu einer gesteigerten Knochenmasse und biomechanischen Stabilität (Li M et al., 2007). Starke Nebenwirkungen wie Diarrhöe, Abgeschlagenheit und Hitzewallungen machen einen klinischen Einsatz jedoch derzeit uninteressant (Komatsu und Warden, 2010).

Mesenchymale Stammzellen müssen zunächst entnommen und expandiert werden. Anschließend müssen sie auf einen entsprechenden Träger aufgebracht werden, welcher dann in die Fraktur chirurgisch implantiert wird (Patterson et al., 2008).

Bei einer koreanischen klinischen Studie an 64 Patienten mit Frakturen der langen Röhrenknochen wurden autologe Osteoblasten direkt in den Frakturspalt injiziert. Hierbei zeigte sich bei den Patienten, welche die Stammzelleninjektion erhalten hatten, eine signifikant 
schnellere Frakturheilung (Kim SJ, 2009 et al.). Die intravenöse Injektion von menschlichen CD34 4 -Zellen aus venösem Blut, welche Ratten mit frischen Femurfrakturen injiziert wurden, führte ebenfalls zu einer besseren Frakturüberbrückung und erhöhte die biomechanische Belastbarkeit der Knochen der behandelten Tiere (Matsumoto et al., 2006).

\subsubsection{Weitere Stimulationsmöglichkeiten der Frakturheilung}

\section{Mechanische Stimulation der Frakturheilung}

Schon Galileo Galilei postulierte 1638, dass es einen Zusammenhang zwischen mechanischer Belastung und der Skelettarchitektur gibt (Adler, 2010). Das 1892 veröffentlichte Wolff'sche Gesetz besagt, dass sich Form und Knochenarchitektur der mechanischen Beanspruchung anpasst (Wolff, 1892). Frost wies 1987 auf das Vorhandensein eines homöostatischen Kontrollmechanismus des Knochens hin, welcher es dem Knochen ermöglicht, auf mechanische Anforderungen, denen er ausgesetzt ist, zu reagieren. Der Knochen passt seine Masse und seinen Aufbau den mechanischen Anforderungen an. Dieser intrinsische „Mechanostat” setzt das Vorhandensein mehrerer unabhängiger Komponenten voraus: Einen mechanischen Reiz, der auf den Knochen wirkt, und ein Rezeptorsystem, welches in der Lage ist, diesen mechanischen Stimulus zu registrieren. Hierdurch wird eine Reaktion ausgelöst, die zu einer Anpassung der Knochenarchitektur an die auf ihn einwirkende mechanische Beanspruchung führt (Frost, 1987; Hughes und Petit, 2010). Osteozyten (vergleiche Abschnitt 2.1.2.2, Seite 5) spielen bei der Rezeption der mechanischen Belastung eine zentrale Rolle. Fällt die mechanische Knochenbeanspruchung unter einen bestimmten Schwellenwert, kommt es zur Apoptose dieser Zellen. Übersteigt die mechanische Beanspruchung die Belastungsgrenze des „Mechanostat” , kommt es zu einer Ausschüttung anaboler Mediatoren und einer Aktivierung von Osteoblasten (vergleiche Abschnitt 2.1.2.1, Seite5) und folglich zum Knochenaufbau.

Die Untersuchung der Oberarmknochen von professionellen Tennisspielern zeigte eine bis zu 45 \% dickere Kortikalis der Oberarmknochen des „Spielarms” im Vergleich zur Gegenseite (Adler, 2010). Fehlende mechanische Beanspruchung führt zu einer Osteopenie. Die konservative Frakturbehandlung beinhaltet häufig eine Ruhigstellung der betroffenen Extremität. Aber auch nach operativer Frakturversorgung kann eine vorübergehende Immobilisierung im Gips notwendig sein. Hierdurch kann es zu einer unzureichenden Kallusüberbrückung kommen, welche in einer verzögerten Knochenheilung oder Pseudarthrose münden kann (Stuermer et al., 2010). Klinische Studien haben gezeigt, dass Mi- 
krobewegungen die Kallusbildung fördern können (Yamaji, 2001). Die biologischen und biomechanischen Grundlagen, welche einen Effekt auf das Skelett haben, sind noch größtenteils unklar (Chao und Inoue, 2003).

In der Klinik stehen verschiedene Verfahren zur Verfügung, welche über eine mechanische Stimulation zur Förderung der Knochenheilung führen.

\section{Ganzkörpervibration}

Hierbei befinden sich die Probanden auf einer Plattform. Diese übt durch oszillierende Bewegungen eine mechanische Stimulation auf den gesamten Körper aus. Sowohl in tierexperimentellen Studien, aber auch am Menschen (Verschueren, 2004) konnte ein positiver Effekt auf die Knochendichte (BMD) nachgewiesen werden. Dies ist insbesondere im Rahmen der Osteoporosetherapie von großem Interesse. Einige tierexperimentelle Studien zeigten darüber hinaus eine die Frakturheilung fördernde Wirkung der Ganzkörpervibration (Stuermer et al., 2010; Ogawa et al., 2011). Hinsichtlich der Wirkung auf die Frakturheilung beim Menschen finden sich in der Literatur keine aussagekräftigen Daten.

\section{Extrakorporale Stoßwellentherapie (ESWT)}

Die hochenergetische extrakorporale Stoßwellentherapie (ESWT) ist ein physikalisches Verfahren. Hierbei werden mechanische Einzelimpulse mit einem Druck- und Zuganteil über eine externe Kopplung in das Gewebe eingeleitet. Die Wirkung entsteht dadurch, dass akustische Energie in mechanische, thermische oder chemische Energie umgewandelt wird. Dies geschieht dadurch, dass verschiedene Gewebe mit unterschiedlichen akustischen Kenndaten durchschallt werden. An den Grenzflächen, z.B. zwischen Bindegewebe und Knochen, treten dann Impedanzsprünge auf. Dadurch kommt es zu einer mechanischen Stimulation, welche sich proportional zur Größe des Impedanzunterschieds verhält. Hierdurch kommt es zu Endotheleinrissen, was zu kleinen Einblutungen und einer Permeabilitätserhöhung der Blutgefäße mit Ödemen führt. Es kommt zu einer Steigerung der Perfusion und damit zu einer besseren Versorgung mit Nährstoffen, wodurch wiederum die lokale Angiogenese gefördert wird. Daten aus klinischen Studien suggerieren einen positiven Effekt auf die Frakturheilung und Pseudarthrosen. Es fehlen jedoch randomisierte, kontrollierte Studien, welche diesen Effekt belegen (Gollwitzer et al., 2006). 


\section{Ultraschall}

Die FDA bewilligte den Einsatz diese Verfahrens erstmals 1994 zur Beschleunigung der Frakturheilung bei konservativ behandelten Frakturen. Seit dem Jahr 2000 ist es auch zur Therapie von Pseudarthrosen genehmigt (Rubin et al., 2001). Der genaue Wirkungsmechanismus auf die Osteoblasten ist unklar. Man geht davon aus, dass es durch Scherkräfte - sogenannte „fluid-induced shear flow” - unter anderem zu einer gesteigerten Zellproliferation sowie Kollagen- und Proteinsynthese kommt. Die Zellmembranpermeabilität wird gesteigert und es kommt zu einem Anstieg der intrazellulären $\mathrm{Ca}^{2+}$-Konzentration (Khan und Laurencin, 2008). Eine Übersichtsarbeit und Metaanalyse von 13 randomisierten, kontrollierten Studien von Busse et al., lieferte eine niedrige bis moderate Evidenz für eine Verbesserung des funktionellen outcomes für Patienten mit einer Fraktur (Busse et al., 2009).

\subsubsection{Kombination verschiedener Faktoren}

Es gibt Hinweise dafür, dass die Kombination verschiedener, den Knochenaufbau fördernder Faktoren zu einer gegenseitigen Potenzierung führt: In einer 2008 veröffentlichten Studie wiesen Morgan et al. eine bessere Frakturheilung bei der kombinierten Anwendung von BMP-7 und Parathormon bei Kaninchen nach als bei der alleinigen Anwendung eines der beiden Präparate (Morgan et al., 2008). Da beide Substanzen unterschiedliche Phasen der Frakturheilung beeinflussen, besteht hier möglicherweise eine positive Ergänzung. In Zukunft sollte neben der weiteren Erforschung der Wirkung der einzelnen Substanzen auch die Möglichkeit einer Kombination verschiedener sich gegenseitig ergänzender Medikamente erforscht werden.

Eine Studie an 224 männlichen Ratten wies einen synergistischen Effekt von PTH im Kombination mit mechanischer Stimulation nach (Kim CH et al., 2003). 


\section{Kapitel 4}

\section{Material und Methoden}

\subsection{Versuchstiere und -haltung, Substanzen und Probenge- winnung}

In der vorliegenden Arbeit wurde die Wirkung von Parathormon auf den Knochen und die Frakturheilung weiblicher Ratten untersucht. Zu Versuchsbeginn erfolgte die Osteotomie beider proximaler Tibiae bei den Tieren. In den folgenden 35 Tagen wurde den Tieren fünf mal pro Woche Placebo oder $40 \mu \mathrm{g} / \mathrm{kg}$ Körpergewicht Parathormon ab dem ersten Tag oder dem siebten Tag nach Osteotomie subkutan injiziert.

Den Tieren wurden zeitlich gestaffelt vier verschiedene Fluorchrome nach einem zuvor definierten Plan (siehe Tabelle 4.1 auf Seite 37) injiziert.

Die Dekapitation der Tiere und die Probengewinnung erfolgte fünf Wochen nach Versuchsbeginn. Eine Übersicht über den zeitlichen Versuchsablauf gibt Abbildung 4.1, auf Seite 34 .

\subsubsection{Versuchstiere}

Es wurden 36, vier Monate alte, gesunde, weibliche Sprague-Dawley-Ratten (Fa. Winkelmann, Borken, Deutschland) in drei Gruppen à 12 Tiere eingeteilt. Die Unterbringung der Tiere erfolgte in Käfigen à fünf Ratten. Die Haltung erfolgte in der zentralen tierexperimentellen Einrichtung der Universitätsmedizin Göttingen. Wasser und sojafreies Futter (ssniff SM R/M, 10 mm-Pellets; ssniff Spezialitäten $\mathrm{GmbH}$, Soest, Deutschland) stand den Tieren zur freien Verfügung bereit. Die Umgebungstemperatur lag bei $22^{\circ} \mathrm{C}\left( \pm 1^{\circ} \mathrm{C}\right)$ bei einer relativen Luftfeuchtigkeit von $55 \%$. Eine Hell-Dunkel-Periodik von jeweils 12 Stunden 

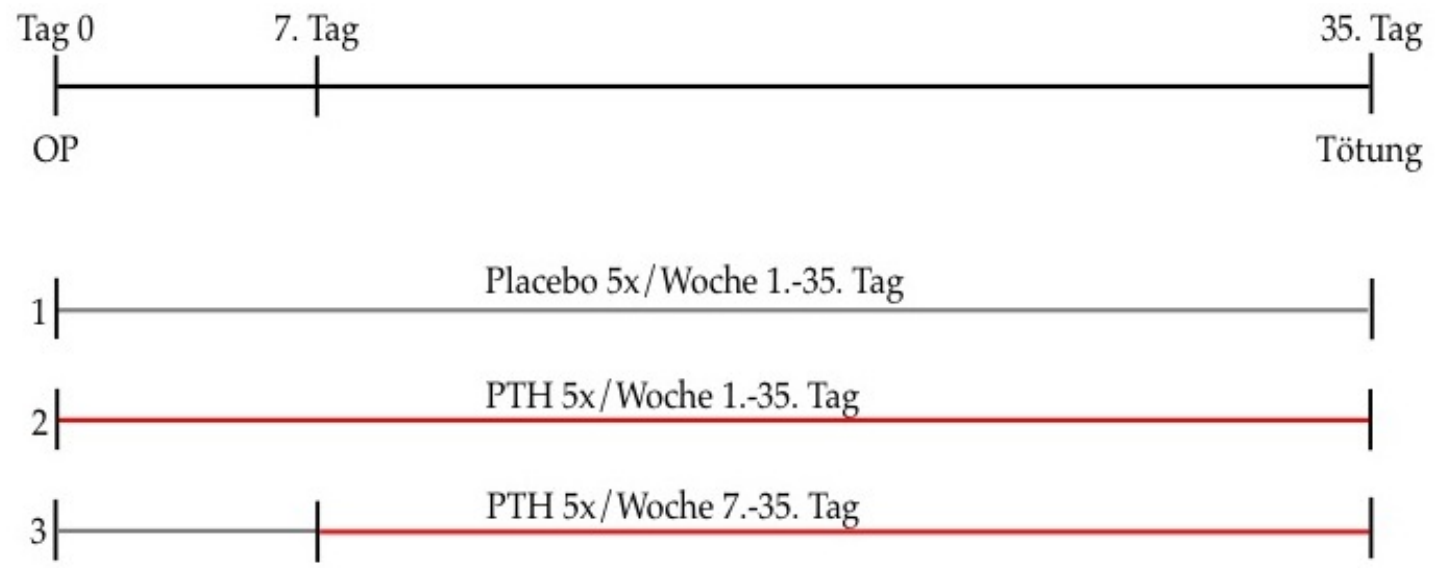

Abbildung 4.1: Die oberste Linie zeigt den zeitlichen Versuchsablauf. Die unteren drei Linien entsprechen den drei Versuchstiergruppen: Gruppe 1 erhielt Placebo vom ersten Versuchstag bis zum 35. Tag, Gruppe 2 erhielt $40 \mu \mathrm{g} / \mathrm{kg}$ Körpergewicht PTH ab dem ersten Tag bis zum 35. Tag und Gruppe 3 wurden $40 \mathrm{\mu g} / \mathrm{kg}$ Körpergewicht PTH ab dem siebten Versuchstag bis Versuchsende appliziert. Alle drei Gruppen wurden fünf mal pro Woche injiziert

wurde eingehalten. Nach 35 Tagen wurden die Tiere getötet und die Proben gewonnen. Der Tierversuch war zuvor von der Bezirksregierung Braunschweig genehmigt worden.

\subsubsection{Osteotomie}

Zunächst wurden die Tiere mit $\mathrm{CO}_{2}$ sediert. Die anschließende intraperitoneale Narkose bestand aus Ketamin $90 \mathrm{mg} / \mathrm{kg}$ KG (Hostaket ${ }^{\circledR}$, Fa. Hoechst, Bad Soden) sowie 7,5 mg/kg KG Xylazin (Rompun ${ }^{\circledR}$, Fa. Bayer, Leverkusen) im Verhältnis 5:3.

Nach Entfernung der Haare an beiden Hinterläufen mit einem Elektrorasierer erfolgte die Desinfektion der unteren Körperhälfte wonach die Tiere auf einem Operationstisch in Rückenlage positioniert wurden.

Der Zugang erfolgte über der ventro-medialen Tibia in Form eines ca. $3 \mathrm{~cm}$ langen Hautschnitts. Nach Darstellung der ventralen Tibiakante erfolgte die scharfe Absetzung der Beugemuskulatur proximal unter Schonung des Periosts. Der Kniegelenkspalt wurde mit einer Kanüle markiert, wonach eine Osteosyntheseminiplatte (5-Loch-Leibinger T-Platte $90^{\circ}$, Titan, Fa. Stryker Leibinger GmbH \& Co.KG, Freiburg, BRD) so anmodelliert wurde, dass sie sich dem Knochen harmonisch anlegte.

Zunächst wurde bei anliegender Platte ein Loch für das proximale, ventrale Schraubenloch gebohrt und dieses mit einer $7 \mathrm{~mm}-1,1 \mathrm{~mm}$-Schraube besetzt (Siehe Abbildung 4.3). Hiernach erfolgte in analoger Weise die Besetzung des distalsten Schraubenloches mit ei- 

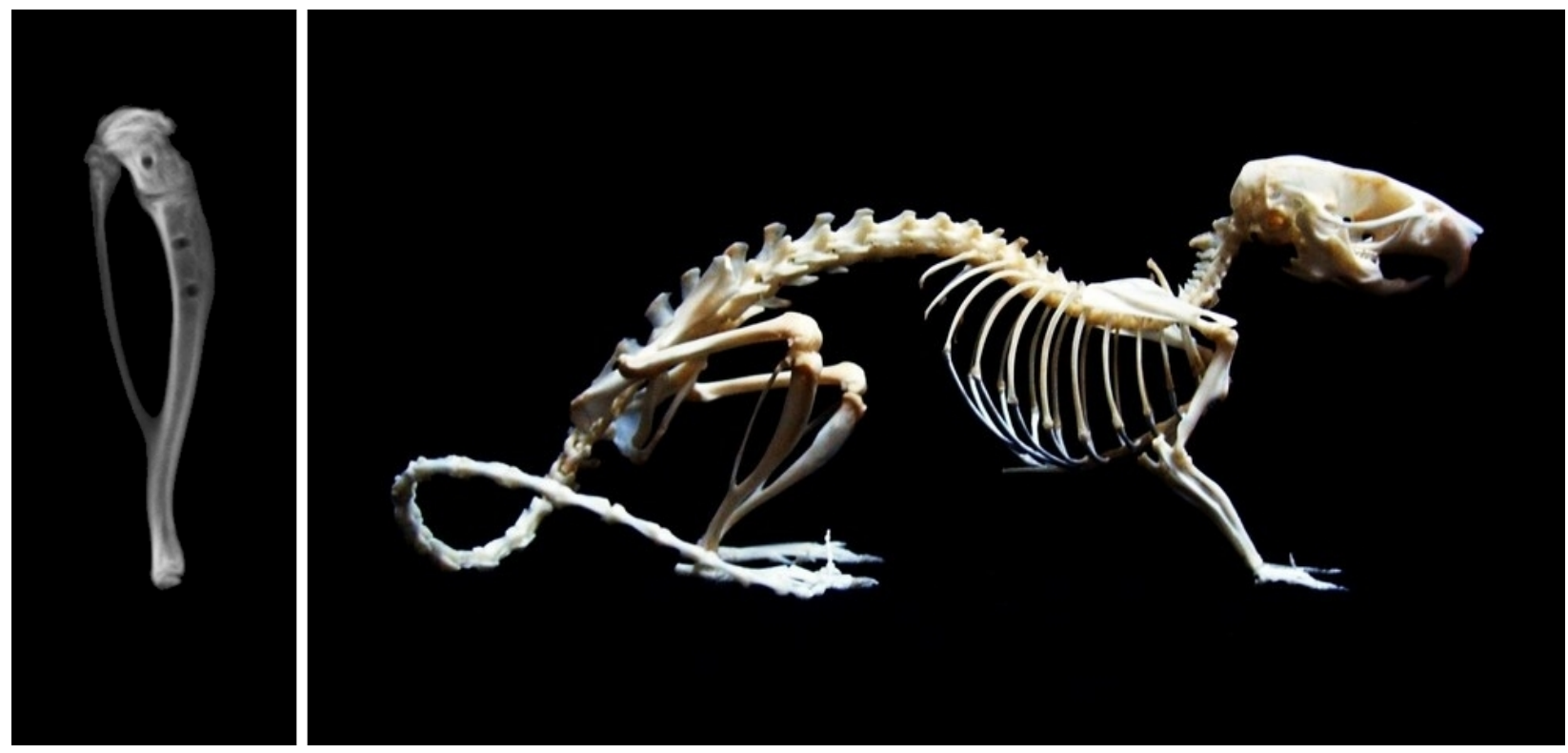

Abbildung 4.2: Links im Bild ist das Röntgenbild einer Tibia mit Fibula zu sehen. Die Löcher stammen von den eingebrachten Schrauben im Rahmen der Plattenosteosynthese. Zu sehen ist ebenfalls der teilweise überbaute metaphysäre Osteotomiespalt. Das rechte Bild zeigt das Präparat eines gesamten Skeletts einer Ratte (mit freundlicher Genehmigung von Enault, 2012)

ner $4 \mathrm{~mm}$ 1,1 $\mathrm{mm}$ Schraube. Die optimale Plattenlage setzte voraus, dass beide proximalen Schraubenlöcher auf Höhe der Epiphysenfuge lagen, wobei die Patellarsehene proximal des geplanten Osteotomiespalts ansetzen sollte. Im Anschluss wurden die Löcher für die restlichen beiden Schrauben gebohrt, jedoch nicht besetzt. Das auf Höhe der geplanten Osteotomie gelegene Plattenloch wurde nicht verwendet. Zunächst wurde die Platte zur Durchführung der Osteotomie wieder entfernt. Dieses Vorgehen garantierte eine anatomisch korrekte Reposition aufgrund der bereits vorgebohrten Schraubenlöcher.

Die Osteotomie erfolgte mit gepulstem Ultraschall (OT 7 Piezosurgery ${ }^{\circledR}$, Mectron Medical Technology, Carasco, Italien) etwa $7 \mathrm{~mm}$ distal der tibialen Gelenkfläche in der proximalen Tibiametaphyse. Der Osteotomiespalt hatte eine Breite von einem mm.

Nach endgültiger Refixation der Platte wurde die zuvor abgelöste Beugemuskulatur mittels einer 4.0-Vicrylnaht (Ethicon, Johnson \& Johnson, Norderstedt, BRD) refixiert und die Cutis nach erneuter Wunddesinfektion mittels Klammerung (Michels wound brackets 7,5 x 1,75 mm, Gebrüder Martin GmbH \& Co.KH, Tuttlingen, BRD) verschlossen.

Die Osteotomie der kontralateralen Tibia erfolgte im Anschluss in analoger Weise. Abschließend wurde den Tieren ein $\mathrm{NaCl}$-Depot von $2 \mathrm{ml}$ s.c. injiziert, um eine postoperative Dehydratation zu vermeiden. Bis zum vollständigen Ausklingen der Narkose wurden die Tiere in einem erwärmten und mit Zellstoff ausgekleideten Käfig platziert. 
a.

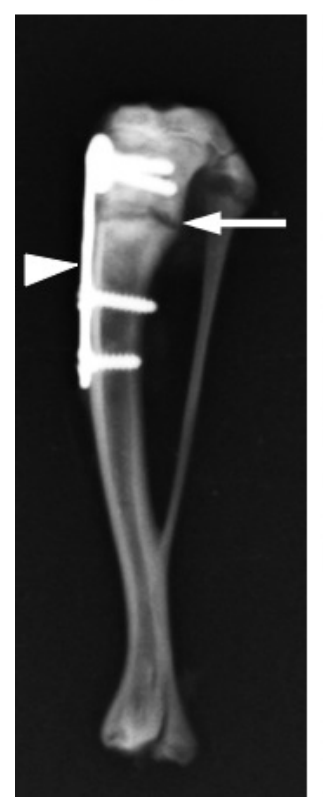

b.

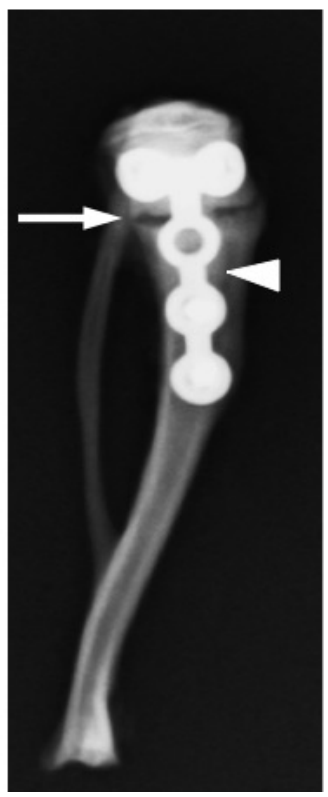

Abbildung 4.3: Die Abbildung zeigt ein Röntgenbild einer osteotomierten und plattenosteosynthetisch versorgten Rattentibia. Links im Bild ist die anterior-posteriore Ebene (a.) zu sehen und rechts die sagittale Projektion (b.). Der schmale Pfeil zeigt auf den Osteotomiespalt. Das Präparat stammt von einem der Tiere, welche PTH ab dem 7. Tag erhalten hatten (Komrakova et al., 2010, S. 3)

\subsubsection{Parathormon}

Nach der Osteotomie erhielten die 12 Tiere der ersten Gruppe Placebo in Form von 0,2 ml s.c. 0,9\%iger Kochsalzlösung. Von den beiden Gruppen, welche mit PTH behandelt wurden, erhielt eine Gruppe ab dem ersten Tag nach Osteotomie $40 \mu \mathrm{g} / \mathrm{kg}$ Körpergewicht PTH auf 0,2 $\mathrm{ml} \mathrm{0,9 \%} \mathrm{ige} \mathrm{NaCl}$ subkutan injiziert. Die Tiere der dritten Gruppe wurden erst ab dem siebten Tag nach Osteotomie mit derselben Dosis PTH behandelt.

\subsubsection{Intravitale Fluoreszenzmarkierung}

Diese Untersuchung ermöglicht es, Informationen im Bezug auf den zeitlichen Ablauf der Umbauprozesse im Knochen zu gewinnen. Für diese Arbeit von besonderer Bedeutung sind diese Vorgänge im Bereich der Frakturzone und des sich bildenden Kallus. Durch die zeitlich zuvor festgelegte intravitale Injektion verschiedener Farbstoffe - sogenannte Fluorochrome - kann die Dynamik der Frakturheilung abgebildet werden (Rahn, 1976). 
Die applizierten Farbstoffe binden an Kalzium, wodurch ein Chelatkomplex entsteht, welcher in dem zu diesem Zeitpunkt mineralisierenden Knochen eingelagert wird. Markiert wird also bereits neu gebildeter und in der Mineralisierungsphase begriffener Knochen, welcher jedoch noch nicht durch einen anderen zuvor applizierten Farbstoff markiert ist. In der vorliegenden Arbeit wurden nacheinander insgesamt vier verschiedene Fluorochrome injiziert. Dadurch bildeten sich farblich unterschiedliche Banden. Einen Überblick über die Farbstoffe, ihre jeweilige Abkürzung und Farbe unter fluoreszentem Licht gibt Tabelle (siehe 4.1 auf Seite 37).

Nach entsprechender Präparation und Aufarbeitung (siehe 4.3.1 auf Seite 41), konnte im Rahmen fluoreszenzmikroskopischer Untersuchungen (siehe Abschnitt 4.4 auf Seite 46) jede Farbbande mit einem Zeitabschnitt, zu dem der entsprechende Farbstoff injiziert worden war, korreliert werden. Die Farbstoffe wurden subkutan als Bolus injiziert. Als Träger diente destilliertes Wasser für XO, CG, $\mathrm{AK}$ und $\mathrm{NaCl}$ für TC. Alizarinkomplexon (AK) wurde zwei mal - am 22. und am 24. Tag - gespritzt, da Vorversuche gezeigt hatten, dass die Färbung ansonsten nur sehr schwach ausgeprägt war.

\begin{tabular}{lcccc}
\hline Fluorochrom & Farbe & $\begin{array}{c}\text { Dosierung } \\
{[\mathrm{mg} / \mathrm{kg}]}\end{array}$ & $\begin{array}{c}\text { Applikations- } \\
\text { tag }\end{array}$ & $\begin{array}{c}\text { Markierungs- } \\
\text { zeitraum }\end{array}$ \\
\hline $\begin{array}{l}\text { Xylenolorange } \\
\text { Tetranatriumsalz (XO) }\end{array}$ & Orange & 90 & 13. & $0 .-13$. \\
\hline $\begin{array}{l}\text { Fluorescein- } \\
\text { komplexon (CG) }\end{array}$ & Grün & 10 & 18. & $13 .-18$. \\
\hline $\begin{array}{l}\text { Alizarin- } \\
\text { komplexon (AK) }\end{array}$ & Rot & 30 & 22. und 24. & 18.-24. \\
\hline $\begin{array}{l}\text { Tetracyclin- } \\
\text { Hydrochlorid (TC) }\end{array}$ & Gelb & 25 & 35. & $24 .-35$. \\
\hline
\end{tabular}

Tabelle 4.1: Die Tabelle gibt einen Überblick über die verwendeten Fluoreszenzmarker und die entsprechende Farbe. Entsprechend dem Zeitpunkt der Applikation des jeweiligen Farbstoffs (Tag nach Osteotomie) wurden diese vom sich neu bildenden Frakturkallus eingebaut (Markierungszeitraum nach Osteotomie). Rückwirkend konnte so das entsprechende Kallusgewebe dem Zeitabschnitt, während dem es gebildet wurde, zugeordnet werden

\subsubsection{Obduktion und Präparation}

Am 35. Tag nach Osteotomie erfolgte die Dekapitation der zuvor mittels $\mathrm{CO}_{2}$ sedierten Tiere. Es erfolgte die Präparation der Tibiae sowie für weitere Untersuchungen im Rahmen anderer Arbeiten der Femora, Wirbelkörper und die Uterus- und Skelettmuskulatur. 


\subsubsection{Präparation der Tibiae}

Zur Entnahme der Tibiae wurde zunächst die Exartikulation in Knie- und anschließend im Sprunggelenk durchgeführt. Tibia und Fibula wurden im Verbund entnommen. Anschließend wurden die Knochen vom restlichen Weichgewebe sorgfältig befreit und das Osteosynthesematerial entfernt.

Die Knochen wurden randomisiert -jeweils links oder rechts- bis zum Beginn der jeweiligen Versuche bei $-20^{\circ} \mathrm{C}$ konserviert. Eine Tibia wurde für den Biegeversuch und die kontralaterale Tibia für die mikroradiographischen und fluoreszenzmikroskopischen Auswertungen verwendet.

\subsection{Biomechanischer Biegeversuch an der Tibia}

Der Biegeversuch an der Tibia erfolgte an einer Kompressionsmaschine zur Festigkeitsuntersuchung für Werkstoffe (Typ 145660 Z020/TND Zwick/Roell, Ulm, Germany). Der Versuchsaufbau war zuvor validiert worden (Stuermer et al., 2006). Der Untersucher wusste zum Zeitpunkt der Messungen nicht, zu welcher Versuchsgruppe das jeweilige Präparat gehörte.

Die Tibiae wurden auf einem Aluminiumblock platziert. Eine in den Block eingefräste Rille, in welcher der dorsale Anteil des Tibiakopfs zu liegen kam, verhinderte das Verrutschen der Proben während des Versuchs. Zusätzlich wurde der Knochen von zwei an jeder Seite angebrachten Inbusschrauben vor seitlichem Verrutschen und Verkippen geschützt (siehe Abbildung 4.4 a.).

Der Stempel, über welchen die Kraftübertragung erfolgte, wurde auf Höhe der Metaphyse heruntergefahren und bei einer Vorlast von $1 \mathrm{~N}$ automatisch angehalten. Nach Überprüfung der korrekten Lage des Knochens und des Stempels, wobei darauf geachtet wurde, dass der Stempel einen Millimeter distal vom Osteotomiespalt ansetzte, wurde der Versuch gestartet. Die Steuerung der Maschine und die Aufzeichnung der Messdaten in Form eines Kraft-Weg-Diagramms erfolgte über die Software „testXpert”. Der Versuch wurde vom Untersucher manuell unterbrochen, sobald es im aufgezeichneten Diagramm zu einem abrupten Abfall der zuvor linear ansteigenden Kurve kam. Dadurch sollte eine erneute Fraktur des ehemaligen Osteotomiespaltes verhindert werden (siehe Abbildung 4.4 b. auf Seite 39). 

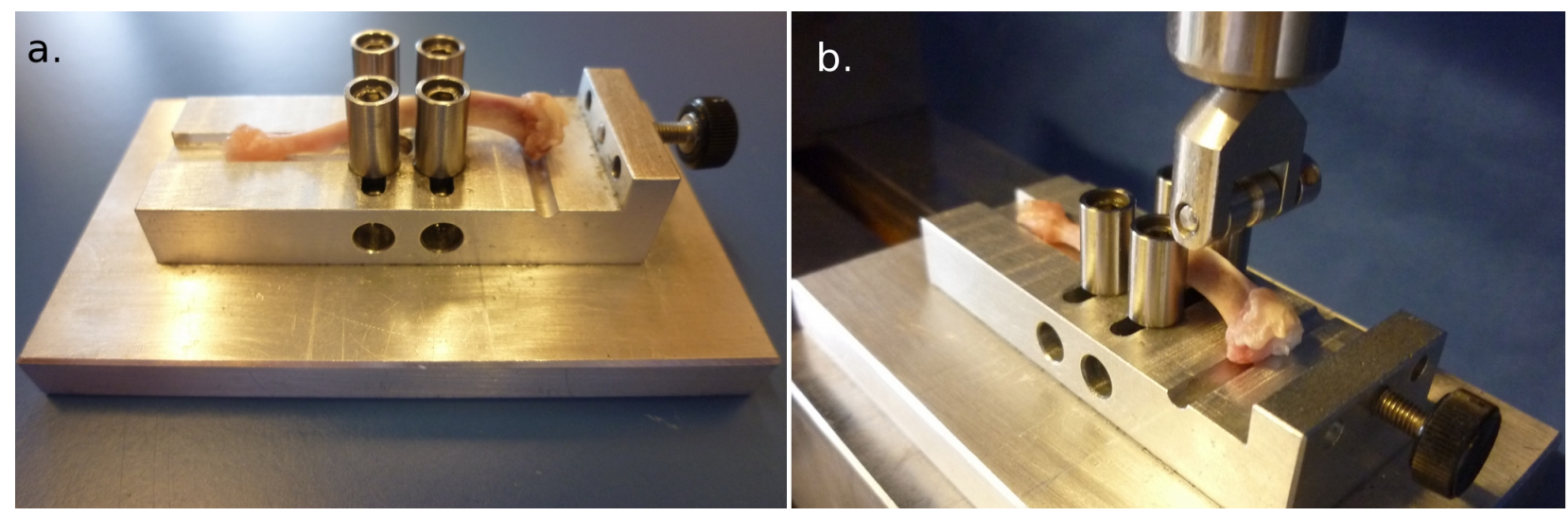

Abbildung 4.4: Biomechanischer Biegeversuch einer Rattentibia, modifiziert nach (Stuermer et al., 2006). Abbildung a. zeigt die Haltevorrichtung für die Tibiae. Der Tibiakopf kommt mit dem dorsalen Anteil in der hierfür vorgesehenen Rille zu liegen. Jeweils zwei Inbusschrauben sichern den Knochen am Schaft vor Verrutschen. Abbildung b. zeigt die Haltevorrichtung in der typischen Position in der Kompressionsmaschine. Am oberen Bildrand über der proximalen Tibia steht der Stempel, über den auf den Knochen Kraft ausgeübt wird. Auch der Stempel hat ein konkaves Rädchen, welches die Position des Knochens sichert

\subsubsection{Messparameter}

Die von der Software "testXpert”ermittelten Rohdaten wurden mit Microsoft Excel ${ }^{\circledR}$ tabellarisch dargestellt und ausgewertet. Ein Beispiel eines solchen Graphen zeigt Abbildung 4.5 auf Seite 40 .

\section{Elastizität}

Der anfängliche lineare Anstieg des Graphen im aufgezeichneten Kraft-Weg-Diagramm entspricht der reversiblen elastischen Verformung des Knochens (Stuermer et al., 2006). Die Angaben erfolgen in Newton (N) pro Millimeter ( $\mathrm{mm})$.

\section{Streckgrenze (yield load)}

Mit zunehmender Krafteinwirkung kommt es zur irreversiblen, sogenannten plastischen oder mechanischen Verformung. Der Graph flacht nun zunehmend ab. Zur genauen Bestimmung dieses Umschlagpunktes wurde die Regressionsgerade aus dem noch zuvor linearen Anstieg des Graphen und die dazugehörige Standardabweichung errechnet. Als Streckgrenze oder "yield load"wird der Punkt, an dem die Kurve den Bereich der doppelten Standardabweichung der Regressionsgeraden verlässt, bezeichnet. Die Angabe erfolgt in Newton (N) (Stuermer et al., 2006). 


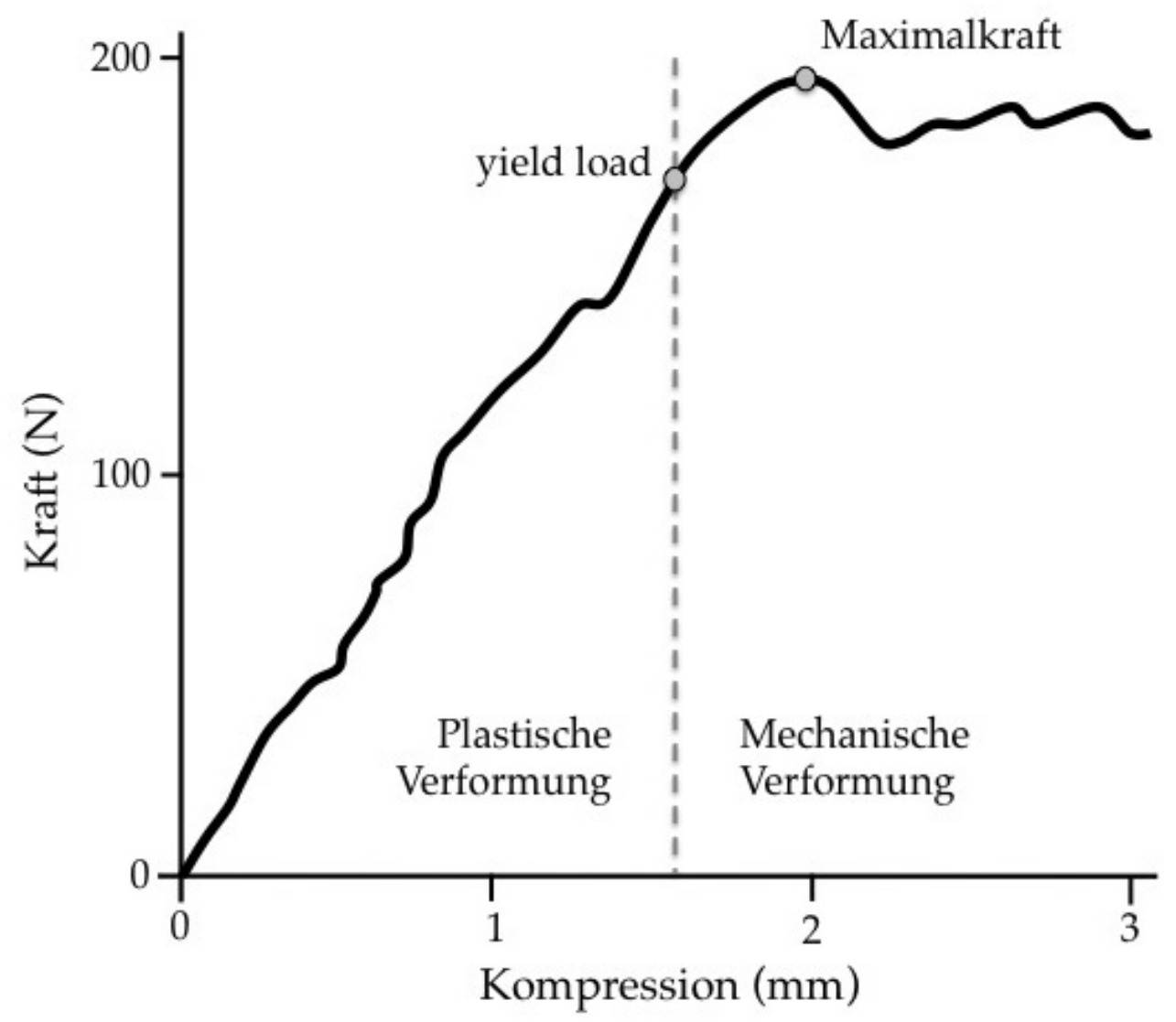

Abbildung 4.5: Die Abbildung zeigt die Kurve im Rahmen einer biomechanischen Untersuchung einer Tibia. Während des initialen linearen Anstiegs unterliegt der Knochen einer plastischen, reversiblen Verformung. Sobald die einwirkende Kraft die reversible Verformung des Knochens übersteigt, kommt es zu einer Abflachung der Kurve und der Knochen beginnt sich irreversibel zu verformen. Nimmt die Kraft weiter zu, kommt es schließlich zur Fraktur, was zu einem abrupten Abfall des Graphen führt (Stuermer et al., 2006) 


\subsubsection{Auswertung}

\subsection{Mikroradiographie}

\subsubsection{Probenerstellung}

Zunächst wurden die Proben über eine ansteigende Alkoholreihe entwässert und entfettet. Die Tibiae wurden für jeweils eine Woche in vergälltem Ethanol der Konzentrationen $40 \%, 70 \%, 80 \%, 100 \%$ aufbewahrt. Nach Zwischenlagerung in einem Gemisch aus Ethanol und Methylmethacrylsäure (MMA) zu gleichen Anteilen folgte die Einbettung. Hierzu wurden die Präparate einzeln in Rollrandflaschen deponiert. Die Flaschen wurden anschließend mit einem Gemisch aus $1000 \mathrm{ml} \mathrm{MMA,} 200 \mathrm{ml}$ Dibutylphthalat und $29 \mathrm{~g}$ Benzoylperoxid (Fa. Merck) befüllt, wobei eine Rollrandflasche ein Volumen von etwa $40 \mathrm{ml}$ fasst.

Nach Aushärtung des Gemisches wurden die Methylmethacrylatblöcke aus den Flaschen entfernt und mit einer Innenlochsäge (Leica Sägemikrotom) in $150 \mu \mathrm{m}( \pm 20 \mu \mathrm{m})$ dicke Schnitte gesägt. Die Schnittebene für das Sägemikrotom wurde so gewählt, dass sie mit der ehemaligen Schraubenebene übereinstimmte.

Drei zentrale Schnitte wurden im Anschluss mit einem Röntgengerät (Cabinet X-RaySystem, Faxitron Series, Modell-Nr. 43855A, Hewlett Packard, San Diego, USA) bei einer Röhrenspannung von $10 \mathrm{kV}$, einer Stromstärke von $0,3 \mathrm{~mA}$ und einer Belichtungszeit von drei Minuten auf langsamem Industriefilm (Kodak Professional Film, INDUSTREX SR45 Film ISO 9002) geröntgt.

Die histologischen Schnitte wurden danach auf Objektträgern $(52 \times 76 \mathrm{~mm})$ mit Eukitt ${ }^{\circledR}(\mathrm{Fa}$. Kindler, Freiburg, Deutschland) staubfrei eingedeckt. und die fertigen Objektträger in willkürlicher Reihenfolge archiviert.

\subsubsection{Auswertung}

\section{Benutzerspezifische Eichung des Messvorgangs}

Zur im Folgenden beschriebenen Auswertung der Mikroradiographien mussten vom Untersucher mehrere Einstellungen und Arbeitsschritte von Hand durchgeführt werden. Zur Minimierung untersucherbedingter Messungenauigkeiten wurden deshalb sämtliche Auswertungen vom selben Untersucher durchgeführt. Außerdem erfolgte vorab eine Überprüfung der Reproduzierbarkeit der Ergebnisse. Hierzu wurden an fünf aufeinanderfolgenden Tagen jeweils fünf Mikroradiographien durch den Untersucher ausgewer- 
tet. Hierbei wich keines der Einzelergebnisse vom Mittelwert um mehr als $\pm 10 \%$ ab.

\section{Einlesen der Mikroradiographie}

Zunächst erfolgte die Digitalisiserung der Präparate. Hierzu wurden sämtliche Präparate möglichst identisch innerhalb des von der Software (Leica Quantimet QWin 2003) vorgegebenen Messrahmens positioniert und von dem Auswertungsprogramm erfasst. Die Osteotomielinie wurde an einer horizontal im Bild verlaufenden Linie zentral ausgerichtet. Die abgebildeten Knochenanteile wurden schematisch in drei Zonen oder sogenannte „regions of interest”(ROI)) eingeteilt:

1. ventro-mediale Zone $(=\mathrm{v})$

2. dorsale Zone $(=\mathrm{d})$

\section{3. endostale Zone $(=\mathrm{e})$}

Demnach wurden die ventral gelegenen Knochenbereiche rechts im Bild und die dorsalen Abschnitte links positioniert. Die proximalen wurden im oberen Bildabschnitt platziert, während die distalen Anteile im unteren Bildrand zu liegen kamen (Siehe Abbildung 4.6 auf Seite 43). Verwendet wurde hierzu eine mit dem Rechner (Intel ${ }^{\circledR}$ Pentium ${ }^{\circledR} 4,2,6 \mathrm{GHz}$ ) verbundene Spezialkamera (Leica DC 300 F). Es wurde ein 1,0 er Objektiv mit 10,0 er Okular eingesetzt. Hieraus ergab sich eine 10-fache Vergrößerung. Die Schnitte wurden dadurch in optimaler Größe auf dem Monitor abgebildet. Für sämtliche Proben wurde eine Belichtungszeit von 345 ms gewählt. Nach dem Einlesen und der Speicherung der Bilder konnten diese mit einem hierfür entwickelten Programm ausgewertet werden.

\section{Festlegung der Grauschwellenwerte}

Auf den Mikroradiographien stellt sich Knochen Weiß bis Dunkelgrau dar. Das abgebildete Knochengewebe wurde von der Software im Rahmen eines automatisierten Schrittes erfasst. Die von der Software getroffene Auswahl musste jedoch in der Regel manuell nachjustiert werden, um zu gewährleisten, dass sämtliches Knochengewebe zur weiteren Bearbeitung ausgewählt war. Hierbei wurde im Zweifel eine Überdetektion präferiert.

\section{Flächendefinition}

Zunächst mussten die jeweilig zu untersuchenden Flächen bestimmt werden. Dies erfolgte manuell über ein Graphik-Pad. Der Untersucher konnte über dieses Pad die jeweilige 

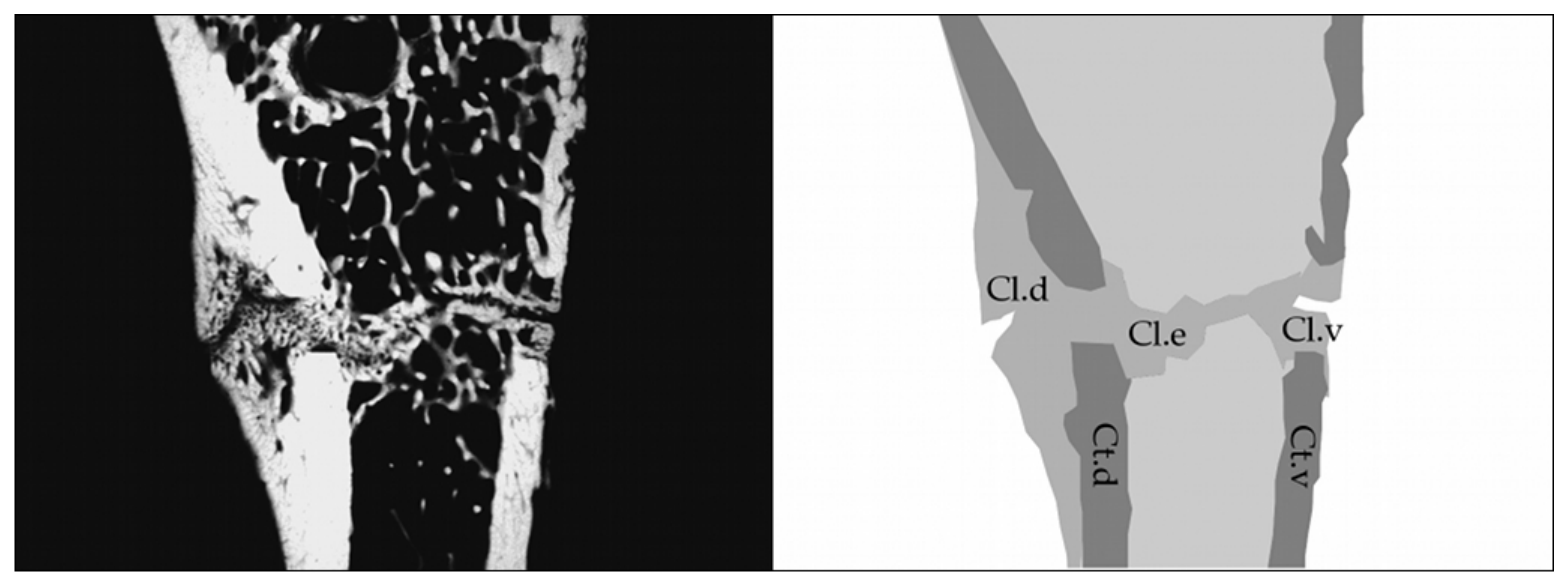

Abbildung 4.6: Die Abbildung zeigt eine Mikroradiographie links. Rechts sind schematisch Kallus ventral (Cl.v), Kallus dorsal (Cl.d) und Kallus endostal (Cl.e) sowie Kortikalis ventral (Ct.v) und Kortikalis dorsal (Ct.d.) dargestellt.

Fläche umfahren, was in Form einer dünnen Linie angezeigt wurde. Im Nachhinein bestand die Möglichkeit, diese Linie bei Ungenauigkeiten manuell zu korrigieren. Da es sich bei den Präparaten um zweidimensionale Abbildungen eines dreidimensionalen Körpers handelte, konnte es sein, dass zusammengehörige Flächen auf der Abbildung getrennt erschienen. Über die Software bestand die Möglichkeit, voneinander getrennte, jedoch zueinander gehörige Areale einzeln auszuwählen und einander zuzuschreiben. Folgende Flächen wurden in diesem Arbeitsschritt bestimmt:

Knochenflüche gesamt, einschließlich des Kallus

Hierzu wurde der gesamte abgebildete Knochen umfahren.

Kortikalisfläche proximal, ventral

Der Untersucher markierte die proximale, ventrale Korikalisfläche

Kortikalisfläche proximal, dorsal

Der Untersucher markierte die proximale, dorsale Korikalisfläche

Kortikalisfläche distal, ventral

Der Untersucher markierte die distale, ventrale Korikalisfläche

Kortikalisfläche distal, dorsal

Der Untersucher markierte die distale, dorsale Korikalisfläche

Kallusfläche ventral

Hierzu wurde die ventrale Kallusfläche markiert

Kallusfläche dorsal

Es wurde die dorsale Kallusfläche umfahren

Kallusfläche endostal 
Der Untersucher markierte den gesamten endostalen Kallus

Trabekelfläche distal

Die distal des Osteotomiespalts gelegene Trabekelfläche wurde umfahren.

\section{Durchmesserbestimmung}

Kortikalisdicke distal, ventral

Hierzu legte der Untersucher fünf Vektoren durch die Kortikalis in unmittelbarer Nähe der Osteotomie. Dabei wurde darauf geachtet, dass die Vektoren beide Kortikalisgrenzen überschritten. Die Software konnte die Vektoren anschließend aufgrund der zuvor definierten Kortikalisfläche (vergleiche Abschnitt 4.3.2 auf Seite 42) entsprechend der tatsächlichen Kortikalisdicke anpassen.

Kortikalisdicke distal dorsal

Die Vektoren wurden analog wie im vorherigen Abschnitt beschrieben platziert, jedoch in der dorsalen - also plattenfernen Kortikalis.

\section{Kallusdicke ventral}

Der Untersucher platzierte zehn Vektoren orthogonal zur Längsachse des Knochens durch den Kallus. Jeweils fünf der Vektoren wurden dabei oberhalb, die anderen fünf unterhalb des Osteotomiespaltes angelegt. Auch hier mussten die Vektoren die Grenzen des Kallus überschreiten. Basierend auf der zuvor definierten Kallusfläche, konnte die Software die Länge der Vektoren der tatsächlichen Kallusausdehnung anpassen.

Kallusdicke dorsal

Vergleiche hierzu die Bestimmung der ventralen Kallusfläche. Es wurde analog, jedoch an der dorsalen - also plattenfernen Kortikalis - verfahren.

\subsubsection{Messparameter}

Tabelle 4.2 auf Seite 45 gibt einen Überblick über die von der Software anhand der zuvor bestimmten Werte errechneten Parameter. 


\begin{tabular}{|c|c|c|}
\hline Parameter & Bedeutung & Einheit \\
\hline $\begin{array}{l}\text { Kortikalisdicke } \\
\text { distal ventral }\end{array}$ & $\begin{array}{l}\text { Arithmetisches Mittel der unter Abschnitt } 4.3 .2 \\
\text { beschriebenen Vektoren }\end{array}$ & $\mathrm{mm}$ \\
\hline $\begin{array}{l}\text { Kortikalisdicke } \\
\text { distal dorsal }\end{array}$ & $\begin{array}{l}\text { Arithmetisches Mittel der unter Abschnitt 4.3.2 } \\
\text { beschriebenen Vektoren }\end{array}$ & $\mathrm{mm}$ \\
\hline $\begin{array}{l}\text { Knochenflächendichte } \\
\text { Trabekel distal }\end{array}$ & $\begin{array}{l}\text { Prozentualer Knochenanteil des zuvor } \\
\text { als "Trabekelfläche distal"definierten Areals }\end{array}$ & $\%$ \\
\hline $\begin{array}{l}\text { Knochenflächendichte } \\
\text { Kortikalis distal ventral }\end{array}$ & $\begin{array}{l}\text { Prozentualer Knochenanteil der zuvor } \\
\text { als "Kortikalis distal plattennah"definierten Fläche }\end{array}$ & $\%$ \\
\hline $\begin{array}{l}\text { Knochenflächendichte } \\
\text { Kortikalis distal dorsal }\end{array}$ & $\begin{array}{l}\text { Prozentualer Knochenanteil der zuvor } \\
\text { als "Kortikalis distal plattenfern"definierten Fläche }\end{array}$ & $\%$ \\
\hline $\begin{array}{l}\text { Knochenflächendichte } \\
\text { Kallus dorsal }\end{array}$ & $\begin{array}{l}\text { Prozentualer Knochenanteil der zuvor } \\
\text { als "Kallus plattenfern"definierten Fläche }\end{array}$ & $\%$ \\
\hline $\begin{array}{l}\text { Knochenflächendichte } \\
\text { Kallus ventral }\end{array}$ & $\begin{array}{l}\text { Prozentualer Knochenanteil der zuvor } \\
\text { als "Kallus plattennah"definierten Fläche }\end{array}$ & $\%$ \\
\hline $\begin{array}{l}\text { Knochenflächendichte } \\
\text { Kallus endostal }\end{array}$ & $\begin{array}{l}\text { Prozentualer Knochenanteil der zuvor } \\
\text { als "Kallus endostal"definierten Fläche }\end{array}$ & $\%$ \\
\hline $\begin{array}{l}\text { Kallusdicke } \\
\text { dorsal }\end{array}$ & $\begin{array}{l}\text { Arithmetisches Mittel der zur Bestimmung der } \\
\text { plattenfernen Kallusdicke angelegten Vektoren }\end{array}$ & $\mathrm{mm}$ \\
\hline $\begin{array}{l}\text { Kallusdicke } \\
\text { ventral }\end{array}$ & $\begin{array}{l}\text { Arithmetisches Mittel der zur Bestimmung } \\
\text { der plattennahen Kallusdicke angelegten Vektoren }\end{array}$ & $\mathrm{mm}$ \\
\hline $\begin{array}{l}\text { Anzahl Trabekel- } \\
\text { kreuzungen }\end{array}$ & $\begin{array}{l}\text { Absolute Anzahl der Trabekelkreuzungen inner- } \\
\text { halb des Areals "Trabekelfläche distal" }\end{array}$ & $\mathrm{n}$ \\
\hline $\begin{array}{l}\text { Dichte Trabekel- } \\
\text { kreuzungen }\end{array}$ & $\begin{array}{l}\text { Anzahl der Trabekelkreuzungen pro } \mathrm{mm}^{2} \text { inner- } \\
\text { halb des Areals "Trabekelfläche distal" }\end{array}$ & $\mathrm{n} / \mathrm{mm}^{2}$ \\
\hline $\begin{array}{l}\text { mittlere Trabekel- } \\
\text { dicke }\end{array}$ & $\begin{array}{l}\text { Arithmetisches Mittel der Trabekeldicke in dem } \\
\text { als "Trabekelfläche distal"beschriebenen Areal }\end{array}$ & $\mu \mathrm{m}$ \\
\hline
\end{tabular}

Tabelle 4.2: Die Messparameter der Mikroradiographie sind in der linken Spalte aufgeführt. Die Bedeutung des jeweiligen Parameters ist in der mittleren Spalte dargelegt. In der rechten Spalte befindet sich die entsprechende Einheit. 


\subsection{Polychrome Fluoreszenzmarkierung}

\subsubsection{Betrachtung und Digitalisierung der histologischen Präparate}

Die zuvor angefertigten histologischen Präparate wurden unter einem Auflicht-Fluoreszenz-Stereomakroskop (Leica Stereomakroskop MZ 7-5 mit FluoCombi III) in Blaufluoreszenz betrachtet. Es wurde ein 1,0er Objektiv und ein 10,0er Okular gewählt, woraus sich eine zehnfache Vergrößerung ergab. Wie im Abschnitt 4.3.1 auf Seite 41 beschrieben, wurden bei den Präparaten zunächst schematisch drei „regions of interest”(ROI) definiert: Eine ventro-mediale Zone $(=\mathrm{v})$, eine dorsale Zone $(=\mathrm{d})$ und eine endostale Zone $(=\mathrm{e})$. Die Ausrichtung der Präparate erfolgte hiernach analog der Platzierung zur mikroradiographischen Untersuchung.

Die Lichtquelle, eine Quecksilberhöchstdrucklampe, hat eine Leistung von 50 Watt. Ein Anregungsfilter für den Wellenlängenbereich von 450 bis $490 \mathrm{~nm}$ ermöglichte die notwendige Fluorochromanregung durch blaues Licht. Die Bilder wurden anschließend über eine Kamera (Leica DC 300F) eingelesen und digital auf einem Computer (Intel ${ }^{\circledR}$ Pentium ${ }^{\circledR} 4$, 2,6 GHz) gespeichert.

Mit der Software Leica Quantimet QWin 2003 kann die Belichtungszeit individuell angepasst werden. In diesem Fall wurde eine Zeit von 9,7 s bis 12,9 s gewählt. Die Bildhelligkeit kann über einen in die Software ebenfalls integrierten Gain-Regler gesteuert werden, wobei für diese Auswertung die Bildhelligkeit um den Faktor drei intensiviert wurde. Diese Einstellungen waren im Rahmen vorausgegangener Versuche bereits getestet und validiert worden (Sehmisch et al., 2009).

\subsubsection{Auswertung}

Die Auswertung erfolgte im Blindversuch über eine eigens hierfür entwickelte Erweiterung, welche für die AuswertungsSoftware (Leica Quantimet QWin 2003) entwickelt worden war.

Die Gruppenzugehörigkeit der einzelnen Präparate war dem Untersucher zum Zeitpunkt der Untersuchung nicht bekannt. 


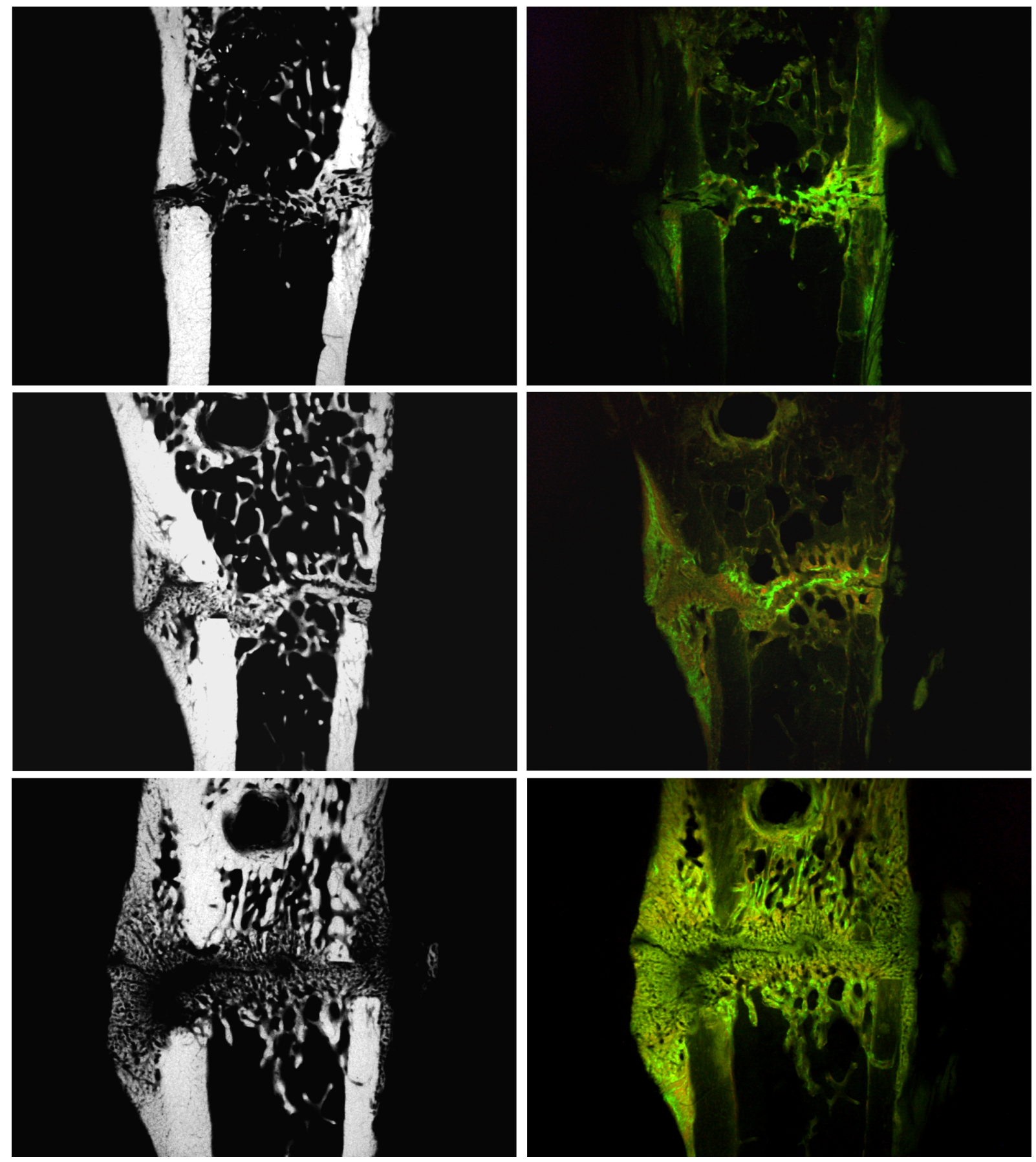

Abbildung 4.7: Dargestellt sind links in Schwarz-Weiß Mikroradiographien und rechts Beispielabbildungen des Fluoreszenzversuches. Es handelt sich um jeweils benachbarte Schnitte desselben Knochens. Von oben nach unten zeigt die oberste Zeile eine Probe der Kontrollgruppe. Die mittlere Zeile entspricht einer Probe der Gruppe, welche PTH ab dem 1. Tag, die untere Zeile einer Probe der Gruppe, welche PTH ab dem 7. Tag bekommen hat. Die im Bild linksseitig liegende Kortikalis entspricht für jede Probe der dorsalen, also plattenfernen Kortikalis. Deutlich zu sehen ist der Kallus, welcher an der dorsalen Kortikalis bei den Tieren welche PTH erhielten, besonders kräftig imponiert. Dabei zeigt sich der Kallus der Tiere der Gruppe drei (PTH ab Tag 7) besonders kräftig. Vergleiche auch Abbildung 4.6 auf Seite 43 


\subsubsection{Messparameter}

Anschließend erfolgte die Bestimmung der in Tabelle 4.3 auf Seite 48 dargestellten Parameter:

\begin{tabular}{|c|c|c|}
\hline Parameter & Bedeutung & Einheit \\
\hline $\begin{array}{l}\text { Gesamtkallusfläche } \\
\text { ventral }\end{array}$ & Absolute Kallusfläche ventral & $\mathrm{mm}^{2}$ \\
\hline $\begin{array}{l}\text { Gesamtkallusfläche } \\
\text { dorsal }\end{array}$ & Absolute Kallusfläche dorsal & $\mathrm{mm}^{2}$ \\
\hline $\begin{array}{l}\text { Gesamtkallusfläche } \\
\text { endostal }\end{array}$ & Absolute Kallusfläche endostal & $\mathrm{mm}^{2}$ \\
\hline $\begin{array}{l}\text { Kallusfläche Fluoresceinkomplexon } \\
\text { (Grün) ventral }\end{array}$ & $\begin{array}{l}\text { Absolute Fläche des ventralen } \\
\text { CG-gefärbten Kallus }\end{array}$ & $\mathrm{mm}^{2}$ \\
\hline $\begin{array}{l}\text { Kallusfläche Fluoresceinkomplexon } \\
\text { (Grün) dorsal }\end{array}$ & $\begin{array}{l}\text { Absolute Fläche des dorsalen } \\
\text { CG-gefärbten Kallus }\end{array}$ & $\mathrm{mm}^{2}$ \\
\hline $\begin{array}{l}\text { Kallusfläche Fluoresceinkomplexon } \\
\text { (Grün) endostal }\end{array}$ & $\begin{array}{l}\text { Absolute Fläche des endostalen } \\
\text { CG-gefärbten Kallus }\end{array}$ & $\mathrm{mm}^{2}$ \\
\hline $\begin{array}{l}\text { Kallusfläche Alizarinkomplexon } \\
\text { (Rot) ventral }\end{array}$ & $\begin{array}{l}\text { Absolute Fläche des ventralen } \\
\text { AK-gefärbten Kallus }\end{array}$ & $\mathrm{mm}^{2}$ \\
\hline $\begin{array}{l}\text { Kallusfläche Alizarinkomplexon } \\
\text { (Rot) dorsal }\end{array}$ & $\begin{array}{l}\text { Absolute Fläche des dorsalen } \\
\text { AK-gefärbten Kallus }\end{array}$ & $\mathrm{mm}^{2}$ \\
\hline $\begin{array}{l}\text { Kallusfläche Alizarinkomplexon } \\
\text { (Rot) endostal }\end{array}$ & $\begin{array}{l}\text { Absolute Fläche des endostalen } \\
\text { AK-gefärbten Kallus }\end{array}$ & $\mathrm{mm}^{2}$ \\
\hline $\begin{array}{l}\text { Kallusfläche Tetracyclin- } \\
\text { Hydrochlorid (Gelb) ventral }\end{array}$ & $\begin{array}{l}\text { Absolute Fläche des ventralen } \\
\text { TC-gefärbten Kallus }\end{array}$ & $\mathrm{mm}^{2}$ \\
\hline $\begin{array}{l}\text { Kallusfläche Tetracyclin- } \\
\text { Hydrochlorid (Gelb) dorsal }\end{array}$ & $\begin{array}{l}\text { Absolute Fläche des dorsalen } \\
\text { TC-gefärbten Kallus }\end{array}$ & $\mathrm{mm}^{2}$ \\
\hline $\begin{array}{l}\text { Kallusfläche Tetracyclin- } \\
\text { Hydrochlorid (Gelb) endostal }\end{array}$ & $\begin{array}{l}\text { Absolute Fläche des endostalen } \\
\text { TC-gefärbten Kallus }\end{array}$ & $\mathrm{mm}^{2}$ \\
\hline
\end{tabular}

Tabelle 4.3: Die linke Spalte listet den jeweiligen Messparameter der Fluoreszenzmikroskopie auf. In der mittleren Spalte ist der jeweilige Parameter erläutert. Die rechte Spalte zeigt die entsprechende Messeinheit

Die mittels Xylenol Orange in der frühen Knochenheilungsphase angefärbte Bande stellte sich nur sehr schmal dar, sodass eine standardisierte Auswertung nicht möglich war, weshalb diese Daten von der Auswertung ausgeschlossen werden mussten. 


\subsection{Statistik}

Sämtliche Signifikanzen wurden mittels der one-way ANOVA und des Tukey-Kramerpost-hoc-Tests ermittelt. Für alle Ergebnisse wurde $\mathrm{p} \leq 0,05$ als signifikant gewertet. Verwendet wurde die Software Prism TM, GraphPad ${ }^{\circledR}$ v4.0, San Diego, USA. 


\section{Kapitel 5}

\section{Ergebnisse}

\subsection{Körpergewicht und Futteraufnahme der Versuchstiere}

Die Versuchstiere wurden vor Versuchsbeginn und im Anschluss einmal wöchentlich gewogen. Tabelle 5.1 gibt eine Übersicht über die Entwicklung des Körpergewichts der Tiere entlang des Versuchs. Die Unterschiede waren nicht signifikant.

Der wöchentliche Futterverbrauch wurde ermittelt, indem am Ende jeder Woche der im Käfig verbliebene Futterrest bestimmt wurde. Zu Beginn jeder Versuchswoche wurde eine vordefinierte Futtermenge in den Käfigen platziert, sodass am Ende die Differenz ermittelt werden konnte. Tabelle 5.2 zeigt die wöchentliche Futteraufnahme der Tiere der drei Gruppen im Verlauf des Versuchs. Es ergaben sich keine signifikanten Unterschiede im Futterverbrauch der Gruppen. 


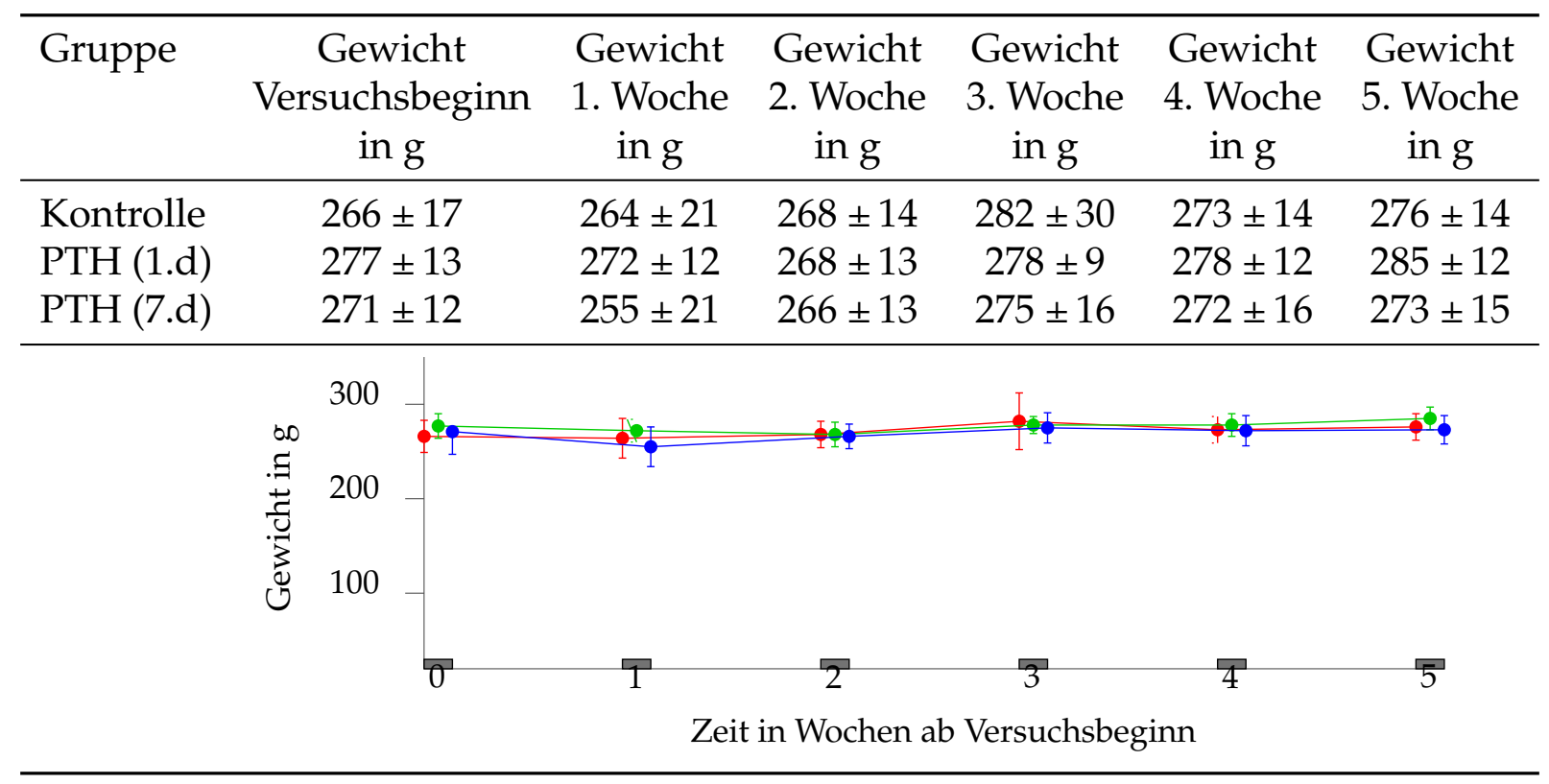

Tabelle 5.1: Tabelle und graphische Darstellung des Körpergewichts mit Standardabweichung der drei Versuchstiergruppen zu Versuchsbeginn und die wöchentliche Entwicklung. Es gab keine signifikanten Unterschiede unter den Gruppen. Graphische Darstellung der Gewichtsentwicklung der Versuchstiere: Werte der Kontrollgruppe in Rot, PTH (1.d) in Grün und PTH (7.d) in Blau.

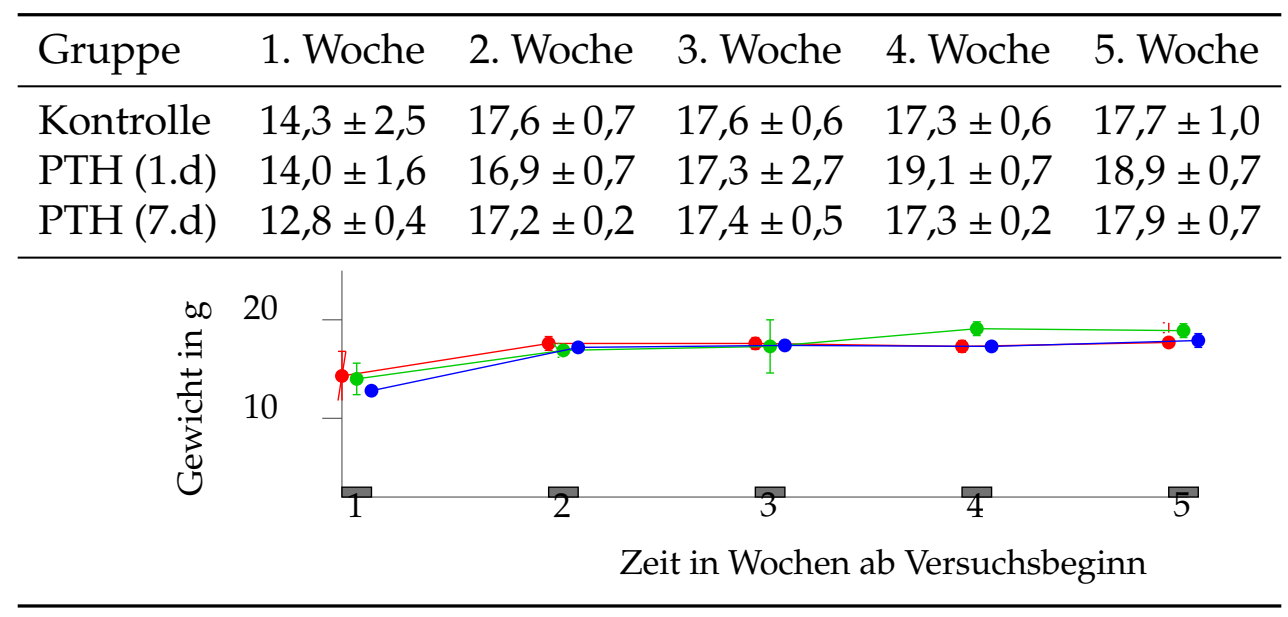

Tabelle 5.2: Die Tabelle zeigt die Mittelwerte der Futteraufnahme für alle drei Versuchstiergruppen und die jeweilige Standardabweichung. Es gab keine signifikanten Unterschiede unter den Gruppen. Graphische Darstellung der Gewichtsentwicklung der Versuchstiere: Werte der Kontrollgruppe in Rot, PTH (1.d) in Grün und PTH (7.d) in Blau. 


\subsection{Ergebnisse des Biegeversuchs an der Tibia}

Die Mittelwerte und jeweiligen Standardabweichungen der Versuchsergebnisse sind tabellarisch aufgeführt. Zur graphischen Darstellung wurden Balkendiagramme gewählt. Signifikanzen sind wie folgt gekennzeichnet: Ein Stern $\left(^{*}\right)$ wurde für signifikante Unterschiede zwischen den beiden PTH-Gruppen und der Kontrollgruppe gewählt. Ein Doppelkreuz (\#) kennzeichnet einen signifikanten Unterschied unter den PTH-Gruppen.

Im Folgenden wird die Kontrollgruppe als Kontrolle bezeichnet. Die Gruppe, welche PTH ab dem ersten Tag erhalten hat wird als PTH (1.d) und die Gruppe, welche PTH ab dem siebten Versuchstag erhalten hat als PTH (7.d) bezeichnet.

Yield Load PTH (7.d) zeigte den höchsten Wert mit 64,33 $\pm 7,526 \mathrm{~N}$, gefolgt von PTH (1.d) mit 49,39 $\pm 3,784 \mathrm{~N}$ und der Kontrolle mit 32,85 $\pm 2,681 \mathrm{~N}$ (siehe Tabelle 5.3). Die Unterschiede zwischen der Kontrolle und PTH (1.d), sowie zwischen der Kontrolle und PTH (7.d) waren signifikant.

\begin{tabular}{|c|c|c|c|c|c|}
\hline Gruppe & $\begin{array}{l}\text { Mittelwert } \\
\text { in N }\end{array}$ & $\begin{array}{l}\text { Standard- } \\
\text { abweichung }\end{array}$ & \multicolumn{3}{|c|}{$\begin{array}{l}\text { Graphische Darstellung } \\
\text { Skala in N }\end{array}$} \\
\hline \multicolumn{6}{|l|}{ Yield Load } \\
\hline Kontrolle & 32,85 & $\pm 2,681$ & & $\square$ & \\
\hline PTH (1.d) & 49,39 & $\pm 3,784$ & & $\square{ }^{*}$ & \\
\hline \multirow[t]{2}{*}{ PTH (7.d) } & 64,33 & $\pm 7,526$ & & $\square$ & \\
\hline & & & 0 & 60 & 80 \\
\hline
\end{tabular}

Tabelle 5.3: Dargestellt sind die Mittelwerte für „yield load" und die korrespondierenden Standardabweichungen 
Steigung Es ergaben sich keine signifikanten Unterschiede. Den höchsten Wert erreichte PTH (7.d) mit 120,70 $\pm 5,795 \mathrm{~N} / \mathrm{mm}$, gefolgt von PTH (1.d) mit $105,50 \pm 7,288 \mathrm{~N} / \mathrm{mm}$ und der Kontrolle mit 90,94 $\pm 13,530 \mathrm{~N} / \mathrm{mm}$ (siehe Tabelle 5.4).

\begin{tabular}{|c|c|c|c|}
\hline Gruppe & $\begin{array}{l}\text { Mittelwert } \\
\text { in } \mathrm{N} / \mathrm{mm}\end{array}$ & $\begin{array}{l}\text { Standard- } \\
\text { abweichung }\end{array}$ & $\begin{array}{l}\text { Graphische Darstellung } \\
\text { Skala in N/mm }\end{array}$ \\
\hline \multicolumn{4}{|l|}{ Steigung } \\
\hline Kontrolle & 90,94 & $\pm 13,530$ & $\longmapsto$ \\
\hline PTH (1.d) & 105,50 & $\pm 7,288$ & $\square$ \\
\hline \multirow[t]{2}{*}{ PTH (7.d) } & 120,70 & $\pm 5,795$ & $\square$ \\
\hline & & & $\begin{array}{l}40 \\
40\end{array}$ \\
\hline
\end{tabular}

Tabelle 5.4: Dargestellt sind die Mittelwerte für die Steigung und die entsprechende Standardabweichung 


\subsection{Ergebnisse der Mikroradiographie}

Im Folgenden sind die Mittelwerte mit der jeweiligen Standardabweichung der mikroradiographischen Analysen tabellarisch aufgeführt und graphisch in Form von Balkendiagrammen dargestellt. Signifikante Unterschiede zwischen den beiden PTH-Gruppen und der Kontrollgruppe sind mit einem Stern $\left(^{*}\right)$ gekennzeichnet. Signifikante Unterschiede zwischen den beiden PTH-Gruppen sind mit einem Doppelkreuz (\#) gekennzeichnet.

Die Kontrollgruppe wird weiterhin als Kontrolle bezeichnet. PTH (1.d) bezieht sich auf die Tiere, welche PTH ab dem ersten Tag erhalten haben und PTH (7.d) auf jene, welche PTH ab dem siebten Versuchstag erhalten haben.

Kortikalisdicke distal ventral Die Kontrolle zeigte mit 0,3684 $\pm 0,0119 \mathrm{~mm}$ den höchsten Wert. Ein annähernd identischer Mittelwert zeigte sich bei PTH (7.d) $(0,3681 \pm 0,0158 \mathrm{~mm})$. PTH (1.d) lag mit 0,3221 $\pm 0,0201 \mathrm{~mm}$ darunter (siehe Tabelle 5.5). Die Differenz wurde als nicht signifikant gewertet.

Kortikalisdicke distal dorsal Die Kontrolle $(0,5245 \pm 0,0131 \mathrm{~mm})$ zeigte gegenüber den beiden anderen Gruppen eine signifikant dickere Kortikalis. Die Unterschiede zwischen PTH (1.d) $(0,3991 \pm 0,0171 \mathrm{~mm})$ und PTH (7.d) $(0,4474 \pm 0,0194 \mathrm{~mm})$ wurden als nicht signifikant gewertet (siehe Tabelle 5.5).

\begin{tabular}{lcccc}
\hline Gruppe & $\begin{array}{c}\text { Mittelwert } \\
\text { in mm }\end{array}$ & $\begin{array}{c}\text { Standard- } \\
\text { abweichung }\end{array}$ & $\begin{array}{c}\text { Graphische Darstellung } \\
\text { Skala in mm }\end{array}$ \\
\hline \multicolumn{7}{l}{ Kortikalisdicke distal ventral } \\
Kontrolle & 0,3684 & $\pm 0,0119$ & \\
PTH (1.d) & 0,3221 & $\pm 0,0201$ & & \\
PTH (7.d) & 0,3681 & $\pm 0,0158$ & 0,4 & 0,6 \\
\hline
\end{tabular}

Tabelle 5.5: Werte und Balkendiagramm zu Kortikalisdicke distal ventral und distal, dorsal. 
Knochenflächendichte Trabekel distal Die Kontrolle $(26,64 \pm 2,2670 \%)$ zeigte gegenüber PTH (1.d) (42,50 \pm 2,1700\%) und PTH (7.d) (41,09 \pm 2,9960\%) eine signifikant geringere Knochenflächendichte im Bereich der distalen Trabekel (siehe Tabelle5.6). Die Dichten von PTH (1.d) und PTH (7.d) unterschieden sich nicht signifikant voneinander.

\begin{tabular}{|c|c|c|c|}
\hline Gruppe & $\begin{array}{l}\text { Mittelwert } \\
\text { in } \%\end{array}$ & $\begin{array}{l}\text { Standard- } \\
\text { abweichung }\end{array}$ & $\begin{array}{c}\text { Graphische Darstellung } \\
\text { Skala in \% }\end{array}$ \\
\hline \multicolumn{4}{|c|}{ Knochenflächendichte Trabekel distal } \\
\hline Kontrolle & 26,64 & $\pm 2,267$ & $\square$ \\
\hline PTH (1.d) & 42,50 & $\pm 2,170$ & $\square^{*}$ \\
\hline \multirow[t]{2}{*}{ PTH (7.d) } & 41,09 & $\pm 2,996$ & $\square *$ \\
\hline & & & $20 \quad 40$ \\
\hline
\end{tabular}

Tabelle 5.6: Werte und Balkendiagramm zu Knochenflächendichte Trabekel distal.

Knochenflächendichte Kortikalis distal ventral Der höchste Wert zeigte sich bei PTH (7.d) $(99,51 \pm 0,0998 \%)$ gefolgt von PTH (1.d) $(99,40 \pm 0,1464 \%)$ und der Kontrolle $(99,35 \pm 0,1656 \%)$ (siehe Tabelle 5.7). Es ergaben sich keine signifikanten Unterschiede.

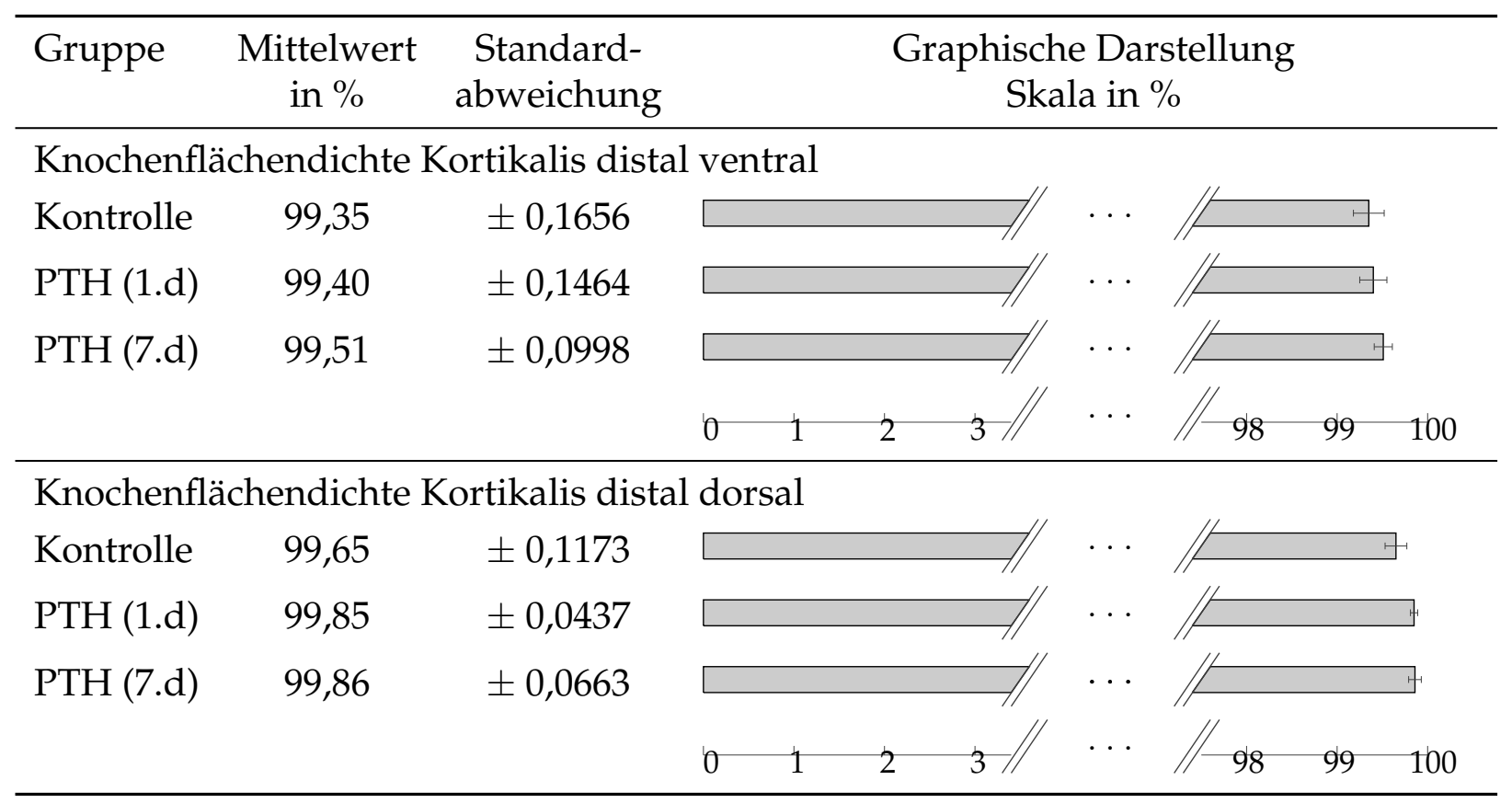

Tabelle 5.7: Werte und Balkendiagramm zu Knochenflächendichte Kortikalis distal, ventral und Kortikalis distal, dorsal. 
Knochenflächendichte Kortikalis distal dorsal Zwischen den drei Gruppen gab es hinsichtlich dieses Parameters keine signifikanten Unterschiede. PTH (7.d) zeigte den höchsten Wert mit 99,86 $\pm 0,0663 \%$, gefolgt von PTH (1.d) mit 99,85 $\pm 0,0437 \%$ und der Kontrolle mit 99,65 $\pm 0,1173 \%$ (siehe Tabelle 5.7).

Knochenflächendichte Kallus ventral PTH (1.d) $(80,27 \pm 2,1910 \%)$ zeigte gegenüber der Kontrolle $(71,42 \pm 2,8140 \%)$ eine signifikant höhere ventrale Kallusdichte. Im Vergleich zu PTH (7.d) (73,90 $\pm 2,4620 \%)$ zeigte sich kein signifikanter Unterschied (siehe Tabelle 5.8).

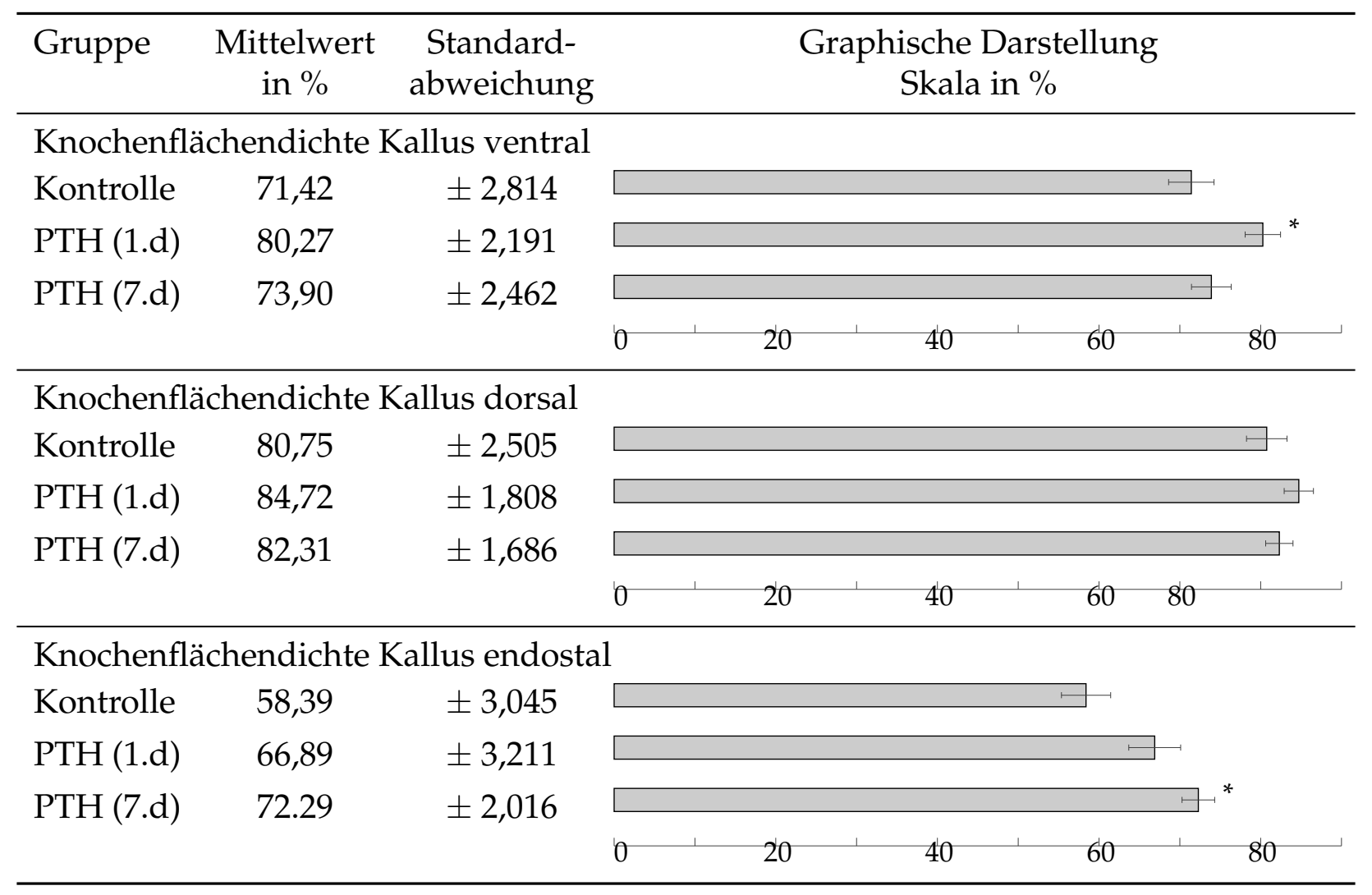

Tabelle 5.8: Werte und Balkendiagramm zu Knochenflächendichte Kallus ventral, Kallus dorsal und Kallus endostal.

Knochenflächendichte Kallus dorsal Den höchsten Wert zeigte PTH (1.d) $84,72 \pm 1,8080 \%$. Es folgten die Werte von PTH (7.d) $(82,31 \pm 1,6860 \%)$ und der Kontrolle $(80,75 \pm 2,5050 \%)$ (siehe Tabelle 5.8). Sämtliche Unterschiede wurden als nicht signifikant gewertet. 
Knochenflächendichte Kallus endostal Der höchste Wert ergab sich für PTH (7.d) mit $72,29 \pm 2,0160 \%$. Gegenüber der Kontrolle (58,39 $\pm 3,0450 \%)$ war er signifikant höher. $\mathrm{Zu}$ PTH (1.d) $(66,89 \pm 3,2110 \%)$ ergaben sich keine signifikanten Unterschiede (siehe Tabelle 5.8).

Kallusdicke ventral Den höchsten Wert zeigte PTH (7.d) $(0,3344 \pm 0,0248 \mathrm{~mm})$, gefolgt von Gruppen zwei $(0,2794 \pm 0,0280 \mathrm{~mm})$ und eins $(0,2728 \pm 0,0309 \mathrm{~mm})$ (siehe Tabelle 5.9). Die Differenzen wurden als nicht signifikant gewertet.

Kallusdicke dorsal Es ergaben sich keine signifikanten Unterschiede zwischen den drei Gruppen. Den höchsten Wert zeigte PTH (7.d) mit 0,5806 0,0324 mm. Für die Kontrolle ergaben sich 0,5639 $\pm 0,0428 \mathrm{~mm}$ und PTH (1.d) 0,5373 $\pm 0,0556 \mathrm{~mm}$ (siehe Tabelle 5.9).

\begin{tabular}{|c|c|c|c|}
\hline Gruppe & $\begin{array}{c}\text { Mittelwert } \\
\text { in } \mathrm{mm}\end{array}$ & $\begin{array}{l}\text { Standard- } \\
\text { abweichung }\end{array}$ & \\
\hline \multicolumn{4}{|c|}{ Kallusdicke ventral } \\
\hline Kontrolle & 0,2728 & $\pm 0,0309$ & $\square$ \\
\hline PTH (1.d) & 0,2794 & $\pm 0,0280$ & $\square$ \\
\hline \multirow[t]{2}{*}{ PTH (7.d) } & 0,3344 & $\pm 0,0248$ & $\square$ \\
\hline & & & $\begin{array}{lllll}0,0 & 0,2 & 0,4 & 0,6\end{array}$ \\
\hline \multicolumn{4}{|c|}{ Kallusdicke dorsal } \\
\hline Kontrolle & 0,5639 & $\pm 0,0428$ & $\begin{array}{r}\square \\
\end{array}$ \\
\hline PTH (1.d) & 0,5373 & $\pm 0,0556$ & $\square$ \\
\hline \multirow[t]{2}{*}{ PTH (7.d) } & 0,5806 & $\pm 0,0324$ & $\square$ \\
\hline & & & $0,0+0,2 \quad 0,4$ \\
\hline
\end{tabular}

Tabelle 5.9: Werte und Balkendiagramm zu Kallusdicke ventral und dorsal.

Anzahl Trabekelkreuzungen PTH (1.d) wies die höchste Anzahl an Kreuzungen auf $(28,88 \pm 2,680)$. Die Kontrolle $(22,03 \pm 2,624)$ und PTH (7.d) $(22,83 \pm 3,008)$ zeigten ähnliche Werte (siehe Tabelle 5.10). Es ergaben sich keine signifikanten Unterschiede. 


\begin{tabular}{|c|c|c|c|}
\hline Gruppe & $\begin{array}{l}\text { Mittelwert } \\
\text { in Stück }\end{array}$ & $\begin{array}{l}\text { Standard- } \\
\text { abweichung }\end{array}$ & $\begin{array}{c}\text { Graphische Darstellung } \\
\text { Skala in Stück }\end{array}$ \\
\hline \multicolumn{4}{|c|}{ Anzahl Trabekelkreuzungen } \\
\hline Kontrolle & 22,03 & $\pm 2,624$ & $\square$ \\
\hline PTH (1.d) & 28,88 & $\pm 2,680$ & $\square$ \\
\hline \multirow[t]{2}{*}{ PTH (7.d) } & 22,83 & $\pm 3,008$ & $\square$ \\
\hline & & & 40 \\
\hline
\end{tabular}

Tabelle 5.10: Werte und Balkendiagramm zu Anzahl Trabekelkreuzungen.

Dichte Trabekelkreuzungen Hinsichtlich dieses Parameters zeigten PTH (1.d) $\left(23,38 \pm 2,187 \mathrm{~mm}^{2}\right)$ und PTH (7.d) $\left(17,68 \pm 3,446 \mathrm{~mm}^{2}\right)$ signifikant höhere Werte als die Kontrolle $\left(8,983 \pm 1,125 \mathrm{~mm}^{2}\right)$ (siehe Tabelle 5.11). Es ergab sich kein signifikanter Unterschied zwischen PTH (1.d) und PTH (7.d).

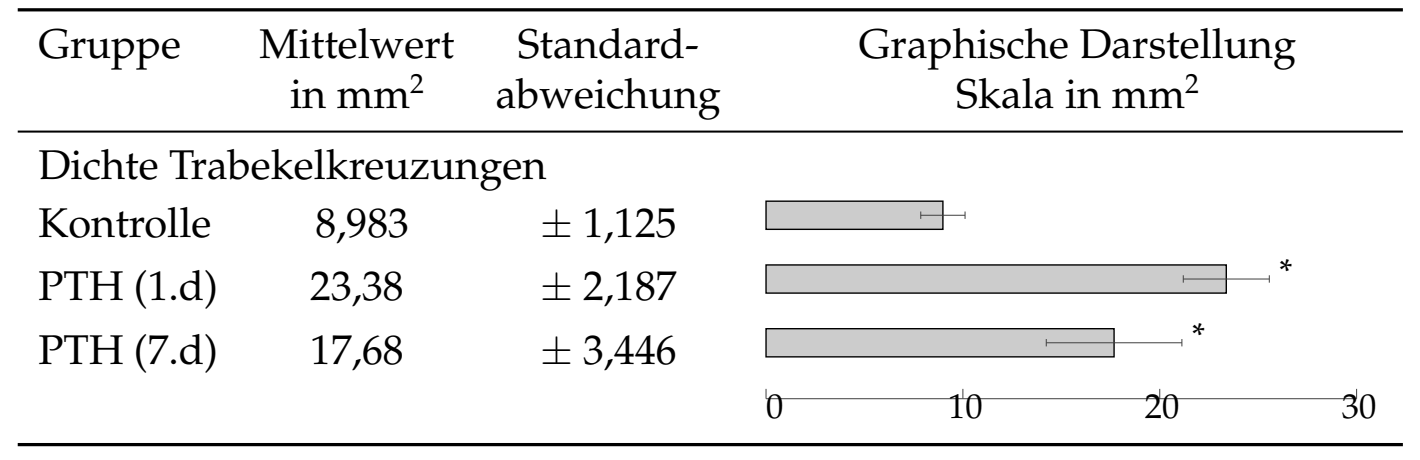

Tabelle 5.11: Werte und Balkendiagramm zu Dichte Trabekelkreuzungen. 
Mittlere Trabekeldicke Die Werte von PTH (1.d) $(7,207 \pm 0,2676 \mu \mathrm{m})$ und PTH (7.d) $(6,664 \pm 0,2341 \mu \mathrm{m})$ waren signifikant höher gegenüber der Kontrolle mit 5,484 $\pm 0,2604 \mu \mathrm{m}$ (siehe Tabelle 5.12).

\begin{tabular}{|c|c|c|c|}
\hline Gruppe & $\begin{array}{l}\text { Mittelwert } \\
\text { in } \mu \mathrm{m}\end{array}$ & $\begin{array}{l}\text { Standard- } \\
\text { abweichung }\end{array}$ & $\begin{array}{l}\text { Graphische Darstellung } \\
\text { Skala in } \mu \mathrm{m}\end{array}$ \\
\hline \multicolumn{4}{|c|}{ Mittlere Trabekeldicke } \\
\hline Kontrolle & 5,484 & $\pm 0,2604$ & $\square$ \\
\hline PTH (1.d) & 7,207 & $\pm 0,2676$ & $\square *$ \\
\hline \multirow[t]{2}{*}{ PTH (7.d) } & 6,664 & $\pm 0,2341$ & $\square$ \\
\hline & & & 6 \\
\hline
\end{tabular}

Tabelle 5.12: Werte und Balkendiagramm zur mittleren Trabekeldicke. 


\subsection{Ergebnisse der polychromen Fluoreszenzmarkierung}

Tabelle 5.13 gibt eine Gesamtübersicht über die im Rahmen der polychromen Sequenzmarkierung gewonnenen Werte.

\begin{tabular}{lccc}
\hline Kallusfläche & Kontrolle & PTH (1.d) & PTH (7.d) \\
\hline Gesamt ventral & $0,6909 \pm 0,0878$ & $0,7219 \pm 0,0708$ & $1,2889 \pm 0,2481$ \\
Gesamt dorsal & $2,2560 \pm 0,1812$ & $1,9220 \pm 0,1341$ & $2,7880 \pm 0,3519$ \\
Gesamt endostal & $4,2620 \pm 0,3796$ & $3,5790 \pm 0,1615$ & $4,9580 \pm 2,5971$ \\
\hline CG ventral & $0,0470 \pm 0,0101$ & $0,0739 \pm 0,1460$ & $0,1180 \pm 0,0319$ \\
CG dorsal & $0,2254 \pm 0,0273$ & $0,2847 \pm 0,0490$ & $0,4343 \pm 0,0844$ \\
CG endostal & $0,5546 \pm 0,0813$ & $0,4938 \pm 0,0572$ & $1,2150 \pm 0,1836$ \\
\hline AK ventral & $0,0924 \pm 0,0177$ & $0,1300 \pm 0,0197$ & $0,2314 \pm 0,0627$ \\
AK dorsal & $0,2488 \pm 0,0317$ & $0,3581 \pm 0,0384$ & $0,5051 \pm 0,0956$ \\
AK endostal & $0,5612 \pm 0,0747$ & $0,7967 \pm 0,0834$ & $1,0740 \pm 0,1271$ \\
\hline TC ventral & $0,3852 \pm 0,0567$ & $0,4500 \pm 0,0490$ & $0,8625 \pm 0,1863$ \\
TC dorsal & $1,2080 \pm 0,1114$ & $1,0540 \pm 0,1080$ & $1,8120 \pm 0,2725$ \\
TC endostal & $1,4800 \pm 0,1503$ & $1,6750 \pm 0,1473$ & $2,2230 \pm 0,3102$ \\
\hline
\end{tabular}

Tabelle 5.13: Die Tabelle zeigt die Mittelwerte der ventralen, dorsalen und endostalen Kallusflächen für die jeweiligen Fluorochrome (CG=Fluoresceinkomplexon (Grün), $A K=$ Alizarinkomplexon (Rot) und $T C=$ Tetracyclin-Hydrochlorid (Gelb)). Außerdem ist die Gesamtkallusfläche (Gesamt) aufgeführt. Die Werte sind mit der entsprechenden Standardabweichung angegeben

Nachstehende Tabellen zeigen die Mittelwerte mit der entsprechenden Standardabweichung der fluoreszenzmikroskopischen Untersuchungen. Die graphische Darstellung erfolgt in Form von Balkendiagrammen. Ein Stern $\left(^{*}\right)$ kennzeichnet signifikante Unterschiede zwischen den beiden PTH-Gruppen und der Kontrollgruppe. Ein Doppelkreuz (\#) kennzeichnet signifikante Unterschiede zwischen den beiden PTH-Gruppen.

Kontrolle bezeichnet die Tiere der Kontrollgruppe. PTH (1.d) und PTH (7.d) steht für die Tiere, denen PTH ab dem 1. bzw. dem 7. Versuchstag appliziert wurde.

Gesamtkallusfläche ventral PTH (7.d) zeigte die größte Kallusfläche mit $1,2890 \pm 0,2481 \mathrm{~mm}^{2}$. Der Wert war gegenüber der Kontrolle $\left(0,6909 \pm 0,0878 \mathrm{~mm}^{2}\right)$ und PTH (1.d) $\left(0,7219 \pm 0,0708 \mathrm{~mm}^{2}\right)$ signifikant höher (siehe Tabelle 5.14).

Gesamtkallusfläche dorsal Hier zeigte PTH (7.d) den höchsten Wert $\left(2,7880 \pm 0,3519 \mathrm{~mm}^{2}\right)$ gefolgt von der Kontrolle $\left(2,2560 \pm 0,1812 \mathrm{~mm}^{2}\right)$ und PTH (1.d) 
$\left(1,9220 \pm 0,1341 \mathrm{~mm}^{2}\right)$ (siehe Tabelle 5.14). Die Differenz zwischen PTH (7.d) und PTH (1.d) war signifikant.

Gesamtkallusfläche endostal Der höchste Wert ergab sich für PTH (7.d) mit $4,9580 \pm 0,5971 \mathrm{~mm}^{2}$. Die Kontrolle folgte mit 4,2620 $\pm 0,3796 \mathrm{~mm}^{2}$. Den niedrigsten Flächenwert wies PTH (1.d) mit 3,5790 $\pm 0,1615 \mathrm{~mm}^{2}$ auf (siehe Tabelle 5.14). Die Unterschiede wurden als nicht signifikant gewertet.

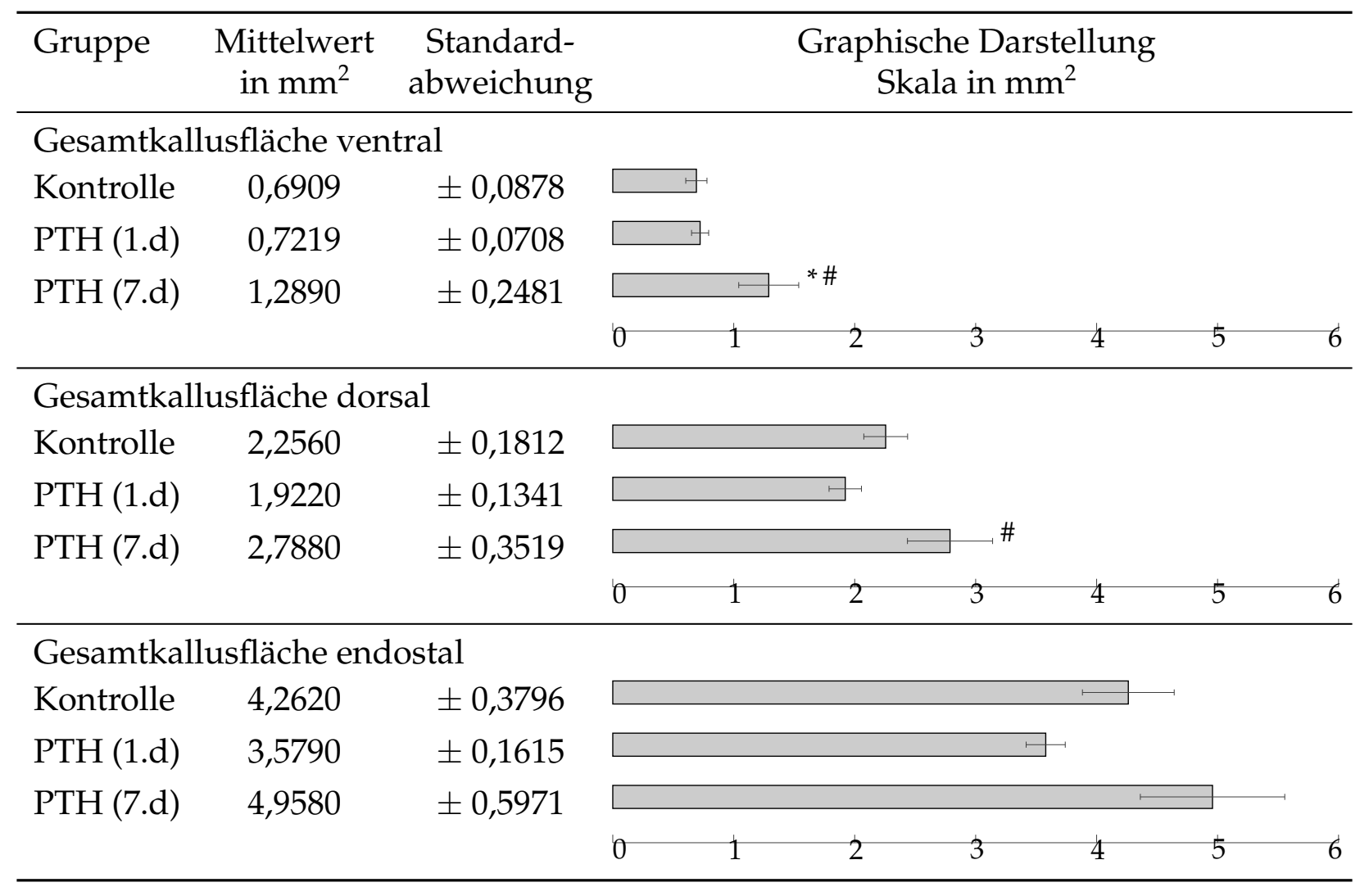

Tabelle 5.14: Werte und Balkendiagramm zu Gesamtkallusfläche ventral, Kallus dorsal und Kallus endostal.

Kallusfläche Fluoresceinkomplexon (Grün) ventral Ein signifikant höherer Wert ergab sich für PTH (7.d) $\left(0,1180 \pm 0,0319 \mathrm{~mm}^{2}\right)$ gegenüber der Kontrolle $\left(0,0470 \pm 0,0101 \mathrm{~mm}^{2}\right)$. Hinsichtlich PTH (1.d) $\left(0,0739 \pm 0,0146 \mathrm{~mm}^{2}\right)$ ergaben sich keine signifikanten Unterschiede (siehe Tabelle 5.15).

Kallusfläche Fluoresceinkomplexon (Grün) dorsal PTH (7.d) $\left(0,4343 \pm 0,0844 \mathrm{~mm}^{2}\right)$ erzielte einen signifikant höheren Wert gegenüber der Kontrolle $\left(0,2254 \pm 0,0273 \mathrm{~mm}^{2}\right)$. Für 
PTH (1.d) betrug der Wert 0,2847 $\pm 0,0490 \mathrm{~mm}^{2}$ (siehe Tabelle 5.15). Es ergaben sich keine weiteren signifikanten Unterschiede.

Kallusfläche Fluoresceinkomplexon (Grün) endostal PTH (7.d) zeigte mit $1,2150 \pm 0,1836 \mathrm{~mm}^{2}$ gegenüber der Kontrolle $\left(0,5546 \pm 0,0813 \mathrm{~mm}^{2}\right)$ und PTH (1.d) $\left(0,4938 \pm 0,0572 \mathrm{~mm}^{2}\right)$ eine signifikant größere Kallusfläche (siehe Tabelle 5.15). Weitere signifikante Unterschiede zeigten sich nicht.

\begin{tabular}{|c|c|c|c|c|c|c|c|c|}
\hline Gruppe & $\begin{array}{l}\text { Mittelwert } \\
\text { in } \mathrm{mm}^{2}\end{array}$ & $\begin{array}{l}\text { Standard- } \\
\text { abweichung }\end{array}$ & \multicolumn{6}{|c|}{$\begin{array}{c}\text { Graphische Darstellung } \\
\text { Skala in } \mathrm{mm}^{2}\end{array}$} \\
\hline \multicolumn{9}{|c|}{ Kallusfläche Fluoresceinkomplexon ventral } \\
\hline Kontrolle & 0,0470 & $\pm 0,0101$ & $\square$ & & & & & \\
\hline PTH (1.d) & 0,0739 & $\pm 0,0146$ & $\square$ & & & & & \\
\hline \multirow[t]{2}{*}{ PTH (7.d) } & 0,1180 & $\pm 0,0319$ & $\square^{*}$ & & & & & \\
\hline & & & $0 \quad 0,2$ & 0,4 & 0,8 & 1,0 & 1,2 & 1,4 \\
\hline \multicolumn{9}{|c|}{ Kallusfläche Fluoresceinkomplexon dorsal } \\
\hline Kontrolle & 0,2254 & $\pm 0,0273$ & $\square$ & & & & & \\
\hline PTH (1.d) & 0,2847 & $\pm 0,0490$ & $\square$ & & & & & \\
\hline \multirow[t]{2}{*}{ PTH (7.d) } & 0,4343 & $\pm 0,0844$ & $\square$ & $\square *$ & & & & \\
\hline & & & $0 \quad 0,2$ & 0,4 & 0,8 & 1,0 & 1,2 & 1,4 \\
\hline \multicolumn{9}{|c|}{ Kallusfläche Fluoresceinkomplexon endostal } \\
\hline Kontrolle & 0,5546 & $\pm 0,0813$ & $\square$ & $\square$ & & & & \\
\hline PTH (1.d) & 0,4938 & $\pm 0,0572$ & $\square$ & $\square$ & & & & \\
\hline \multirow[t]{2}{*}{ PTH (7.d) } & 1,2150 & $\pm 0,1836$ & & & & & $\square$ & \\
\hline & & & $0 \quad 0,2$ & $0,4 \quad 0,6$ & 0,8 & 1,0 & 1,2 & 1,4 \\
\hline
\end{tabular}

Tabelle 5.15: Werte und Balkendiagramm zu Kallusfläche Fluoresceinkomplexon (Grün) ventral, dorsal und endostal.

Kallusfläche Alizarinkomplexon (Rot) ventral Die größte Fläche ergab sich für PTH (7.d) $\left(0,2314 \pm 0,0627 \mathrm{~mm}^{2}\right)$ gefolgt von PTH (1.d) $\left(0,1300 \pm 0,0197 \mathrm{~mm}^{2}\right)$. Die Fläche für die Kontrolle betrug 0,0924 $\pm 0,0177 \mathrm{~mm}^{2}$ ) (siehe Tabelle 5.16). Der Unterschied zwischen PTH (7.d) und der Kontrolle war signifikant.

Kallusfläche Alizarinkomplexon (Rot) dorsal PTH (7.d) hatte eine Fläche von $0,5051 \pm 0,0956 \mathrm{~mm}^{2}$. Sie war signifikant größer als die der Kontrolle $\left(0,2488 \pm 0,0317 \mathrm{~mm}^{2}\right)$. 
Die Fläche von PTH (1.d) betrug 0,3581 $\pm 0,0384 \mathrm{~mm}^{2}$ ) und zeigte keine signifikanten Unterschiede zu den beiden anderen Gruppen (siehe Tabelle 5.16).

Kallusfläche Alizarinkomplexon (Rot) endostal Den größten Wert zeigte PTH (7.d) $\left(1,0740 \pm 0,1271 \mathrm{~mm}^{2}\right)$. Im Vergleich zur Kontrolle $\left(0,5612 \pm 0,0745 \mathrm{~mm}^{2}\right)$ war dieser Wert signifikant höher. PTH (1.d) zeigte mit 0,7967 $\pm 0,0834 \mathrm{~mm}^{2}$ keine signifikanten Differenzen zu den beiden anderen Gruppen (siehe Tabelle 5.16).

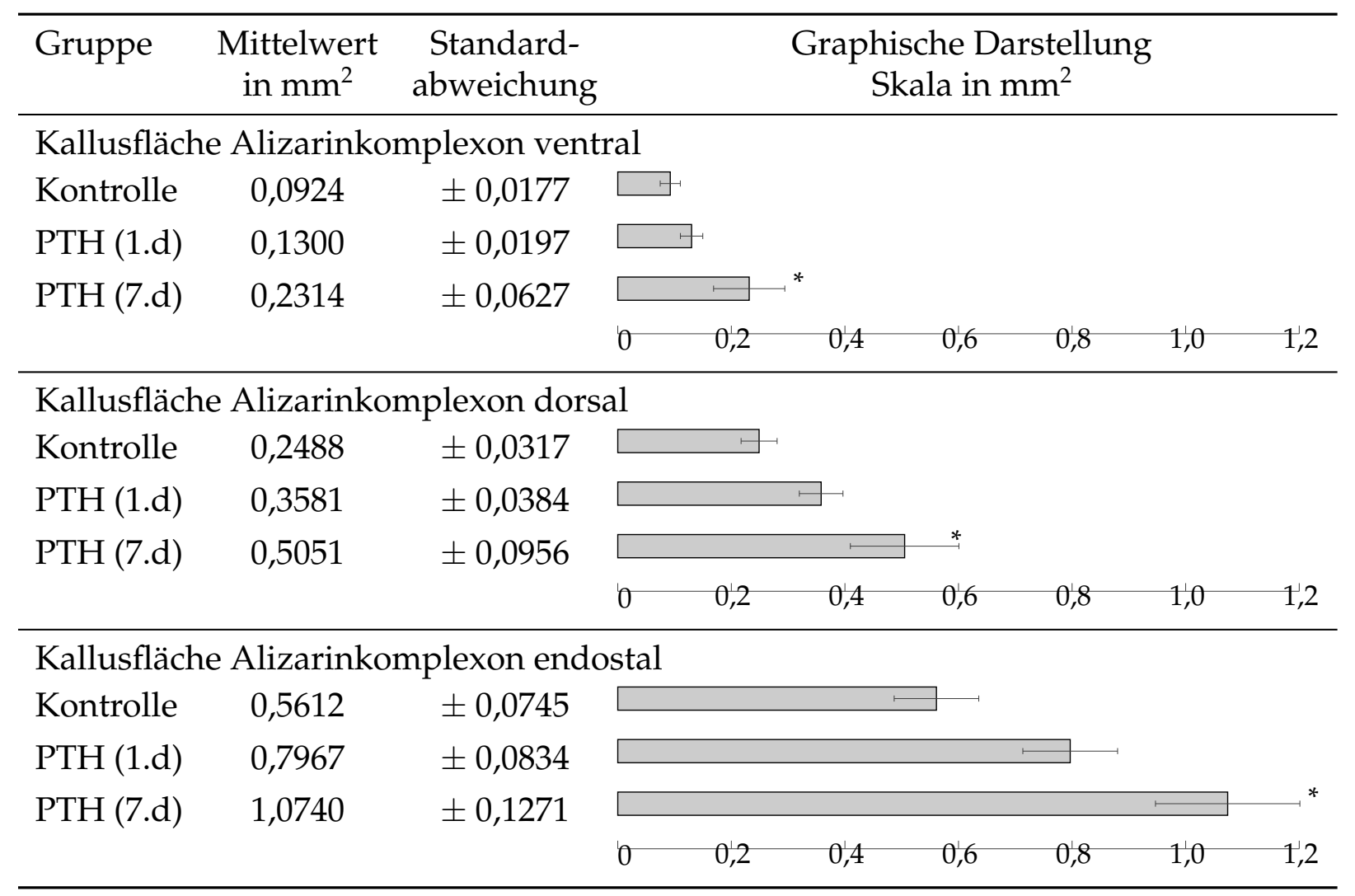

Tabelle 5.16: Werte und Balkendiagramm zu Kallusfläche Alizarinkomplexon (Rot) ventral, dorsal und endostal.

Kallusfläche Tetracyclin-Hydrochlorid (Gelb) ventral Signifikant größer war die Fläche von PTH (7.d) $\left(0,8625 \pm 0,1863 \mathrm{~mm}^{2}\right)$ gegenüber denen der Kontrolle $\left(0,3852 \pm 0,0567 \mathrm{~mm}^{2}\right)$ und PTH (1.d) $\left(0,4500 \pm 0,0490 \mathrm{~mm}^{2}\right)$ (siehe Tabelle 5.17).

Kallusfläche Tetracyclin-Hydrochlorid (Gelb) dorsal Die größte Fläche zeigte PTH (7.d) mit $1,8120 \pm 0,2725 \mathrm{~mm}^{2}$. Sie war signifikant größer als die Fläche der beiden anderen 
Gruppen. Die Fläche der Kontrolle betrug 1,2080 $\pm 0,1114 \mathrm{~mm}^{2}$, die von PTH (1.d) $1,0540 \pm 0,1080 \mathrm{~mm}^{2}$ (siehe Tabelle 5.17).

Kallusfläche Tetracyclin-Hydrochlorid (Gelb) endostal PTH (7.d) $\left(2,223 \pm 0,3102 \mathrm{~mm}^{2}\right)$ zeigte eine signifikant größere Kallusfläche als die Kontrolle $\left(1,4800 \pm 0,1503 \mathrm{~mm}^{2}\right)$. Die Fläche für PTH (1.d) betrug 1,6750 $\pm 0,1473 \mathrm{~mm}^{2}$ (siehe Tabelle 5.17).

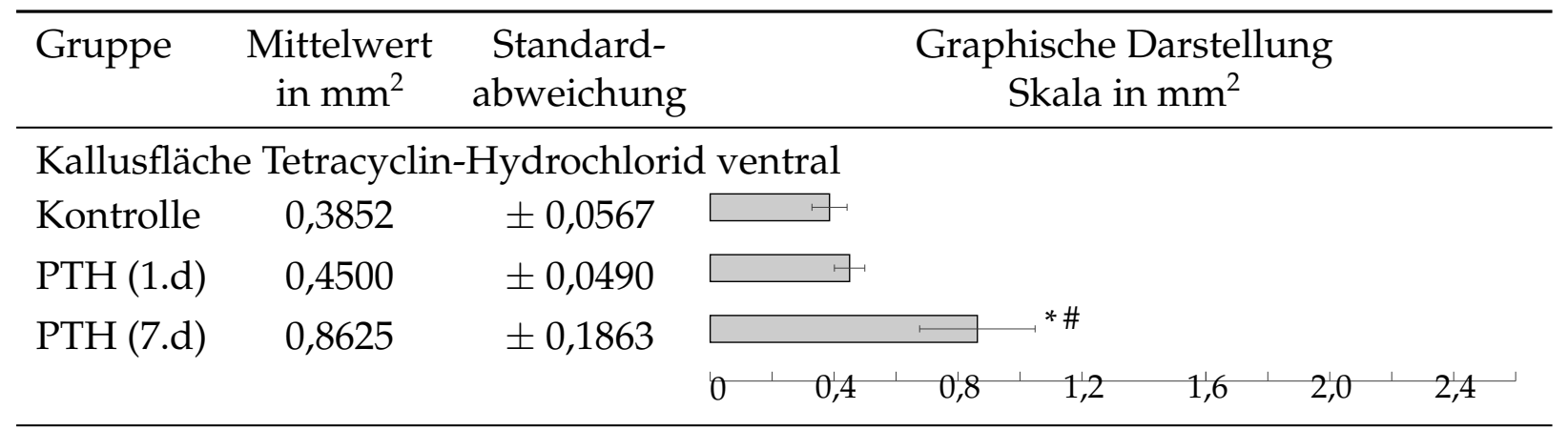

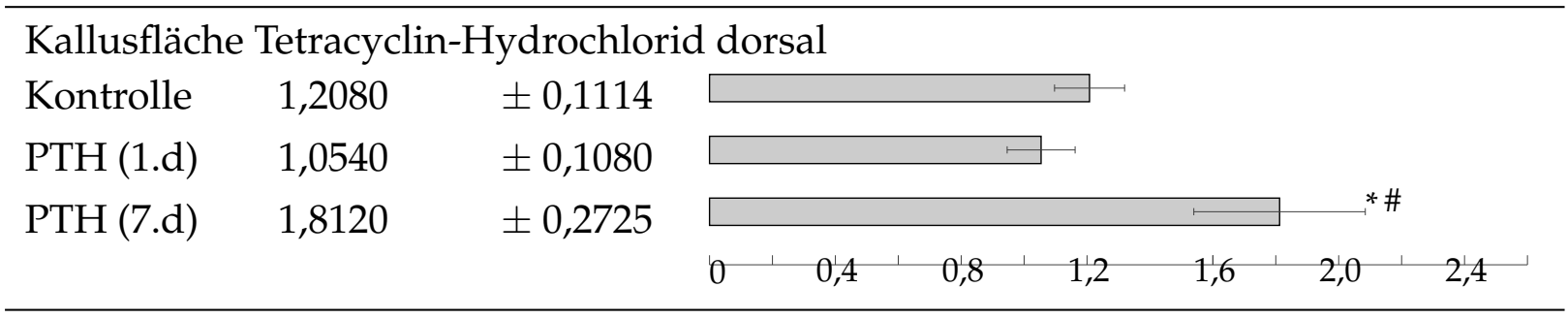

Kallusfläche Tetracyclin-Hydrochlorid endostal

$\begin{array}{lll}\text { Kontrolle } & 1,4800 & \pm 0,1503 \\ \text { PTH (1.d) } & 1,6750 & \pm 0,1473 \\ \text { PTH (7.d) } & 2,2230 & \pm 0,3102\end{array}$

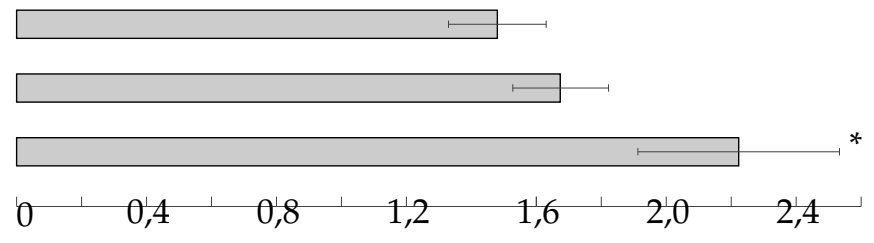

Tabelle 5.17: Werte und Balkendiagramm zu Kallusfläche Tetracyclin-Hydrochlorid (Gelb) ventral, dorsal und endostal. 


\subsection{Gesamtübersicht über die Versuchsergebnisse}

Im Folgenden sind für die Mikroradiographie, die polychrome Sequenzmarkierung und den biomechanischen Biegeversuch sämtliche Werte mit entsprechenden Signifikanzen tabellarisch dargestellt. Es handelt sich dabei um Mittelwerte und die jeweiligen Standardabweichungen. Verglichen wurden die Werte der Gruppe, welche PTH ab dem 1. Tag erhielt, mit denen der Kontrolle (PTH ab 1.d vs. Kontrolle), die Werte der Tiere, welche PTH ab dem 7. Tag erhielten, mit denen der Kontrolle (PTH ab 7.d vs. Kontrolle) und die Werte der beiden PTH-Gruppen (PTH ab 7.d vs. PTH ab 1.d) untereinander. Signifikante Unterschiede sind mit einem Doppelpfeil ( $\Uparrow$, wenn signifkant größer oder $\Downarrow$, wenn signifikant kleiner) dargestellt. Tendenzen sind mit einem einfachen Pfeil ( $\uparrow$ oder $\downarrow$ ) dargestellt. Ein horizontaler Pfeil $(\leftrightarrow)$ wurde gewählt, wenn sich zwischen den Gruppen keine Unterschiede ergaben.

\subsubsection{Biomechanischer Biegeversuch}

\begin{tabular}{lccc}
\hline Parameter & $\begin{array}{c}\text { PTH ab 1.d } \\
\text { vs. Kontrolle }\end{array}$ & $\begin{array}{c}\text { PTH ab 7.d } \\
\text { vs. Kontrolle }\end{array}$ & $\begin{array}{c}\text { PTH ab 7.d } \\
\text { vs. PTH ab 1.d }\end{array}$ \\
\hline Yield load & $\Uparrow$ & $\Uparrow$ & $\uparrow$ \\
\hline Steigung & $\uparrow$ & $\uparrow$ & $\uparrow$ \\
\hline
\end{tabular}

Tabelle 5.18: Die Tabelle zeigt eine Gesamtübersicht des biomechanischen Biegeversuchs. Verglichen wurden die Werte der Gruppe, welche PTH ab dem 1. Tag erhielt, mit denen der Kontrolle (PTH ab 1.d vs. Kontrolle), die Werte der Tiere, welche PTH ab dem 7. Tag erhielten, mit denen der Kontrolle (PTH ab 7.d vs. Kontrolle) und die Werte der beiden PTH-Gruppen (PTH ab 7.d vs. PTH ab 1.d) untereinander. Einfacher Pfeil zeigt Tendenz, Doppelpfeil Signifikanz im Vergleich. 


\subsubsection{Mikroradiographie}

\begin{tabular}{|c|c|c|c|}
\hline Parameter & $\begin{array}{c}\text { PTH ab 1.d } \\
\text { vs. Kontrolle }\end{array}$ & $\begin{array}{c}\text { PTH ab 7. d } \\
\text { vs. Kontrolle }\end{array}$ & $\begin{array}{c}\text { PTH ab 7.d } \\
\text { vs. PTH ab 1.d }\end{array}$ \\
\hline Kortikalisdicke distal ventral & $\leftrightarrow$ & $\leftrightarrow$ & $\leftrightarrow$ \\
\hline Kortikalisdicke distal dorsal & $\Downarrow$ & $\Downarrow$ & $\leftrightarrow$ \\
\hline \multicolumn{4}{|l|}{ Knochenflächendichte } \\
\hline Trabekel distal & $\Uparrow$ & $\Uparrow$ & $\leftrightarrow$ \\
\hline \multicolumn{4}{|l|}{ Knochenflächendichte } \\
\hline Kortikalis distal ventral & $\leftrightarrow$ & $\leftrightarrow$ & $\leftrightarrow$ \\
\hline Knochenflächendichte & & & \\
\hline Kortikalis distal dorsal & $\leftrightarrow$ & $\leftrightarrow$ & $\leftrightarrow$ \\
\hline \multicolumn{4}{|l|}{ Knochenflächendichte } \\
\hline Kallus ventral & $\Uparrow$ & $\leftrightarrow$ & $\downarrow$ \\
\hline Knochenflächendichte & & & \\
\hline Kallus dorsal & $\leftrightarrow$ & $\leftrightarrow$ & $\leftrightarrow$ \\
\hline \multicolumn{4}{|l|}{ Knochenflächendichte } \\
\hline Kallus endostal & $\uparrow$ & $\Uparrow$ & $\uparrow$ \\
\hline Kallusdicke ventral & $\leftrightarrow$ & $\uparrow$ & $\uparrow$ \\
\hline Kallusdicke dorsal & $\leftrightarrow$ & $\leftrightarrow$ & $\leftrightarrow$ \\
\hline Anzahl Trabekelkreuzungen & $\uparrow$ & $\leftrightarrow$ & $\downarrow$ \\
\hline Dichte Trabekelkreuzungen & $\Uparrow$ & $\uparrow$ & $\downarrow$ \\
\hline Mittlere Trabekeldicke & $\Uparrow$ & $\Uparrow$ & $\downarrow$ \\
\hline
\end{tabular}

Tabelle 5.19: Die Tabelle zeigt die Gesamtübersicht über die Ergebnisse der mikroradiographischen Analysen. Verglichen wurden die Werte der Gruppe, welche PTH ab dem 1. Tag erhielt, mit denen der Kontrolle (PTH ab 1.d vs. Kontrolle), die Werte der Tiere, welche PTH ab dem 7. Tag erhielten, mit denen der Kontrolle (PTH ab 7.d vs. Kontrolle) und die Werte der beiden PTH-Gruppen (PTH ab 7.d vs. PTH ab 1.d) untereinander. Einfacher Pfeil zeigt Tendenz, Doppelpfeil Signifikanz, horizontaler Pfeil keine Unterschiede im Vergleich. 


\subsubsection{Fluoreszenz}

\begin{tabular}{lccc}
\hline Parameter & $\begin{array}{c}\text { PTH ab 1.d } \\
\text { vs. Kontrolle }\end{array}$ & $\begin{array}{c}\text { PTH ab 7.d } \\
\text { vs. Kontrolle }\end{array}$ & $\begin{array}{c}\text { PTH ab 7.d } \\
\text { vs. PTH ab 1.d }\end{array}$ \\
\hline Gesamtkallusfläche ventral & $\leftrightarrow$ & $\Uparrow$ & $\Uparrow$ \\
Gesamtkallusfläche dorsal & $\downarrow$ & $\uparrow$ & $\Uparrow$ \\
Gesamtkallusfläche endostal & $\downarrow$ & $\uparrow$ & $\uparrow$ \\
\hline Kallusfläche Grün ventral & $\uparrow$ & $\Uparrow$ & $\uparrow$ \\
Kallusfläche Grün dorsal & $\uparrow$ & $\Uparrow$ & $\uparrow$ \\
Kallusfläche Grün endostal & $\downarrow$ & $\Uparrow$ & $\Uparrow$ \\
\hline Kallusfläche Rot ventral & $\uparrow$ & $\Uparrow$ & $\uparrow$ \\
Kallusfläche Rot dorsal & $\uparrow$ & $\Uparrow$ & $\uparrow$ \\
Kallusfläche Rot endostal & $\uparrow$ & $\Uparrow$ & $\uparrow$ \\
\hline Kallusfläche Gelb ventral & $\uparrow$ & $\Uparrow$ & $\Uparrow$ \\
Kallusfläche Gelb dorsal & $\downarrow$ & $\Uparrow$ & $\uparrow$ \\
Kallusfläche Gelb endostal & $\uparrow$ & $\Uparrow$ & $\uparrow$ \\
\hline
\end{tabular}

Tabelle 5.20: Die Tabelle zeigt eine Gesamtübersicht der Ergebnisse aus den fluoreszenzmikroskopischen Untersuchungen. Verglichen wurden die Werte der Gruppe, welche PTH ab dem 1. Tag erhielt, mit denen der Kontrolle (PTH ab 1.d vs. Kontrolle), die Werte der Tiere, welche PTH ab dem 7. Tag erhielten, mit denen der Kontrolle (PTH ab 7.d vs. Kontrolle) und die Werte der beiden PTH-Gruppen (PTH ab 7.d vs. PTH ab 1.d) untereinander. Einfacher Pfeil zeigt Tendenz, Doppelpfeil Signifikanz, horizontaler Pfeil keine Unterschiede im Vergleich. 


\section{Kapitel 6}

\section{Diskussion}

\subsection{Frakturheilung und Heilungsverzögerung}

Der Frakturheilungsprozess ist ein komplexer Mechanismus, der die Wiederherstellung der biomechanischen Eigenschaften und somit der Funktion des Knochens zum Ziel hat (Komatsu und Warden, 2010). Der normale Heilungsprozess verläuft über mehrere Wochen und beinhaltet fünf Phasen, welche sich teilweise überschneiden (Mutschler und Haas, 2004).

In etwa $10 \%$ aller Frakturen kommt es zu Problemen bei der Konsolidierung mit einem protrahierten Verlauf. Beim Vorliegen von Risikofaktoren wie Vorerkrankungen (z.B. Diabetes mellitus), Einnahme von Medikamenten (z.B. Glukokortikoide), Noxeneinfluss (z.B. Nikotin) oder ungünstige Eigenschaften der Verletzung (z.B. schwerer Weichteilschaden, offene Frakturen) sowie hohes Patientenalter sind es sogar 30 \% der Fälle (Zimmermann et al., 2006) (Siehe auch Tabelle3.1 auf Seite 19). Dies resultiert in einer schwerwiegenden Belastung für den betroffenen Patienten (Starr, 2008), birgt aber in der Summe auch enorme sozioökonomische Belastungen (Andersson et al., 2011) für die Gesellschaft, da sich hieraus weitere diagnostische und therapeutische Maßnahmen mit häufig längerer Krankenhausverweildauer und protrahierter oder keiner Rückkehr in das Erwerbsleben ergeben. Etwa $4 \%$ der Gesamtbevölkerung der Vereinigten Staaten von Amerika leidet unter einer Beeinträchtigung in Folge einer Fraktur - in der Bevölkerungsgruppe der über 65-Jährigen sind es mehr als $10 \%$ (Andersson et al., 2011).

Eine mangelnde Durchblutung der Frakturregion, unzureichender Kontakt der Knochenfragmente sowie Instabilität der Fraktur verzögern oder verhindern den Knochenheilungsprozess und können zu einer Pseudarthrose führen. Für die Gefäßversorgung entscheidend ist die Schwere der Verletzung, aber auch die Technik der Osteosynthese im 
Falle einer operativen Frakturversorgung. Von besonderer Bedeutung ist ebenfalls die Reposition der Fraktur, bei der auf eine Wiederherstellung der Knochenkontinuität zu achten ist. Eine mangelnde Retention der Fraktur führt zu unerwünschten Bewegungen und Störungen des Heilungsprozesses (Stürmer, 1996).

Weltweit steigt der Anteil der alten und hochalten Menschen in der Gesamtbevölkerung stetig an. Bevölkerungsschätzungen zufolge wird im Jahr 2050 die Hälfte der Bevölkerung älter als 48 Jahre sein und ein Drittel 60 Jahre und älter (Raschke und Stange, 2009). Mit zunehmendem Alter nimmt die Gesamtmorbidität zu. Gleichzeitig steigt auch das Risiko, eine Fraktur zu erleiden, nicht zuletzt auch aufgrund der Osteoporoseprävalenz innerhalb dieser Bevölkerungsgruppe. Die altersabhängige Inzidenz, eine hüftgelenknahe Fraktur zu erleiden, liegt für die 60- bis 64-Jährigen bei 0,06 \% und nimmt mit zunehmendem Alter exponentiell zu (Frerichmann et al., 2007). Aber auch das Risiko für Störungen der Knochenheilung nimmt mit zunehmendem Alter zu (Zimmermann et al., 2006; Heppert et al., 2005; Runkel und Rommens, 2000).

In der Literatur finden sich wenig aktuelle Daten zu den durch verzögerte Frakturheilung und Pseudarthrosen in Deutschland entstandenen Mehrkosten. Neben dem verbesserten „outcome”für jeden einzelnen Patienten und der Vermeidung von zusätzlichem Leiden würde sich jedoch durch die Optimierung der Frakturheilung auch eine bedeutende Kostenreduktion der durch verzögerte Frakturheilung entstehenden finanziellen Belastung für das Gesundheitssystem ergeben.

\subsection{Stimulationsmöglichkeiten der Frakturheilung}

Es stehen chirurgische, medikamentöse und mechanische Therapieoptionen zur Verfügung. Im Gegensatz zu den chirurgischen Therapieoptionen, welche dann angewendet werden, wenn es bereits zu einer verzögerten Frakturheilung oder einer manifesten Pseudarthrose gekommen ist, können medikamentöse und mechanische Stimulatoren schon präventiv, z.B. beim Vorliegen von Risikofaktoren (siehe 6.1 auf Seite 68) angewendet werden. Pseudarthrosen können auf dem Boden mechanischer oder biologischer Ursachen entstehen. Häufig kommen verschiedene Faktoren gleichzeitig zum Tragen. Entsprechend der zugrundeliegenden Ursache erscheint die Pseudarthrose in der bildgebenden Diagnostik hypertroph, atroph oder als Defekt. Ein Sonderfall stellt die Infektpseudarthrose dar, die auf der Grundlage einer Infektion entsteht. Je nach Pseudarthrosentyp stehen verschiedene chirurgische Therapieoptionen zur Verfügung (Raschke und Gasch, 2011). Zunächst soll hier auf die medikamentösen Optionen eingegangen werden: 


\subsection{Medikamentöse Stimulation der Frakturheilung}

\subsubsection{Parathormon (PTH)}

Die osteoanabole Wirkung von Parathormon ist vielfach analysiert worden. Zur Therapie der Osteoporose ist es im Jahr 2002 von der Food and Drug Administration (FDA) zugelassen worden. Es ist das einzige zur Therapie und Prävention der Osteoporose eingesetzte Präparat mit knochenaufbauender Wirkung. Sämtliche andere im Rahmen der Osteoporosetherapie verwendeten Präparate wirken, indem sie die Knochenresorption bremsen oder verhindern. Zur Therapie verzögerter Frakturheilung beim Menschen ist PTH nicht zugelassen.

Ziel der vorliegenden Arbeit war es zu zeigen, ob die Behandlung mit PTH die metaphysäre Frakturheilung bei gesunden Ratten verbessert.

\subsubsection{Analyse der Ergebnisse}

\section{Biomechanischer Biegeversuch}

Die biomechanischen Untersuchungen (vergleiche Abschnitt 4.2 auf Seite 38) zeigten eine signifikant höhere mechanische Belastbarkeit der Knochen beider mit PTH behandelten Gruppen. Dieses Ergebnis spiegelt die größere Kallusfläche wider, die sich in Folge der Behandlung mit PTH ergab. Dabei zeigte die Gruppe, welche PTH erst ab dem 7. Tag erhielt, entsprechend der größeren Kallusfläche tendenziell eine höhere mechanische Belastbarkeit als die Gruppe, welche PTH ab dem 1. Tag erhielt.

Die höhere biomechanische Belastbarkeit der mittels PTH behandelten Frakturen bedeutet eine frühere Belastbarkeit der entsprechenden Extremität und in Folge eine Reduktion der durch lange Bettlägerigkeit und Immobilisation hervorgerufenen Komplikationen wie z.B. Thrombose, oder Embolie (Mutschler und Haas, 2004).

Bei allen Tieren kam es unter dem Einfluss von PTH zu einer signifikanten Zunahme der Trabekeldicke und einer Zunahme der Trabekelkreuzungsdichte. Die trabekuläre Struktur ist bekanntermaßen für die biomechanische Belastbarkeit des Knochens maßgeblich (Pauwels, 1954). Auch in vorausgegangenen Untersuchungen am Rattenmodell ist die Korrelation zwischen zunehmender trabekulärer Knochenmasse und Trabekeldicke und einer erhöhten biomechanischen Belastbarkeit belegt worden (Morley et al., 1997).

Die signifikant höhere biomechanische Widerstandsfähigkeit der Knochen nach PTH-Gabe ist demzufolge auf die größere Kallusfläche, aber auch auf die gesteigerte Trabekeldicke und Dichte der Trabekelkreuzungen zurück zu führen. 


\section{Mikroradiographie}

Die Beschleunigung des Remodelings führt zu einer erhöhten Knochendichte (Hodsman et al., 2005). In der vorliegenden Arbeit spiegelte sich dies insbesondere im Rahmen der mikroradiographischen Untersuchungen in Form einer signifikant gesteigerten distalen Trabekelflächendichte bei den mit PTH behandelten Tieren wider. Außerdem war bei beiden PTH-Gruppen die Trabekeldicke signifikant größer als bei der Kontrollgruppe. Hinsichtlich der kortikalen Knochenflächendichte ergab sich kein Unterschied zwischen den Gruppen. Die Kortikalisdicke war bei der Kontrollgruppe jedoch signifikant höher, als bei den Tieren beider PTH-Gruppen.

Mehrere klinische Studien am Menschen zeigten, dass die anabole Wirkung von PTH vor allem in trabekulären Knochenanteilen zum Tragen kommt, wohingegen die kortikalen Anteile unwesentliche Strukturveränderungen unter dem Einfluss von PTH aufwiesen (Neer et al., 2001; Rosen und Bilezikian, 2001; Hodsman et al., 1997; Cosman und Lindsay, 1998; Finkelstein et al., 1998). In vorausgegangenen Studien am Rattenmodell zeigte sich unter dem Einfluss von PTH allerdings eine Zunahme der trabekulären und der kortikalen Knochenmasse (Cosman und Lindsay, 1998; Dempster et al., 1994; Rosen und Bilezikian, 2001; Thomsen et al., 1999).

In Abhängigkeit der Dosierung, der Frequenz der Verabreichung und der Länge der Behandlung kann die anabole oder katabole Wirkung von PTH auf den Knochen überwiegen. In der Regel kommt es unter dem Einfluss von PTH am gesunden Knochen zu einer koordinierten Steigerung der Knochenneubildung und des Abbaus, weshalb es keine nennenswerte Veränderung der Knochenmasse gibt. Allerdings kann es durch das gesteigerte Remodeling zu einer Umgestaltung der Knochenarchitektur kommen (Hock, 2001). Interessanterweise zeigt sich in den vorliegenden Ergebnissen eine signifikante Zunahme der mittleren Trabekeldicke bei den beiden mit PTH behandelten Gruppen. Gleichzeitig zeigt sich bei diesen beiden Gruppen eine signifikant dünnere dorsale Kortikalis im Vergleich zur Kontrollgruppe. Möglicherweise hat PTH in diesem Fall zu einer Umverteilung an Knochensubstanz zu Gunsten der Trabekel geführt. Die Wirkung von PTH auf das normale Remodeling des gesunden Knochens ist deutlich geringer als auf sich neu bildenden Knochen, wie es z.B. im Rahmen der Frakturheilung der Fall ist (Skripitz et al., 2000). Das Kallusremodeling beginnt etwa ab dem 14. Tag. Um die hier stattfindenden Prozesse gänzlich zu erfassen, sind Langzeitstudien über mindestens zwölf Wochen notwendig (Takahata et al., 2011). 


\section{Polychrome Fluoreszenzmarkierung}

Die mit PTH behandelten Tiere zeigten in der fluoreszenzmikroskopischen Untersuchung eine größere Kallusfläche (vergleiche Abschnitt 4.4 auf Seite 46) als die Tiere der Kontrollgruppe, welche mit Placebo behandelt wurden. Dabei waren die Unterschiede bei den Tieren, die PTH erst ab dem siebten Tag erhielten, signifikant größer. Beim Menschen, wie bei der Ratte, läuft die indirekte Frakturheilung in Phasen ab. Während der Granulationsphase, die beim Menschen etwa in der vierten bis sechsten Woche nach Fraktur abläuft, füllt sich der Frakturspalt sukzessiv mit Knorpelzellen auf. Dieser Prozess wird maßgeblich von einer Reihe Wachstumsfaktoren beeinflusst (Mutschler und Haas, 2004). Die Wirkung von PTH auf die Chondrogenese ist vielfach belegt (Alkhiary et al., 2005; Nakazawa et al., 2005; Okazaki et al., 2003), ebenso wie die Wirksamkeit von PTH auf die frühe Frakturheilungsphase (Kakar et al., 2007).

Bei der Ratte läuft die Phase der Chondrogenese schon etwa ab dem 5. Tag bis zum 14./15. Tag nach Fraktur ab (Voggenreiter, 2009), weshalb die Gabe von PTH bei der Ratte möglicherweise zu diesem Zeitpunkt zu einer Stimulation der Kallusformation führt. Die nur sehr schmal ausgeprägte orange Bande von Xylenolorange-Tetranatriumsalz $(\mathrm{XO})$ ist möglicherweise auch auf den zeitlichen Ablauf der Frakturheilung bei der Ratte zurück zu führen. Der Farbstoff wurde am 13. Tag nach Osteotomie gespritzt und markiert somit den Zeitraum von der Osteotomie bis zum 13. Tag. Der Farbstoff wird vor allem in den mineralisierenden Knochen eingelagert. Diese Phase setzt schwerpunktmäßig jedoch erst später ein, weshalb Xylenolorange-Tetranatriumsalz möglicherweise nur minimal im sich bildenden weichen Kallus eingelagert wurde.

Fluoresceinkomplexon, welches eine grüne Färbung bewirkt, wurde zwischen Tag 13 und 18 nach Osteotomie in den Knochen eingelagert und fällt somit fast gänzlich in die Phase der Chondrogenese und enchondralen Ossifikation bei der Ratte.

Nakazawa et al. sahen im Frakturkallus von mit PTH behandelten Ratten eine vermehrte Expression von mesenchymalen Chondroprogenitor-Zellen und eine erhöhte Synthese von Typ-II-Kollagen. Sie wiesen in den ersten 14 Tagen nach Femurosteotomie eine signifikant größere Kallusfläche nach als bei der Kontrollgruppe, welche kein PTH erhalten hatte. Dieses Phänomen war ab Tag 21 nicht mehr nachweisbar, was ebenfalls eine Stimulation von PTH der frühen Heilungsphase belegt (Nakazawa et al., 2005).

Wenige Studien haben die Spätphase der Frakturheilung bei der Ratte untersucht. Diese beinhaltet das Remodeling, also den Umbau des Kallus von Geflechtknochen zu Lamellenknochen. Die Phase der enchondralen Ossifikation, welche beim Menschen ca. drei bis vier Monate dauert, läuft bei der Ratte zwischen dem 8. und 21. Tag ab (Voggenreiter, 
2009). Okazaki et al. zeigten, dass PTH auch während dieser Phase eine tragende Rolle hat, indem es mesenchymale Stammzellen, Chondrozyten und Osteoblasten stimuliert (Okazaki et al., 2003).

Bei den drei Tiergruppen der vorliegenden Arbeit war der dorsale Kallus in sämtlichen Färbungen prominenter als der ventrale, plattennahe Kallus. Da es sich bei der dorsalen Fläche um das plattenferne Areal handelt, ist davon auszugehen, dass hier mehr Mikrobewegungen stattfinden konnten als in unmittelbarer Nähe des Implantats, wodurch es möglicherweise $\mathrm{zu}$ einer mechanischen Induktion der Kallusbildung kam. Vielfache Studien am Tiermodell belegen, dass mechanische Stimulation die Osteogenese und die Frakturheilung positiv beeinflussen können (Goodship et al., 2009; Sehmisch et al., 2009; Leung et al., 2009; Stuermer et al., 2010).

Im Bezug auf die Knochenflächendichte des Kallus zeigten die vorliegenden Ergebnisse den markantesten Effekt auf den endostalen Kallusanteil. In vorausgegangenen Arbeiten hatte sich bereits eine gesteigerte, vor allem endostal betonte Zunahme der Kortikalisdicke unter dem Einfluss von PTH gezeigt (Dempster et al., 2001).

Manabe et al. zeigten, dass die PTH-Gabe vor Frakturentstehung keinen positiven Einfluss auf die Frakturheilung hat, wohingegen die PTH-Therapie nach Frakturentstehung den Heilungsprozess fördert (Manabe et al., 2007). In der vorliegenden Arbeit war die Gesamtkallusfläche ventral und endostal bei den Tieren, welche PTH unmittelbar, also am ersten Tag nach Frakturentstehung, erhalten hatten, im Gegensatz zu den Tieren, welche PTH erst ab dem siebten Tag bekamen, signifikant kleiner. Während der ersten drei bis fünf Tage nach Fraktur läuft bei der Ratte die Entzündungsphase ab. Die Geflechtknochenbildung und Chondrogenese setzen erst ab dem 4. -7. Tag ein. Im weiteren Verlauf setzt etwa eine Woche nach Verletzung der Prozess der enchondralen Ossifikation und nach etwa zwei Wochen das Remodeling ein (Hadjiargyrou et al., 2002). Wie bereits erwähnt, ist die Wirkung von PTH auf Chondrogenese und Remodeling belegt, und diese Ergebnisse stehen mit diesen Erkenntnissen in Einklang (Alkhiary et al., 2005; Nakazawa et al., 2005; Okazaki et al., 2003; Voggenreiter, 2009).

Die Kallusdicke zeigte keine signifikanten Unterschiede. Die Kallusflächendichte der ab dem ersten Tag nach Osteotomie therapierten Tiere war ventral signifikant höher. Bei den Tieren, welche PTH ab dem siebten Tag erhalten hatten, war die Kallusflächendichte endostal gegenüber der Kontrollgruppe signifikant höher. Alkhiary et al. untersuchten den Effekt von PTH auf die Heilung von Femurosteotomien bei männlichen Ratten. Die Knochenflächendichte nahm bei den mit PTH behandelten Tieren gegenüber der unbehandelten Kontrollgruppe signifikant zu (Alkhiary et al., 2005). Auch beim Menschen führt PTH 
zu einer Steigerung der Knochendichte (Neer et al., 2001).

Es liegen wenig Daten aus klinischen Studien vor, welche den Einfluss von PTH auf die Frakturheilung belegen. Aspenberg et al. führten die bislang einzige randomisierte, placebokontrollierte Doppelblindstudie durch. 102 postmenopausale Patientinnen mit konservativ behandelter Radiusfraktur wurden in die Studie eingeschlossen. Die Patientinnen wurden in drei Gruppen à 34 randomisiert und erhielten einmal täglich subkutane Injektionen Placebo, $20 \mu \mathrm{g} / \mathrm{kg}$ oder $40 \mu \mathrm{g} / \mathrm{kg}$ Teriparatid über einen Zeitraum von acht Wochen. Die Medikamentenapplikation wurde innerhalb von 10 Tagen nach Fraktur begonnen. Röntgenkontrollen wurden alle zwei Wochen durchgeführt. Eine Fraktur wurde als verheilt gewertet, wenn röntgenologisch drei von vier Kortikalis in zwei Ebenen durchbaut waren. Es zeigte sich kein signifikanter Unterschied unter den Gruppen. Die Gruppe mit $20 \mu \mathrm{g} / \mathrm{kg}$ Teriparatid zeigte jedoch eine kürzere Frakturüberbrückungszeit als die Placebogruppe.

In der Literatur finden sich eine Reihe an Fallbeispielen, sogenannten "case reports", die eine Frakturheilungsförderung durch PTH suggerieren: Bei fünf älteren Patientinnen mit Frakturen der Rami ossis pubii des Beckens kam es nach Behandlung mit PTH bereits nach acht Wochen, anstatt der üblicherweise zu erwartenden 12 bis 16 Wochen, zu Schmerzfreiheit und Frakturkonsolidierung (Peichl et al., 2011). Bei einer 79-jährigen Patientin kam es unter der laufenden antiosteoporotischen Therapie mit PTH bereits nach 25 Tagen zur Konsolidierung einer proximalen Humerusfraktur (Resmini und Iolascon, 2007).

Der in tierexperimentellen Studien nachgewiesene positive Effekt auf die Knorpelregeneration (Sampson et al., 2011; Sampson, 2009a,b; Kudo et al., 2011) wurde bisher noch nicht im Rahmen von klinischen Studien untersucht. Auf diesem Gebiet sind in den kommenden Jahren interessante neue Erkenntnisse zu erwarten.

\subsubsection{Kosteneffektivität}

Die Tagestherapiekosten für Teriparatid bei einer Tagesdosierung von $20 \mu \mathrm{g} / \mathrm{kg}$ belaufen sich auf 20,28€. Bisher ist der Einsatz dieses Medikaments auf die Therapie der Osteoporose über einen Zeitraum von maximal 18 Monaten beschränkt, was mit Kosten in Höhe von 11.072,00€ einhergeht. Zur Optimierung der Frakturheilung, welche über einen Zeitraum von 6 Wochen bis zu 3 Monaten abläuft (vergleiche hierzu 6.1 auf Seite 68), ist von deutlich niedrigeren Kosten auszugehen. Für eine Behandlung über 6 Wochen würden sich die Gesamttherapiekosten auf $851,76 €$ belaufen (Bundesanstalt für Arbeitsschutz und Arbeitsmedizin, 2011). 
Im Jahr 2004 verursachten Unfälle insgesamt 56,97 Millionen Arbeitsunfähigkeitstage, was einem Anteil von 12,94\% aller Arbeitsausfalltage entspricht. Der dadurch verursachte Produktionsausfall wird mit 5,2 Mrd. $€$ der Ausfall an Bruttowertschöpfung mit 9,1 Mrd. $€$ angegeben. Diese Zahlen beinhalten keine Kosten durch Rehabilitationsmaßnahmen oder etwaige Rentenansprüche (Deutsche Gesellschaft für Unfallchirurgie e.V., 2006). In den USA kommt es bei 5-20\% der Frakturen zu einer verzögerten oder insuffizienten Heilung (Aspenberg et al., 2010). Es ist davon auszugehen, dass die Zahlen für die BRD vergleichbar sind. Eine Optimierung der Frakturheilung ist somit von hohem Interesse, nicht nur für den einzelnen Patienten, sondern auch aus sozioökonomischer Sicht. Die zusätzlichen Kosten der Teriparatidtherapie erscheinen vor diesem Hintergrund gerechtfertigt. Bisher existieren keine Daten bezüglich der Kosteneffektivität von Teriparatid in Bezug auf die Frakturheilung beim Menschen. In tierexperimentellen Studien wurde die positive Wirkung auf die Frakturheilung durch Parathormon jedoch vielfach belegt. Sollten sich diese Ergebnisse im Rahmen von klinischen Studien bestätigen, ist mit einer effektiven Reduktion der Probleme durch eine verzögerte Knochenheilung und einer damit verbundenen Kostenersparnis zu rechnen.

\subsubsection{Nebenwirkungen}

Als häufigste allgemeine Nebenwirkungen werden in der Literatur Übelkeit, Kopfschmerzen, Schwindel und Benommenheit beschrieben (Neer et al., 2001). Es kann zu geringfügigen Anstiegen des Kalziumserumspiegels innerhalb von sechs Stunden nach Verabreichung kommen. In einer Studie an 350 postmenopausalen Osteoporosepatientinnen überstiegen die Werte jedoch nicht die physiologischen Werte (Satterwhite et al., 2010). Als Zeichen einer Hyperkalzämie kann es zu Beinkrämpfen, Verstopfung, Abgeschlagenheit und Muskelschwäche kommen (Cipriano et al., 2009).

Bei Ratten, denen über einen Zeitraum von zwei Jahren tägliche PTH-Dosen von $5 \mu \mathrm{g} / \mathrm{kg}$, $30 \mu \mathrm{g} / \mathrm{kg}$, oder $75 \mu \mathrm{g} / \mathrm{kg}$ subkutan injiziert wurden, kam es in allen drei Gruppen zu Osteosarkomen. Dieser Zeitraum entspricht mit 70-80\% fast der gesamten Lebensspanne der Tiere. Darüber hinaus beinhaltete der Versuch die Jugendphase der Tiere, in der das Längenwachstum am schnellsten abläuft. Im Gegensatz hierzu wird Teriparatid zur Osteoporsetherapie bei älteren Patienten über einen maximalen Zeitraum von 24 Monaten eingesetzt, was etwa 2-3\% der menschlichen Lebenszeit ausmacht. Auch sind die verwendeten Dosierungen bei den Versuchstieren im Vergleich zur Dosierung beim Menschen mehr als 200 -mal höher (Vahle et al., 2002).

Die Literatur weist zwei Fälle von Osteosarkomneuerkrankungen bei Menschen nach Be- 
ginn einer Therapie mit Teriparatid auf. In einem von Subbiah et al. veröffentlichen Fall wurde bei einem 67-jährigen Patienten ein Osteosarkom zwei Monate nach Therapiebeginn diagnostiziert. Bei dem Patienten war 16 Jahre zuvor erstmals ein Prostatakarzinom diagnostiziert worden. Neun Jahre nach radikaler Prostatektomie war es zu einem Lokalrezidiv gekommen, welches mit Radiatio behandelt worden war. Sieben Jahre später wurde am linken Ramus ossis pubis ein Osteosarkom diagnostiziert. Die anatomische Lokalisation des Tumors und der Zeitpunkt der Manifestation sprechen gegen eine Induktion durch Teriparatid, da Osteosarkome in der Regel an den langen Röhrenknochen auftreten (Subbiah et al., 2010).

Im Rahmen einer Studie, bei der Affen PTH in einer Dosierung von $5 \mu \mathrm{g} / \mathrm{kg}$ über einen Zeitraum vom 18 Monaten subkutan injiziert wurde, traten im 4,5-jährigen Beobachtungszeitrahmen keine Knochentumoren auf (Vahle et al., 2008). Diese Studie suggeriert eine Unbedenklichkeit bezüglich der Induktion von Neoplasien durch PTH auf das Skelett von Primaten. Bis zum Vorliegen aussagekräftiger Studien, welche keine erhöhten Risiken in Verbindung mit längeren Applikationszeiträumen als zwei Jahre belegen, sollte die Gabe von PTH jedoch beim Menschen auf diesen Zeitraum begrenzt bleiben (Cipriano et al., 2009; Madore et al., 2004).

Im Fokus zukünftiger Studien sollten die verschiedenen potentiellen Risikofaktoren stehen. Darüber hinaus muss geklärt werden, ob die verschiedenen Faktoren additiv das Risiko für Osteosarkome erhöhen (Subbiah et al., 2010).

Diese Fragen sind von besonderer Bedeutung, um das Patientenkollektiv, welches sich für eine Therapie mit PTH eignet, genau zu definieren.

\subsubsection{Alternative medikamentöse Stimulatoren der Frakturheilung}

\section{Bone morphogenetic protein - BMP}

Diese Substanzgruppe wurde von der US-amerikanischen FDA (Food and Drug Administration) im Jahr 2001 erstmals zur Behandlung von Pseudarthrosen langer Röhrenknochen am Menschen zugelassen. Sie gilt als die am besten erforschte Substanzklasse zur Optimierung der Frakturheilung (Komatsu und Warden, 2010).

Alt et al. zeigten, dass der Einsatz von BMP bei lumbalen Ein-Segment-Spondylodesen zu einer signifikant früheren Rückkehr der Patienten zum Arbeitsplatz führt. Weiterhin zeigten sie in einer Kosten-Nutzen-Analyse, dass der Einsatz von BMP-2 bei bestimmten offenen Tibiafrakturen Einsparungen von $2.797 €$ erzielen lässt. Diese Einsparungen resultieren aus einer verkürzten Krankheitsdauer und einer geringeren Revisions- und In- 
fektrate unter dem Einsatz von BMP-2 (Alt et al., 2006a).

Die hohen Kosten des Präparats von etwa 4.000 - 5.000€ (Zimmermann et al., 2006) können von den Kosten einer verzögerten Knochenheilung rasch überstiegen werden, wie in Abschnitt 6.3.1.2 auf Seite 75 beschrieben. Erste Studien zeigen potentielle Einsparungen durch den Einsatz von BMP-2. (Alt et al., 2006b,a).

Diesen Kosten stehen den deutlich geringeren Kosten von 851,76€ , welche bei einer Behandlung über 6 Wochen mit Teriparatid anfallen, gegenüber (Bundesanstalt für Arbeitsschutz und Arbeitsmedizin, 2011).

Ein Nachteil ist, dass die Substanz im Rahmen eines chirurgischen Eingriffs in die entsprechende Stelle eingebracht werden muss. Wie bei jeder Operation ergeben sich hierdurch Risiken wie Infektion, Wundheilungsstörung, Verletzung von Nerven und Gefäßen, Thrombose und Embolie. Auch kann es zu narkosebedingten Komplikationen kommen. Weitere Substanzen, welche gegenwärtig erforscht werden, sind andere Wachstumsfaktoren (z.B. PDGF, GDF-5, BMP-14, TGF-ß, IGF-1 und GH), Hypoxia-inducible-Factor 1 alpha $(\mathrm{HIF}-1 \alpha)$, Prostaglandine. Außerdem wird die Transplantation mesenchymaler Stammzellen in den Frakturspalt untersucht. In Tierversuchen, aber auch im Rahmen klinischer Studien, haben einige dieser Substanzen eine Effektivität im Rahmen der Behandlung verzögerter Frakturheilung gezeigt, und es ist davon auszugehen, dass sich hier interessante Therapieoptionen im Laufe der nächsten Jahre ergeben werden.

\subsection{Mechanische Stimulation der Frakturheilung}

Mechanische Beanspruchung führt zu einer Stimulation der Osteogenese und kann die Frakturheilung positiv beeinflussen (Stuermer et al., 2010; Adler, 2010).

Ultraschall stellt eine Möglichkeit der mechanischen Stimulation der Frakturheilung dar. Die Effektivität wurde von Busse et al. im Rahmen einer Übersichtsarbeit untersucht (Busse et al., 2009). Hierbei ergab sich nur eine niedrige bis moderate Evidenz für eine Verbesserung des funktionellen „outcomes”für Patienten mit einer Fraktur.

Die extrakorporale Stoßwellentherapie (ESWT) ist bisher nicht Gegenstand kontrollierter, randomisierter klinischer Studien gewesen. Daten verschiedener Studien legen einen positiven Effekt dieses Verfahrens auf die Knochenheilung nahe (Gollwitzer et al., 2006).

Die Ganzkörpervibration wird bereits zur Therapie der Osteoporosetherapie eingesetzt (Slatkovska et al., 2010; Zha et al., 2011). Erste tierexperimentelle Studien zum Einfluss auf die Frakturheilung zeigen einen positiven Effekt (Stuermer et al., 2010).

Zusammenfassend lässt sich festhalten, dass es wenig aussagekräftige Daten bezüglich 
der Effektivität der mechanischen Stimulation zur Optimierung der Frakturheilung gibt. Es fehlen aussagekräftige kontrollierte, randomisierte klinische Studien, welche die Effektivität belegen.

\subsection{Die Ratte als Versuchstier für die Frakturheilung}

Aerssens et al. verglichen Knochen verschiedener Spezies (Mensch, Hund, Schwein, Kuh, Schaf, Huhn und Ratte). Sie analysierten die Zusammensetzung und Dichte. Außerdem führten sie mechanische Belastungstests der Knochen durch. Die Versuche zeigten markante Unterschiede bezüglich der Knochenzusammensetzung, aber auch hinsichtlich der mechanischen Belastbarkeit bei den untersuchten Spezies. Die größte Ähnlichkeit zum menschlichen Knochen ergab sich bei Hundeknochen (Aerssens et al., 1998).

Die Knochenheilung kann schwerpunktmäßig über Osteoblasten oder über Chondroblasten ablaufen. In ersterem Fall wird Knochen direkt gebildet, im zweiten Fall findet die Knochenneubildung über den Weg der enchondralen Ossifikation statt. Im Gegensatz zum Menschen läuft die Frakturheilung bei Nagetieren (z.B. Ratten, Mäusen) überwiegend über die enchondrale Ossifikation ab. Unterschiede zeigen sich auch beim jeweils ausgebildeten Kallus: Bei der Ratte läuft die Heilung fast ausschließlich über den äußeren, periostalen Kallus ab. Bei Hunden und Primaten heilt der Knochen über einen kräftiger endostal/intramedullär ausgebildeten Kallus. Dies bedingt auch die Unterschiede hinsichtlich des zeitlichen Ablaufs des Heilungsprozesses unter den Spezies (O'Loughlin et al., 2008).

Die Ratte gehört zu den am häufigsten verwendeten Versuchstieren überhaupt und zu dem häufigsten Tiermodell zur Untersuchung der Frakturheilung (O'Loughlin et al., 2008). Ratten sind günstig in der Beschaffung, unkompliziert in der Haltung und gesellschaftlich weniger umstritten als größere Tiere wie das Schaf oder der Hund (Liebschner, 2004). Zusätzlich lässt ihre Größe Versuche mit einer hohen Anzahl an Tieren zu. Die Frakturheilung läuft schneller ab als bei größeren Tieren (O'Loughlin et al., 2008) und ihre kurze Lebensspanne ermöglicht die Untersuchung von Alterungsprozessen und deren Einflüsse auf das Skelett und die Knochenheilung (Liebschner, 2004).

Besonders im Rahmen der Osteoporoseforschung gibt es entscheidende zu berücksichtigende Unterschiede zwischen Ratten- und Menschenknochen. Bei der Ratte läuft auch nach Ovariektomie, die zu einem signifikanten Verlust an Knochensubstanz - ähnlich wie bei der Osteoporose - führt, das Remodeling weiter. Außerdem ist die Osteoblastenaktivität im Gegensatz zum osteoporotischen Menschenknochen nicht im selben Maße einge- 
schränkt (Liebschner, 2004). Beides bedingt eine deutlich bessere Regenerationsfähigkeit des Rattenknochens gegenüber dem menschlichen Knochen - auch beim Vorhandensein einer Osteoporose.

Erhebliche Unterschiede zwischen dem Organismus des Menschen und dem der Ratte werfen Fragen hinsichtlich der Übertragbarkeit von Ergebnissen aus tierexperimentellen Studien an der Ratte in den klinischen Alltag auf. Dies ist auch im Hinblick auf mögliche, durch PTH verursachte unerwünschte Nebenwirkungen, insbesondere die potentielle Gefahr eines Osteosarkoms, zu bedenken. 


\section{Kapitel 7}

\section{Zusammenfassung}

Die verzögerte Knochenheilung und Pseudarthrosenbildung stellt eine große Belastung für den betroffenen Patienten dar. Die sozioöknomischen Folgen sind enorm. Derzeit beschäftigt sich eine Vielzahl an Gruppen mit der Erforschung von Substanzen, welche die Frakturheilung positiv beeinflussen.

Zahlreiche tierexperimentelle Studien haben die induktive Wirkung von PTH auf die Frakturheilung gezeigt. Auch beim Vorliegen eines erhöhten Pseudarthroserisikos beeinflusst PTH die Frakturheilung positiv.

Seit Jahren ist Teriparatid im Rahmen der Osteoporosebehandlung im klinischen Einsatz. Erste Ergebnisse aus klinischen Studien zeigen einen positiven Effekt von PTH auf die Frakturheilung beim Menschen, wodurch möglicherweise die Zahl der verzögert oder nicht heilenden Frakturen und die damit verbundene enorme sozioökonimische Belastung reduziert werden können.

Ein Vorteil gegenüber dem bereits im klinischen Alltag erfolgreich eingesetzten Wachstumshormon BMP stellt die Möglichkeit der systemischen Applikation für PTH dar. Dadurch werden Risiken und Kosten eines erneuten chirurgischen Eingriffs vermieden. Bisher erfolgt die Applikation als tägliche subkutane Injektion. Die Entwicklung eines oral einnehmbaren Präparats würde PTH noch interessanter als Therapeutikum zur Optimierung der Frakturheilung machen.

Das in der Literatur beschriebene Osteosarkomrisiko unter dem Einfluss einer PTH-Therapie erscheint bei der Frakturbehandlung gering, da sich die Therapiedauer auf wenige Wochen belaufen würde. Die Therapie mit PTH sollte jedoch bei Patienten mit besonderen Risikofaktoren unterbleiben.

Die Frakturheilung ist ein komplexes Zusammenspiel zahlreicher Schritte, welches nicht vollständig untersucht ist. Auch hier sind weitere Erkenntnisse nötig, um bei Problemen 
der Frakturheilung gezielte therapeutische Ansätze anwenden zu können. Im Rahmen weiterer Studien sollte der Einfluss von PTH auf die verschiedenen Schritte weiter untersucht werden, um den optimalen Zeitraum für eine Therapie einzugrenzen.

Es ist zu bezweifeln, dass die alleinige systemische PTH-Gabe zur Behandlung manifester Pseudarthrosen geeignet ist, da hierzu meistens eine chirurgische Intervention erforderlich ist. Hierzu liegen bisher keine Daten vor. PTH hat jedoch das Potential, einen festen Stellenwert im Rahmen der Frakturbehandlung bei pseudarthrosegefährdeten Patienten zu erlangen. Hier besteht auch ein gewaltiges Potential bei Patienten mit konservativ behandelten Frakturen.

Die im Rahmen dieser Arbeit erhobenen Daten bestätigen die vorliegenden Erkenntnisse aus anderen tierexperimentellen Studien. Basierend auf den vielversprechenden Ergebnissen dieser Studien zur Frakturheilung am Tiermodell sollten unter Berücksichtigung vorliegender Risikofaktoren für ein Osteosarkom randomisierte, kontrollierte klinische Studien erfolgen. 


\section{Abkürzungsverzeichnis}

$\begin{array}{ll}\text { AK } & \text { Alizarin-Komplexon } \\ \text { BMD } & \text { bone mass density } \\ \text { BMP } & \text { bone morphogenetic protein } \\ \text { BMU } & \text { bone metabolizing unit } \\ \mathrm{Ca}^{2+} & \text { Kalzium } \\ \mathrm{CG}_{\mathrm{CO}_{2}} & \text { Fluorescein-Komplexon } \\ \mathrm{COX}-2 & \text { Kohlendioxid } \\ \mathrm{cm} & \text { Cyclooxygenase-2 } \\ / \mathrm{d} & \text { Zentimeter }\end{array}$

ESBL-Bildner „,extended spectrum beta lactamase” -Bildner

ESWT Extrakorporale Stoßwellentherapie

$€ \quad$ Euro

FDA Food and Drug Administration

g Gramm

GDF-5 growth and differentiation factor-5

ggf. gegebenenfalls

$\mathrm{GH}$ growth hormone

$\mathrm{GHz} \quad$ Gigahertz

${ }^{\circ} \mathrm{C} \quad$ Grad Celsius

HIF-1 $\alpha$ hypoxia-inducible-factor 1 alpha

HIV human immunodeficiency virus

IGF-1 insulin-like growth factor

ISS injury severity score

kg Kilogramm

$\mathrm{kV} \quad$ Kilovolt

LC-DCP less contact dynamic compression plate 


\begin{tabular}{|c|c|}
\hline LCP & less contact plate \\
\hline$\mu g$ & Mikrogramm \\
\hline$\mu \mathrm{m}$ & Mikrometer \\
\hline $\mathrm{mA}$ & Milliampere \\
\hline $\mathrm{mg}$ & Milligramm \\
\hline $\mathrm{ml}$ & Milliliter \\
\hline $\mathrm{mm}$ & Millimeter \\
\hline $\mathrm{mm}^{2}$ & Quadratmillimeter \\
\hline MMA & Methylmethacrylsäure \\
\hline MRSA & Methicillinresistenter Staphylococcus aureus \\
\hline $\mathrm{ms}$ & Millisekunde \\
\hline $\mathrm{N}$ & Newton \\
\hline $\mathrm{NaCl}$ & Natriumchlorid \\
\hline $\mathrm{nm}$ & Nanometer \\
\hline NSAR & Nichtsteroidales Antirheumatikum \\
\hline OPG & Osteoprotegerin \\
\hline ORSA & Oxacillinresistenter Staphylococcus aureus \\
\hline pAVK & periphere arterielle Verschlusskrankheit \\
\hline PDGF & platelet-derived growth factor \\
\hline PRP & platelet rich plasma \\
\hline PTH & Parathormon \\
\hline RANK & receptor activator of NF-kB \\
\hline RANKL & receptor activator of NF-kB ligand \\
\hline ROI & region of interest \\
\hline $\mathrm{s}$ & Sekunde \\
\hline s.c. & subkutan \\
\hline $\mathrm{TC}$ & Tetracyclin-Hydrochlorid \\
\hline TGF- $ß$ & transforming growth factor- $\mathbb{B}$ \\
\hline TNF & Tumornekrosefaktor \\
\hline US\$ & US-Dollar \\
\hline $\mathrm{XO}$ & Xylenolorange-Tetranatriumsalz \\
\hline z.B. & zum Beispiel \\
\hline
\end{tabular}




\section{Literaturverzeichnis}

Adler RA, editor (2010): Osteoporosis - Pathophysiology and Clinical Management. Human Press, Springer Science+Business Media, New York, USA, 2 edition

Aerssens J, Boonen S, Lowet G und Dequeker J (1998): Interspecies differences in bone composition, density, and quality: potential implications for in vivo bone research. Endocrinology $\underline{139}$, 663-670

Al-Zube L, Breitbart EA, O'Connor JP, Parsons JR, Bradica G, Hart CE und Lin SS (2009): Recombinant human platelet-derived growth factor BB (rhPDGF-BB) and betatricalcium phosphate/collagen matrix enhance fracture healing in a diabetic rat model. J Orthop Res 27, 1074-1081

Alkhiary YM, Gerstenfeld LC, Krall E, Westmore M, Sato M, Mitlak BH und Einhorn TA (2005): Enhancement of experimental fracture-healing by systemic administration of recombinant human parathyroid hormone (PTH 1-34). J Bone Joint Surg Am 87, 731-741

Alt V, Eicher A, Bitschnau A und Schnettler R (2006a): Kosten-Nutzen-Betrachtung des Einsatzes von rhBMP-2 bei offenen Tibiafrakturen Nettoeinsparungen aus Krankenkassensicht erzielbar. Unfallchirurg 109, 463-470

Alt V, Haas H, Rauschmann MA, Carstens C, Franke J, Eicher A, Bitschnau A und Schnettler R (2006b): Gesundheitsökonomische Überlegungen für den Einsatz des Knochenwachstumsfaktors BMP-2 in der Wirbelsäulenchirurgie für das deutsche Gesundheitssystem. Z Orthop Ihre Grenzgeb 144, 577-582

Altman RD, Latta LL, Keer R, Renfree K, Hornicek FJ und Banovac K (1995): Effect of nonsteroidal antiinflammatory drugs on fracture healing: A laboratory study in rats. J Orthop Trauma $\underline{5}, 392-400$

Andersson GBJ, Bouchard J, Bozic KJ, Campbell, R M Jr, Cisternas MG, Correa A, Cosman F, Cragan JD, D'Andrea, K, Doernberg N et al. (2011): United States Bone and Joint Decade: The Burden of Musculoskeletal Diseases in the United States - Chapter 6: Musculoskeletal Injuries. The Burden of Musculoskeletal Diseases in the United States, Rosemont, IL, USA, online (http:/ / www.boneandjointburden.org) edition

Aspenberg P, Genant HK, Johansson T, Nino AJ, See K, Krohn K, García-Hernández Pa, Recknor CP, Einhorn Ta, Dalsky GP et al. (2010): Teriparatide for acceleration of fracture repair in humans: a prospective, randomized, double-blind study of 102 postmenopausal women with distal radial fractures. J Bone Miner Res 25, 404-414 
Aspenberg P und Johansson T (2010): Teriparatide improves early callus formation in distal radial fractures. Acta Orthop $\underline{81}, 234-236$

Barnes GL, Kakar S, Vora S, Morgan EF, Gerstenfeld LC und Einhorn Ta (2008): Stimulation of fracture-healing with systemic intermittent parathyroid hormone treatment. J Bone Joint Surg Am 90, 120-127

Bartl R (2008): Osteoporose - Prävention, Diagnostik, Therapie. Georg Thieme Verlag, Stuttgart, BRD, 3. edition

Beck A, Krischak G, Sorg T, Augat P, Farker K, Merkel U, Kinzl L und Claes L (2003): Influence of diclofenac (group of nonsteroidal anti-inflammatory drugs) on fracture healing. Arch Orthop Trauma Surg 123, 327-332

Beck A, Salem K, Krischak G, Kinzl L, Bischoff M und Schmelz A (2005): Nonsteroidal anti-inflammatory drugs (NSAIDs) in the perioperative phase in traumatology and orthopedics effects on bone healing. Oper Orthop Traumatol 17, 569-578

Broadhead ML, Clark JCM, Myers DE, Dass CR und Choong PFM (2011): The molecular pathogenesis of osteosarcoma: a review. Sarcoma Article ID 959248, 1-12

Brown KM, Saunders MM, Kirsch T, Donahue HJ und Reid JS (2004): Effect of COX-2specific inhibition on fracture-healing in the rat femur. J Bone Joint Surg Am $\underline{86-\mathrm{A}}$, 116-123

Bukata SV und Puzas JE (2010): Orthopedic uses of teriparatide. Curr Osteoporos Rep $\underline{8}$, 28-33

Bundesanstalt für Arbeitsschutz und Arbeitsmedizin (2011): Volkswirtschaftliche Kosten durch Arbeitsunfühigkeit 2009 - Stand April 2011. Bundesanstalt für Arbeitsschutz und Arbeitsmedizin, Dortmund, BRD

Burger EH und Klein-Nulend J (1999): Mechanotransduction in bone-role of the lacunocanalicular network. FASEB J 13 Suppl, S101-S112

Busse JW, Bhandari M, Sprague S, Johnson-Masotti AP und Gafni A (2008): An economic analysis of management strategies for closed and open grade I tibial shaft fractures. Acta Orthop 76, 705-712

Busse JW, Kaur J, Mollon B, Bhandari M, Tornetta P, Schunemann HJ und Guyatt GH (2009): Low intensity pulsed ultrasonography for fractures: systematic review of randomised controlled trials. BMJ $\underline{338}, 1-9$

Calori GM, Donati D, Di Bella C und Tagliabue L (2009): Bone morphogenetic proteins and tissue engineering: future directions. Injury $\underline{40}$, S67-S76

Chalidis B, Tzioupis C, Tsiridis E und Giannoudis PV (2007): Enhancement of fracture healing with parathyroid hormone: preclinical studies and potential clinical applications. Expert Opin Investig Drugs 16, 441-449 
Chao EYS und Inoue N (2003): Biophysical stimulation of bone fracture repair, regeneration and remodelling. Eur Cell Mater $\underline{6}, 72-85$

Cipriano CA, Issack PS, Shindle L, Werner CML, Helfet DL und Lane JM (2009): Recent advances toward the clinical application of PTH (1-34) in fracture healing. HSS J $\underline{5}$, 149-153

Cosman F und Lindsay R (1998): Is parathyroid hormone a therapeutic option for osteoporosis? A review of the clinical evidence. Calcif Tissue Int $\underline{62}, 475-480$

Courteix D, Lespessailles E, Peres SL, Obert P, Germain P und Benhamou CL (1998): Effect of physical training on bone mineral density in prepubertal girls: a comparative study between impact-loading and non-impact-loading sports. Osteoporos Int $\underline{8}, 152-158$

Dayer R, Badoud I, Rizzoli R und Ammann P (2007): Defective implant osseointegration under protein undernutrition: prevention by PTH or pamidronate. J Bone Miner Res $\underline{22}$, 1526-1533

Dayer R, Rizzoli R, Kaelin A und Ammann P (2006): Low protein intake is associated with impaired titanium implant osseointegration. J Bone Miner Res 21, 258-268

Dempster DW, Cosman, F, Parisien M, Shen V und Lindsay R (1994): Anabolic actions of parathyroid hormone on bone. Endocr Rev 15, 690-709

Dempster DW, Zhou H, Cosman F, Nieves J, Adachi JD und Fraher LJ (2001): PTH treatment directly stimulates bone formation in cancellous and cortical bone in humans. J Bone Miner Res $\underline{16}$, S179

den Uyl D, Bulting IE und Lems WF (2011): Glucocorticoid-induced osteoporosis. Clin Exp Rheumatol 29, S93-S98

Deutsche Gesellschaft für Unfallchirurgie eV, editor (2006): Weißbuch - Empfehlungen zur Struktur, Organisation und Ausstattung der Schwerverletzten-Versorgung in der Bundesrepublik Deutschland. Deutsche Gesellschaft für Unfallchirurgie e.V., Berlin, BRD

Doyon AR, Ferries IK und Li J (2010): Glucocorticoid attenuates the anabolic effects of parathyroid hormone on fracture repair. Calcif Tissue Int $\underline{87}, 68-76$

Drenckhahn D und Zenker W, editors (1994): Benninghoff Anatomie - Makroskopische Anatomie, Embryologie und Histologie des Menschen, Band 1. Urban \& Schwarzenberg, München, BRD, 15 edition

Einhorn TA (1995): Enhancement of fracture-healing. J Bone Joint Surg Am 77, 940-956

Ellegaard M, Jørgensen NR und Schwarz P (2010): Parathyroid hormone and bone healing. Calcif Tissue Int $\underline{\text { 87, }}$ 1-13

Enault S (2012): Bestiarium osteology, http: / / bestiarumosteology.com 
Endo K, Sairyo K, Komatsubara S, Sasa T, Egawa H, Ogawa T, Yonekura D, Murakami RI und Yasui N (2005): Cyclooxygenase-2 inhibitor delays fracture healing in rats. Acta Orthop $\underline{76}, 470-474$

Finkelstein JS, Klibanski A, Arnold AL, Toth TL, Hornstein MD und Neer RM (1998): Prevention of estrogen deficiency-related bone loss with human parathyroid hormone(1-34): a randomized controlled trial. JAMA $\underline{280}$, 1067-1073

Frerichmann U, Raschke MJ, Stöckle U, Wöhrmann S und Lohmann R (2007): Proximale Femurfrakturen im Alter. Krankenkassendaten von über 23 Mio. Versicherten - Teil 2. Unfallchirurg 110, 610-616

Frick H, Leonhardt H und Starck D, editors (1992): Taschenlehrbuch der gesamten Anatomie: Allgemeine Anatomie, volume 1. Georg Thieme Verlag, Stuttgart, BRD, 4 edition

Frost KM (1987): Bone „mass” and the „mechanostat”. A proposal. Anat Rec 219, 1-9

Gollwitzer H, Brandner H und Gloeck T (2006): Extrakorporale Stoßwellentherapie bei Knochenheilungsstörungen. Trauma Berufskrankh $\underline{8}$, 142-152

Goodship AE, Lawes TJ und Rubin CT (2009): Low-magnitude high-frequency mechanical signals accelerate and augment endochondral bone repair: preliminary evidence of efficacy. J Orthop Res 27, 922-930

Gruber R, Koch H, Doll BA, Tegtmeier F, Einhorn TA und Hollinger JO (2006): Fracture healing in the elderly patient. Exp Gerontol 41, 1080-1093

Hadjiargyrou M, Lombardo F, Zhao S, Ahrens W, Joo J, Ahn H, Jurman M, White, DW und Rubin, CT (2002): Transcriptional profiling of bone regeneration. insight into the molecular complexity of wound repair. J Biol Chem 277, 30177-30182

Hakimi M, Jungbluth P, Thelen S, Betsch M, Linhart W, Flohé S, Windolf J und Wild M (2011): Platelet-rich plasma combined with autologous cancellous bone: an alternative therapy for persistent non-union? Unfallchirurg 114, 998-1006

Heppert V, Wagner C, Scherf K und Wentzensen A (2005): Infekt-/Defektpseudarthrose. Trauma Berufskrankh 7, S110-S119

Hock JM (2001): Anabolic actions of PTH in the skeletons of animals. J Musculoskel Neuron Interact 2, 33-47

Hodsman AB, Bauer DC, Dempster DW, Dian L, Hanley Da, Harris ST, Kendler DL, McClung MR, Miller PD, Olszynski WP et al. (2005): Parathyroid hormone and teriparatide for the treatment of osteoporosis: a review of the evidence and suggested guidelines for its use. Endocr Rev 26, 688-703

Hodsman AB, Fraher LJ, Watson PH, Ostbye T, Stitt LW, Adachi JD, Taves DH und D D (1997): A randomized controlled trial to compare the efficacy of cyclical parathyroid hormone versus cyclical parathyroid hormone and sequential calcitonin to improve bone mass in postmenopausal women with osteoporosis. J Clin Endocrinol Metab $\underline{82}$, $620-628$ 
Hollinger JO, Hart CE, Hirsch SN, Lynch S und Friedlaender GE (2008): Recombinant human platelet-derived growth factor: biology and clinical applications. J Bone Joint Surg Am 90, 48-54

Hollinger JO, Schmitt JM, Hwang K, Soleymani P und Buck D (1999): Impact of nicotine on bone healing. J Biomed Mater Res $\underline{45}$, 294-301

Huddleston PM, Steckelberg JM, Hanssen AD, Rouse MS, Bolander ME und Patel R (2000): Ciprofloxacin inhibition of experimental fracture healing. J Bone Joint Surg Am 82, 161-173

Hughes JM und Petit MA (2010): Biological underpinnings of Frost's mechanostat thresholds: the important role of osteocytes. J Musculoskelet Neuronal Interact 10, 128-135

Jacobs C, Moghaddam A, Wölfl C, Linden P, Wentzensen A und Zimmermann G (2008): Wachstumshormone und BMP. Trauma Berufskrankh 10, 226-229

Jilka RL (2007): Molecular and cellular mechanisms of the anabolic effect of intermittent PTH. Bone $\underline{40}, 1434-1446$

Jørgensen N und Schwarz P (2011): Effects of anti-osteoporosis medications on fracture healing. Curr Osteoporos Rep 9, 149-155

Junqueira LC, Carneiro J und Kelley RO, editors (2001): Histologie. Springer, Berlin, BRD, 5 edition

Kaback L, Soung do Y, Naik A, Geneau G, Schwarz EM, Rosier RN, O'Keefe RJ und Drissi $\mathrm{H}$ (2008): Teriparatide (1-34 human PTH) regulation of osterix during fracture repair. J Cell Biochem 105, 219-26

Kakar S, Einhorn TA, Vora S, Miara LJ, Hon G, Wigner NA, Toben D, Jacobsen KA, AlSebaei MO, Song M et al. (2007): Enhanced chondrogenesis and Wnt signaling in PTHtreated fractures. J Bone Miner Res 22, 511-520

Khan Y und Laurencin CT (2008): Fracture repair with ultrasound: clinical and cell-based evaluation. J Bone Joint Surg Am 90, 138-144

Kim CH, Takai E, Zhou H, von Stechow D, Müller R und Dempster XE D W amd Guo (2003): Trabecular bone response to mechanical and parathyroid hormone stimulation: the role of mechanical microenvironment. J Bone Miner Res 18, 2116-2125

Kim SJ, Shin YW, Yang KH, Kim SB, Yoo MJ, Han SK, Im SA, Won YD, Sung YB, Jeon TS et al. (2009): A multi-center, randomized, clinical study to compare the effect and safety of autologous cultured osteoblast(ossron) injection to treat fractures. BMC Musculoskelet Disord $\underline{10}, 20$

Komatsu DE und Warden SJ (2010): The control of fracture healing and its therapeutic targeting: improving upon nature. J Cell Biochem 109, 302-311 
Komatsubara S, Mori S, Mashiba T, Nonaka K, Seki A, Akiyama T, Miyamoto K, Cao Y, Manabe T und Norimatsu H (2005): Human parathyroid hormone (1-34) accelerates the fracture healing process of woven to lamellar bone replacement and new cortical shell formation in rat femora. Bone $\underline{36}, 678-687$

Komrakova M, Krischek C, Wicke M, Sehmisch S, Tezval M, Rohrberg M, Brandsch T, Stuermer KM und Stuermer EK (2011): Influence of intermittent administration of parathyroid hormone on muscle tissue and bone healing in orchiectomized rats or controls. J Endocrinol 209, 9-19

Komrakova M, Stuermer EK, Werner C, Wicke M, Kolios L, Sehmisch S, Tezval M, Daub F, Martens T, Witzenhausen P et al. (2010): Effect of human parathyroid hormone hPTH (1-34) applied at different regimes on fracture healing and muscle in ovariectomized and healthy rats. Bone $\underline{47}, 480-492$

Kudo S, Mizuta H, Takagi K und Hiraki Y (2011): Cartilaginous repair of full-thickness articular cartilage defects is induced by the intermittent activation of PTH/PTHrP signaling. Osteoarthritis Cartilage 19, 886-894

Lanyon LE (1996): Using functional loading to influence bone mass and architecture: objectives, mechanisms, and relationship with estrogen of the mechanically adaptive process in bone. Bone 18, 37S-43S

Leone-Bay A, Sato M, Paton D, Hunt A, Sarubbi D, Carozza M, Chou J, McDonough J und Baughman R (2001): Oral delivery of biologically active parathyroid hormone. Pharm Res $\underline{18}, 964-970$

Leung KS, Shi HF, Cheung WH, Qin L, Ng WK, Tam KF und Tang N (2009): Lowmagnitude high-frequency vibration accelerates callus formation, mineralization, and fracture healing in rats. J Orthop Res $27,458-465$

Li M, Thompson DD und Paralkar VM (2007): Prostaglandin $E_{2}$ receptors in bone formation. Int Orthop $\underline{31}, 767-772$

Liebschner M (2004): Biomechanical considerations of animal models used in tissue engineering of bone. Biomaterials 25, 1697-1714

Loder RT (1988): The influence of diabetes mellitus on the healing of closed fractures. Clin Orthop Relat Res 232, 210-216

Lögters T, Windolf J und Flohé S (2009): Femurschaftfrakturen. Unfallchirurg 112, 635650; quiz 651

Ma YL, Cain RL, Halladay DL, Yang X, Zeng Q, Miles RR, Chandrasekhar S, Martin TJ und Onyia JE (2001): Catabolic effects of continuous human PTH (1-38) in vivo is associated with sustained stimulation of RANKL and inhibition of osteoprotegerin and gene-associated bone formation. Endocrinology 142, 4047-4054

Madore GR, Sherman PJ und Lane JM (2004): Parathyroid hormone. J Am Acad Orthop Surg 12, 67-71 
Manabe T, Mori S, Mashiba T, Kaji Y, Iwata K, Komatsubara S, Seki A, Sun YX und Yamamoto T (2007): Human parathyroid hormone (1-34) accelerates natural fracture healing process in the femoral osteotomy model of cynomolgus monkeys. Bone $\underline{40}, 1475-1482$

Marcus R, Feldman D, Nelson DA und Rosen CJ (2010): Fundamentals of Osteoporosis. Academic Press, Elsevier, Burlington, USA

Matsumoto T, Kawamoto A, Kuroda R, Ishikawa M, Mifune Y, Iwasaki H, Miwa M, Horii M, Hayashi S, Oyamada A et al. (2006): Therapeutic potential of vasculogenesis and osteogenesis promoted by peripheral blood CD 34-positive cells for functional bone healing. Am J Pathol 169, 1440-1457

Meiners J, Gerlach U, Mägerlein S, Jürgens C und Faschingbauer M (2009): Pseudarthrosen. Chirurg $\underline{80}, 979-986$

Meyer RAJ, Tsahakis PJ, F MD, Banks DM, E HM und Kiebzak GM (2001): Age and ovariectomy impair both the normalization of mechanical properties and the accretion of mineral by the fracture callus in rats. J Orthop Res $\underline{19}, 428-435$

Mirabello L, Troisi RJ und Savage SA (2009): Osteosarcoma incidence and survival rates from 1973 to 2004: Data from the surveillance, epidemiology, and end results program. Epidemiology 115, 1531-1543

Morgan EF, Mason ZD, Bishop G, Davis AD, Wigner NA, Gerstenfeld LC und Einhorn TA (2008): Combined effects of recombinant human BMP-7 (rhBMP-7) and parathyroid hormone (1-34) in metaphyseal bone healing. Bone $\underline{43}, 1031-1038$

Morley P, Whitfield JF und Willick GE (1997): Anabolic effects of parathyroid hormone on bone. Trends Endocrinol Metab $\underline{8}, 225-231$

Mutschler W und Haas NP, editors (2004): Praxis der Unfallchirurgie. Georg Thieme Verlag, Stuttgart, BRD, 2 edition

Nakajima A, Shimoji N, Shiomi K, Shimizu S, Moriya H, Einhorn TA und Yamazaki M (2002): Mechanisms for the enhancement of fracture healing in rats treated with intermittent low-dose human parathyroid hormone (1-34). J Bone Miner Res 17, 2038-2047

Nakazawa T, Nakajima A, Shiomi K, Moriya H, Einhorn, TA und Yamazaki M (2005): Effects of low-dose, intermittent treatment with recombinant human parathyroid hormone (1-34) on chondrogenesis in a model of experimental fracture healing. Bone $\underline{37}$, $711-719$

Neer RM, Arnaud CD, Zanchetta JR, Prince R, Gaich Ga, Reginster JY, Hodsman AB, Eriksen EF, Ish-Shalom S, Genant HK et al. (2001): Effect of parathyroid hormone (1-34) on fractures and bone mineral density in postmenopausal women with osteoporosis. $\mathrm{N}$ Engl J Med 344, 1434-1441

Ogawa T, Zhang X, Naert I, Vermaelen P, Deroose CM, Sasaki K und Duyck J (2011): The effect of whole-body vibration on peri-implant bone healing in rats. Clin Oral Implants Res 22, 302-307 
Okazaki K, Jingushi S, Ikenoue T, Urabe K, Sakai H und Iwamoto Y (2003): Expression of parathyroid hormone-related peptide and insulin-like growth factor I during rat fracture healing. J Orthop Res 21, 511-520

O'Loughlin P, Morr S, Bogunovic L, Kim, AD, Park B und Lane, JM (2008): Selection and development of preclinical models in fracture-healing research. J Bone Joint Surg Am 90, 79-84

Papachroni KK, Karatzas DN, Papavassiliou Ka, Basdra EK und Papavassiliou AG (2009): Mechanotransduction in osteoblast regulation and bone disease. Trends Mol Med $\underline{15}$, 208-216

Patterson TE, Kumagai K, Griffith L und Muschler GF (2008): Cellular strategies for enhancement of fracture repair. J Bone Joint Surg Am 90, 111-119

Pauwels F (1954): Über die Verteilung der Spongiosadichte im coxalen Femurende und ihre Bedeutung für die Lehre vom funktionellen Bau des Knochens. Siebenter Beitrag zur funktionellen Anatomie und kausalen Morphologie des Stützapparates. Morph Jb $\underline{95}, 35-54$

Peichl P, Holzer LA, Maier R und Holzer G (2011): Parathyroid hormone 1-84 accelerates fracture-healing in pubic bones of elderly osteoporotic women. J Bone Joint Surg Am $\underline{93}, 1583-1587$

Rahn DA (1976): The fluorochrome sequence labelling of the bone. Nova Acta Leopold $\underline{44}, 249-255$

Raikin SM, Landsman JC, Alexander VA, Froimson MI und Plaxton NA (1998): Effect of nicotine on the rate and strength of long bone fracture healing. Clin Orthop Relat Res $\underline{353}, 231-237$

Raschke MJ und Gasch A (2011): Verzögerte Frakturheilung. Trauma Berufskrankh 14, 85-89

Raschke MJ und Stange R, editors (2009): Alterstraumatologie - Prophylaxe, Therapie und Rehabilitation. Elsevier GmbH, Urban und Fischer Verlag, München, BRD, 1 edition

Resmini G und Iolascon G (2007): 79-year-old post-menopausal woman with humerus fracture during teriparatide treatment. Aging Clin Exp Res 19, 30-31

Retzepi M und Donos N (2010): The effect of diabetes mellitus on osseous healing. Clin Oral Implants Res 21, 673-681

Reverte MM, Dimitriou R, Kanakaris NK und Giannoudis PV (2011): What is the effect of compartment syndrome and fasciotomies on fracture healing in tibial fractures? Injury 42, 1402-1407

Rosen CJ und Bilezikian PJ (2001): Anabolic therapy for osteoporosis. J Clin Endocrinol Metab 6, 957-964 
Rubin C, Bolander M, Ryaby JP und Hadjiargyrou M (2001): The use of low-intensity ultrasound to accelerate the healing of fractures. J Bone Joint Surg Am 83-A , 259-270

Rüedi, Buckley und Moran, editors (2008): AO-Prinzipien des Frakturmanagements. Georg Thieme Verlag, Stuttgart, BRD, 2 edition

Runkel M und Rommens PM (2000): Pseudarthrosen. Unfallchirurg 103, 51-63

Rüter A und Mayr E (1999): Pseudarthrosen. Chirurg 70, 1239-1245

Sampson ER (2009a): Intermittent PTH(1-34) and PTHrP Enhance Hyaline Cartilage Regeneration in a Rabbit Full-Thickness Defect Model. Conference Poster, ASBMR Topical Meeting, September 13, 2009

Sampson ER (2009b): PTH(1-34) Protects Against Articular Cartilage Degeneration Following Meniscal/ligamentous Injury in a Mouse Model of Osteoarthritis. Conference Poster, ASBMR Topical Meeting, September 13, 2009

Sampson ER, Hilton MJ, Tian Y, Chen D, Schwarz EM, Mooney RA, Bukata SV, O'Keefe RJ, Awad H, Puzas JE et al. (2011): Teriparatide as a chondroregenerative therapy for injury-induced osteoarthritis. Sci Transl Med $\underline{3}$, 101ra93

Satterwhite J, Heathman M, Miller PD, Marín F, Glass EV und Dobnig H (2010): Pharmacokinetics of teriparatide (rh-PTH[1-34]) and calcium pharmacodynamics in postmenopausal women with osteoporosis. Calcif Tissue Int $\underline{87,485-492}$

Schmidt R und Thews G, editors (1995): Physiologie des Menschen. Springer, Berlin, BRD, 26 edition

Sehmisch S, Galal R, Kolios L, Tezval M, Dullin C, Zimmer S, Stuermer KM und Stuermer EK (2009): Effects of low-magnitude, high-frequency mechanical stimulation in the rat osteopenia model. Osteoporos Int 20, 1999-2008

Siegenthaler W, editor (2006): Klinische Pathophysiologie. Thieme, Stuttgart, Stuttgart, BRD, 8 edition

Skripitz R, Andreassen TT und Aspenberg P (2000): Strong effect of PTH (1-34) on regenerating bone: a time sequence study in rats. Acta Orthop Scand 71, 619-624

Slatkovska L, Alibhai SM, Beyene J und Cheung AM (2010): Effect of whole-body vibration on BMD: a systematic review and meta-analysis. Osteoporos Int 21, 1969-1980

Starr AJ (2008): Fracture repair: successful advances, persistent problems, and the psychological burden of trauma. J Bone Joint Surg Am 90, 132-137

Stuermer EK, Komrakova M, Werner C und Wicke M (2010): Musculoskeletal response to whole-body vibration during fracture healing in intact and ovariectomized rats. Calcif Tissue Int $\underline{87}, 168-180$ 
Stuermer EK, Seidlová-Wuttke D, Sehmisch S, Rack T, Wille J, Frosch KH, Wuttke W und Stürmer KM (2006): Standardized bending and breaking test for the normal and osteoporotic metaphyseal tibias of the rat: Effect of estradiol, testosterone, and raloxifene. J Bone Miner Res 21, 89-96

Stürmer KM (1996): Pathophysiologie der gestörten Knochenheilung. Orthopäde 25, 386393

Subbiah V, Madsen VS, Raymond aK, Benjamin RS und Ludwig Ja (2010): Of mice and men: divergent risks of teriparatide-induced osteosarcoma. Osteoporos Int 21, 10411045

Takahata M, Awad HA, O'Keefe RJ, Bukata SV und Schwarz EM (2011): Endogenous tissue engineering: PTH therapy for skeletal repair. Cell Tissue Res Epub ahead of print

Thomsen JS, Mosekilde LI und Gasser JA (1999): Long-term therapy of ovariectomyinduced osteopenia with parathyroid hormone analog SDZ PTS 893 and bone maintenance in retired breeder rats. Bone $\underline{25}, 561-569$

Vahle JL, Sato M, Long GG, Young JK, Francis PC, Engelhardt JA, Westmore MS, Linda $Y$ und Nold JB (2002): Skeletal changes in rats given daily subcutaneous injections of recombinant human parathyroid hormone (1-34) for 2 years and relevance to human safety. Toxicol Pathol $\underline{30}, 312-321$

Vahle JL, Zuehlke U, Schmidt A, Westmore M, Chen P und Sato M (2008): Lack of bone neoplasms and persistence of bone efficacy in cynomolgus macaques after long-term treatment with teriparatide [rhPTH(1-34)]. J Bone Miner Res 23, 2033-2039

Verschueren S (2004): Effect of 6-month whole body vibration training on hip density, muscle strength, and postural control in postmenopausal women: a randomized controlled pilot study. J Bone Miner Res 19, 352-359

Voggenreiter G (2009): Fracture healing. Perioperative Medizin 1, 86-95

Wang YH, Liu Y, Buhl K und W RD (2005): Comparison of the action of transient and continuous PTH on primary osteoblast cultures expressing differentiation stage-specific GFP. J Bone Miner Res 20, 5-14

Waters RV, Gamradt SC, Asnis P, Vickery BH, Avnur Z, Hill E und Bostrom M (2000): Systemic corticosteroids inhibit bone healing in a rabbit ulnar osteotomy model. Acta Orthop Scand $\underline{71}, 316-321$

Werle M, Samhaber A und Bernkop-Schnürch A (2006): Degradation of teriparatide by gastro-intestinal proteolytic enzymes. J Drug Target 14, 109-115

Wild S, Roglic G, Green A, Sicree R und King H (2004): Global prevalence of diabetes: estimates for the year 2000 and projections for 2030. Diabetes care 27, 1047-1053

Wolff J (1892): Das Gesetz von der Transformation der Knochen. Hirschwald, Berlin, Deutschland 
Yamaji T (2001): The effect of micromovement on callus formation. J Orthop Sci $\underline{6}, 571-575$

Zatzick D, Jurkovich G, Russo J, Roy-Byrne P, Katon W, Wagner A, Dunn C, Uehara E, Wisner D und Rivara F (2004): Posttraumatic distress, alcohol disorders, and recurrent trauma across level 1 trauma centers. J Trauma 57, 360-366

Zerwekh JE, Ruml LA, Gottschalk F und Pak CY (1998): The effects of twelve weeks of bed rest on bone histology, biochemical markers of bone turnover, and calcium homeostasis in eleven normal subjects. J Bone Miner Res $\underline{13}$, 1594-1601

Zha DS, Zhu QA, Pei WW, Zheng JC, Wu SH, Xu ZX, Li T und Chen JT (2011): Does wholebody vibration with alternative tilting increase bone mineral density and change bone metabolism in senior people? Aging Clin Exp Res Epub ahead of print

Zheng LW, Ma L und Cheung LK (2008): Changes in blood perfusion and bone healing induced by nicotine during distraction osteogenesis. Bone $\underline{43}$, 355-361

Zimmermann G, Müller U, Löffler C, Wentzensen A und Moghaddam A (2007): Therapeutic outcome in tibial pseudarthrosis: bone morphogenetic protein 7 (BMP-7) versus autologous bone grafting for tibial fractures. Unfallchirurg $\underline{110}$, 931-938

Zimmermann G, Wagner C, Moghaddam A und Wentzensen A (2006): Need for bone morphogenetic proteins in fracture treatment. Trauma Berufskrankh $\underline{8}, \mathrm{~S} 45-\mathrm{S} 48$ 